Portland State University

PDXScholar

Summer 9-5-2013

\title{
Kinetics and Mechanism of S-Nitrosation and Oxidation of Cysteamine by Peroxynitrite
}

Wilbes Mbiya

Portland State University

Follow this and additional works at: https://pdxscholar.library.pdx.edu/open_access_etds

Part of the Chemical Actions and Uses Commons, and the Organic Chemicals Commons Let us know how access to this document benefits you.

\section{Recommended Citation}

Mbiya, Wilbes, "Kinetics and Mechanism of S-Nitrosation and Oxidation of Cysteamine by Peroxynitrite" (2013). Dissertations and Theses. Paper 1413.

https://doi.org/10.15760/etd.1413

This Thesis is brought to you for free and open access. It has been accepted for inclusion in Dissertations and Theses by an authorized administrator of PDXScholar. Please contact us if we can make this document more accessible: pdxscholar@pdx.edu. 
Kinetics and Mechanism of S-Nitrosation and Oxidation of Cysteamine by Peroxynitrite

by

Wilbes Mbiya

A thesis submitted in partial fulfillment of the requirements for the degree of

\author{
Master of Science \\ in \\ Chemistry
}

Thesis Committee:

Reuben H. Simoyi, Chair

Dean Atkinson

Albert S. Benight

Portland State University

2013 
(C) 2013 Wilbes Mbiya 


\begin{abstract}
Cysteamine (CA), which is an aminothiol drug medically known as Cystagon® was studied in this thesis. Cysteamine was reacted with a binary toxin called peroxynitrite (PN) which is assembled spontaneously whenever nitric oxide and superoxide are produced together and the decomposition of peroxyinitrite was monitored. PN was able to nitrosate $\mathrm{CA}$ in highly acidic medium and excess CA to form $\mathrm{S}$-nitrosocysteamine (CANO) in a 1:1 with the formation of one mole of CANO from one mole of ONOOH. In excess oxidant (PN) the following 1:2 stoichiometric ratio was obtained; $\mathrm{ONOO}^{-}+$ $2 \mathrm{CA} \rightarrow \mathrm{CA}-\mathrm{CA}+\mathrm{NO}_{2}^{-}+\mathrm{H}_{2} \mathrm{O}$. In alkali medium the oxidation of $\mathrm{CA}$ went through a series of stages from sulfenic acid, sulfinic acid and then sulfonic acid which was followed by the cleavage of the $\mathrm{C}-\mathrm{S}$ bond to form a reducing sulfur leaving group, which is easily oxidized to sulfate
\end{abstract}

The nitrosation reaction was first order in peroxynitrite, thus implicating it as a nitrosating agent in highly acidic $\mathrm{pH}$ conditions. Acid catalyzes nitrosation reaction, whitst nitrate catalyzed and increased the amount of CANO product, This means that the nitrosonium cation, $\mathrm{NO}^{+}$which is produced from the protonation of nitrous acid(in situ) as also contributing to the nitrosation of CA species in highly acidic environments. The acid catalysis at constant peroxynitrite concentrations suggests that the protonated peroxynitrous acid nitrosates at a much higher rate than the peroxynitrite and peroxynitrous acid. 
Bimolecular rate constants for the nitrosation of $\mathrm{CA}$, was deduced to be $10.23 \mathrm{M}^{-1} \mathrm{~s}^{-1}$. A linear correlation was obtained between the initial rate constants and the $\mathrm{pH}$. The oxidation of CA was modeled by a simple reaction scheme containing 12 reactions. 


\section{DEDICATION}

This thesis is dedicated to my treasure:

My Lord and Savior Jesus Christ 


\section{ACKNOWLEDGEMENTS}

First of all I will like to thank God for His grace, strength and wisdom to do this work. I would thank my supervisor "Oga" Professor Simoyi for being there whenever I needed him, for patience, mentorship, and guidance in my in this project. A special word of thanks is due to my son 'my best friend' Ariel Macwilbes Mbiya, you are my source of pride and joy and my wife (Patience), thanks you for being there for me during my studies. To my father Ephta Mbiya and mum Tsisti Mbiya, I thank you for believing in me and may the good Lord continue to bless you. I love you all.

I am indebted to the members of my thesis committee: Drs Dean Atkinson and Albert Benight. To Dr Shankar B. Rananavare you are special to me. I wish to express my gratitude to members of Simoyi Research Group 'thee family', both past and present, for their invaluable suggestions, friendship and assistance. I am especially grateful to the current members, Risikat Ajibola, Morgen Mhike, Kudzanai Chipiso, Troy Wahl, William DeBenedetti, Klimentina Risteska, Tomoko Hockens, Ashley Sexton, Anh Tran and Thai Tran (thank you buddy). I wish them success in their studies and endeavors. In addition, I wish that they will continue to accept the guidance of Professor Simoyi and maintaintheir motivation in this area of chemistry. Finally, I want to acknowledge Department of Chemistry at Portland StateUniversity for their support, and the National Science Foundation (Grant Number CHE 1056311) for the financial support. 


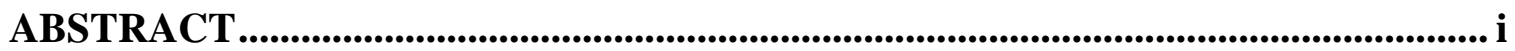

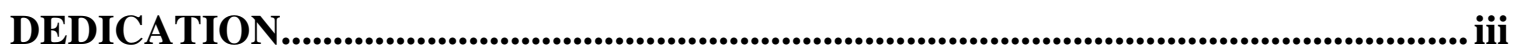

ACKNOWLEDGEMENTS .............................................................................................. iv

LIST OF TABLE(S) ................................................................................................... viii

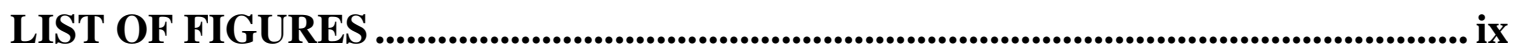

LIST OF SCHEMES .................................................................................................................. xii

LIST OF ABBREVIATIONS .............................................................................ii

CHAPTER ONE ........................................................................................................................... 1

1.0 INTRODUCTION

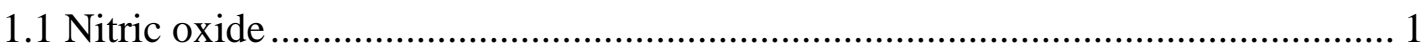

1.2 Importance of NO

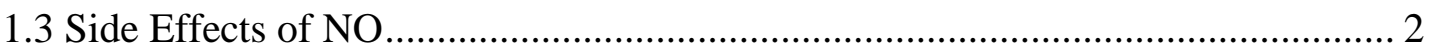

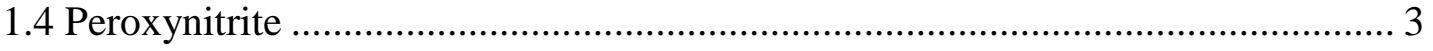

1.4.1 Peroxynitrite Chemistry.......................................................................... 3

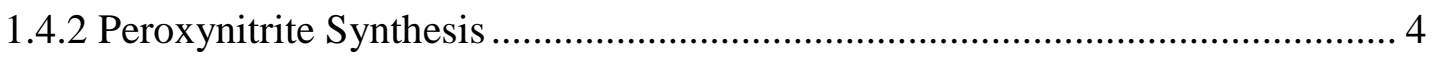

1.4.3 Synthesis of Peroxinitrite in the Physiological Environment ............................. 5

1.4.4 Peroxynitrite and Carbon Dioxide .............................................................. 6

1.5 Thiols (Mercaptans) Biological Chemistry ……………........................................ 7 
1.7 Physiological Functions of RSNOs ............................................................. 9

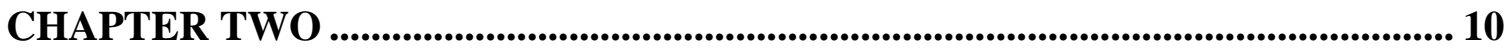

INSTRUMENTATION, MATERIALS AND METHODS .................................... 10

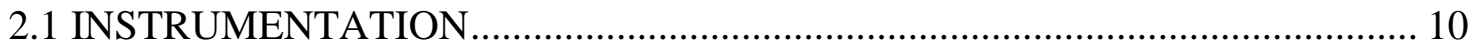

2.1.1 Conventional UV/Vis Spectrophotometry........................................... 10

2.1.2 Stopped Flow Spectrophotometry ................................................... 10

2.1.3 Electron Paramagnetic Resonance (EPR) Spectroscopy .............................. 12

2.1.4 Electrospray-Ionization Mass Spectrometry (ESI-MS).............................. 14

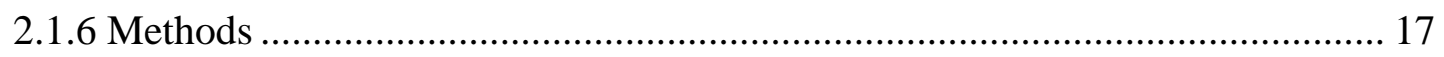

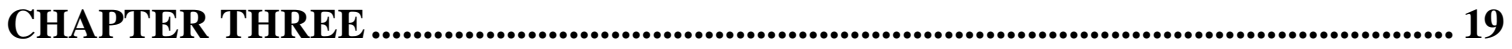

KINETICS AND MECHANISMS OF NITROSATION OF CYSTEAMINE AND

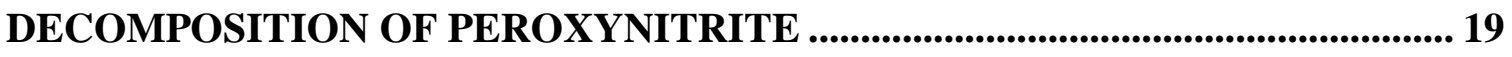

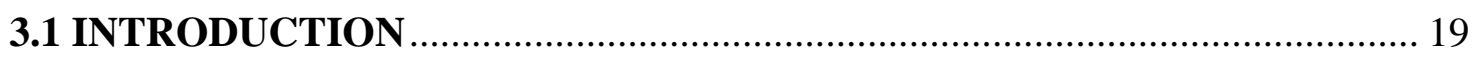

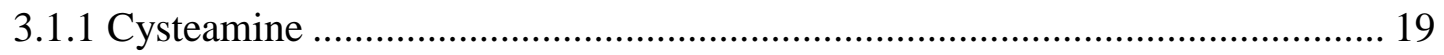

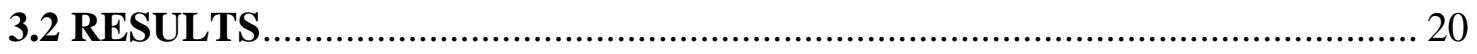

3.2.2 Stoichiometric Determinations ............................................................ 21

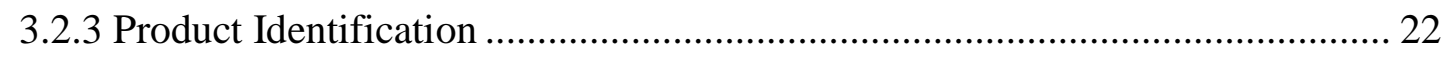


3.2.4 Electrospray-Ionization Mass Spectrometer (ESI-MS) Study on the Oxidation

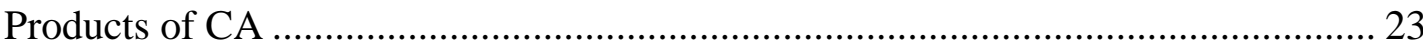

3.3 Peroxynitrite Oxidation Pathways ............................................................ 25

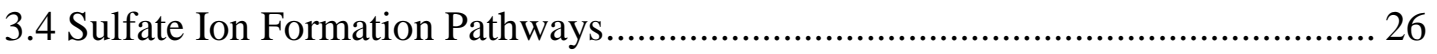

3.5 Peroxynitrite and Free Radical Formation................................................. 31

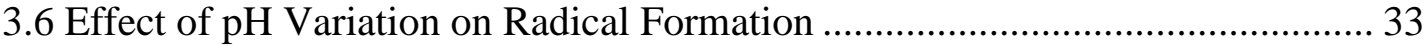

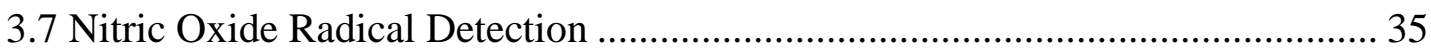

3.8 Effect of Peroxynitrite Variation on S-nitrosocysteamine Formation ................... 36

3.9 Effect CA Variation on the Formation of CANO............................................ 39

3.10 Effect of acid variation on the Formation of S-nitrosocysteamine ................... 41

3.11 Effect Nitrite Variation on CANO Formation ................................................ 45

3.12 Effect of Cysteamine Dependence ........................................................... 47

3.13 Effect of Peroxynitrite Dependence .................................................... 48

3.14 Effect of $\mathrm{pH}$ Variation on Peroxynitrite Stability .......................................... 50

3.15 Comparison of Phosphate Buffer to Bicarbonate Buffer................................. 53

3.16 Computer Simulation and Detailed Mechanism.......................................... 54

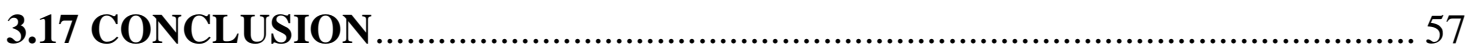

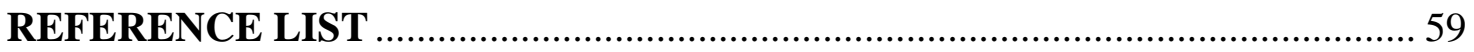




\section{LIST OF TABLE(S)}

Table 3. 1: Detailed Mechanism of the Cysteamine-Peroxynitrite Reaction................... 56 


\section{LIST OF FIGURES}

Figure 1. 1: Multifaceted biological effects of nitric oxide (NO) .................................. 1

Figure 1. 2: Alveolar macrophages produce peroxynitrite. ............................................ 6

Figure 2. 1: Sample Handling Unit (SHU) flow circuit diagram for the SF61-DX2 Hi-

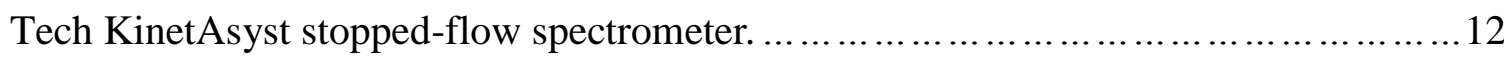

Figure 2. 2: Zeeman splitting of the two spin Eigenstates of an electron in an external magnetic field. The classical analogue to bar magnets is indicated on the right.............. 13

Figure 2. 3: Schematic representation of the electrospray ionization(ESI) process....... 15

Figure 3. 1: Spectral scans of CA, PN, and the product of a mixture of acidified PN and

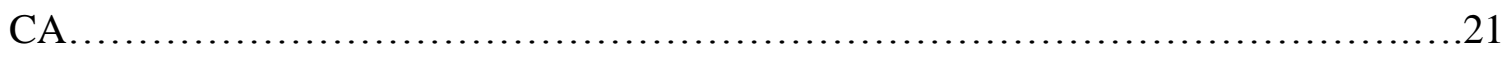

Figure 3. 2: Positive ESI-MS spectrum of a stoichiometric CA-PN in basic medium

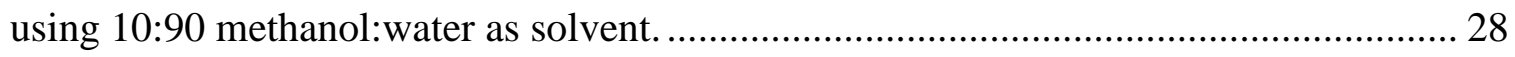

Figure 3. 3: Negative ESI-MS spectrum of a stoichiometric CA-PN in basic medium

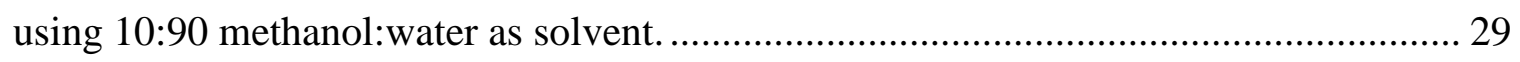

Figure 3. 4: Positive ESI-MS spectrum of a stoichiometric CA-PN in acidic medium

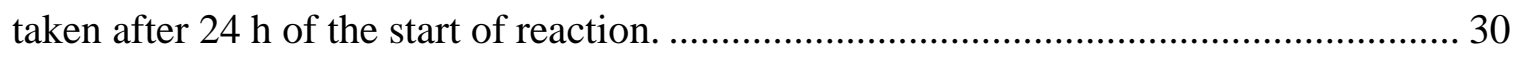

Figure 3. 5: The EPR spectra of peroxynitrite and cysteamine on different pHs........... 32 Figure 3. 6: Plot of changes in EPR signal intensity DMPO-SAC with $\mathrm{pH}$ variation at 25

${ }^{\circ} \mathrm{C}$ 34

Figure 3. 7: Identification of NO as a product of decomposition of S-nitrosocysteamine

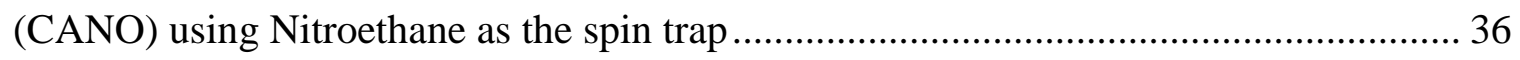


Figure 3. 8: Effect of peroxynitrite variation on Nitroso-cysteamine formation.

Figure 3. 9: This plot shows that there is a direct relationship between the initial rates and Peroxynitrite concentration for conditions shown in Figure 3.8.......................... 38

Figure 3. 10: Effect of CA variation on Nitroso-cysteamine formation....................... 39

Figure 3. 11: A plot of initial rate of nitrosation of CA versus CA concentrations showing sigmoidal increase in the rate of formation of CANO with increase in the initial

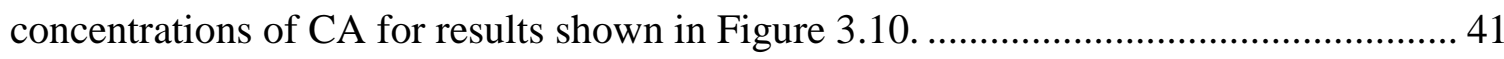

Figure 3. 12: Effect of acid variation on nitroso-cysteamine formation........................ 43

Figure 3. 13: Shows that there is a direct relationship between initial rates and acid

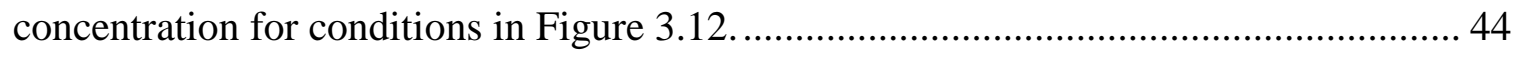

Figure 3. 14: Effect of nitrite variation on nitroso-cysteamine formation..................... 45

Figure 3. 15: Shows that there is a direct relationship between initial rates and nitrite

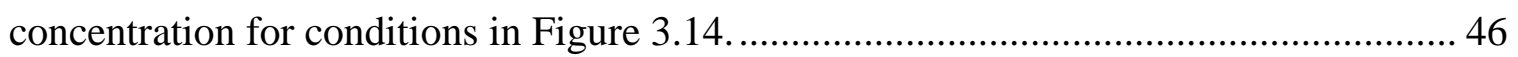
Figure 3. 16: Absorbance traces from the PN-CA reaction and the reaction was done in less than 15 seconds.

Figure 3. 17: Shows that there is a direct relationship between initial rates and CA concentration for conditions in Figure 3.9 (a). 48

Figure 3. 18: Absorbance traces showing the effect of varying PN concentrations on its S-nitrosation by CA.

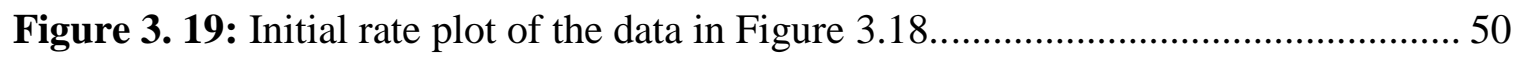
Figure 3. 20: Absorbance traces showing the effect of $\mathrm{pH}$ varying on $\mathrm{PN}$ depletion at 302 $\mathrm{nm}$. 
Figure 3. 21: This plot shows that there is a direct inverse relationship between the initial

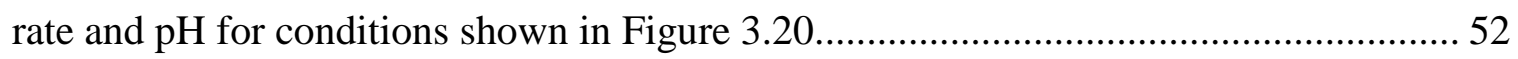

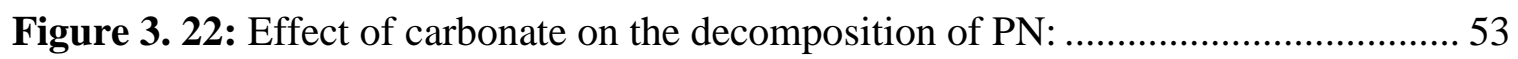

Figure 3. 23: Computer modeling for reaction for the data shown in Figure 3.8 using the scheme shown in Table 3.1. There seems to a satisfactory agreement between experiments and the model. 57 


\section{LIST OF SCHEMES}

Scheme 3. 1: (i) Two-electron oxidation pathway. (ii) One-electronoxidation pathway. Peroxynitrous acid reacts with the thiol producing the thiyl radical. The latter can dimerize to the disulphide, or can react with the nitroso radical yielding the S-

nitrosocysteamine.

Scheme 3. 2: Two-electron oxidation pathway of CA. Peroxynitrite reacts with the thiol group producing the unstable sulphenic acid which reacts with water to form a primary alcohol which can be further oxidized to form a carboxylic acid. 26

Scheme 3. 3: Shows one-electron oxidation of cysteamine radial to form cystamine (dimer). The C-S bond can break to form (2-aminoethyl)disulfen-1-ium ion and 2aminoethane carbocation with can be oxidized to give 2-minoacetic acid.

Scheme 3. 4: Proposed reaction of peroxynitrite in (a) acidic and (b) basic medium respectively 33

Scheme 3. 5: In acidic medium peroxynitrite gets protonated (R route) to form a cation of peroxynitrous acid which then reacts with $\mathrm{CA}$ to form CANO or decompose to form nitrate ion ( $\mathrm{L}$ route). 


\section{LIST OF ABBREVIATIONS}

CA cysteamine

CANO

S-nitrosocysteamine

CA-CA

cystamine (dimer of cysteamine)

CTNS

cystinosin, lysosomal cystine transporter

DMPO

5,5-dimethyl-pyrroline $\mathrm{N}$-oxide

ESI-MS

electrospray ionization mass spectrometry

GSNO

S-nitrosoglutathione

HOONO

peroxynitrous acid

NOS

nitric oxide synthase

PN

peroxynitrite

RNOs

reactive nitrogen/oxygen species

RONO

alkyl nitrites

sGC

guanylate cyclase 


\section{CHAPTER ONE}

\subsection{INTRODUCTION}

\subsection{Nitric oxide}

Nitric oxide is the smallest, lightest molecule-and the first gas-known to act as a biological messenger in mammals. The molecule has one unpaired electron, making it a free radical that avidly reacts with other molecules. In the presence of oxygen, nitric oxide (NO) may vanish a few seconds after it forms, although its lifespan in the human body is unknown. ${ }^{1}$

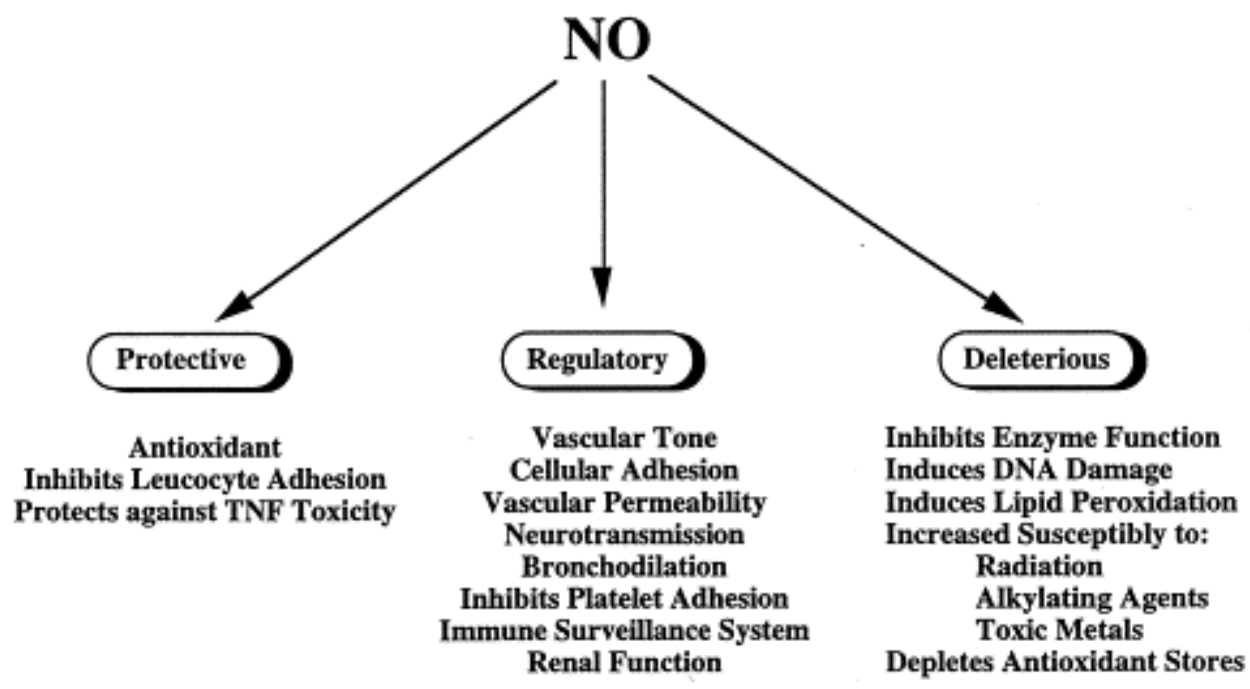

Figure 1. 1: Multifaceted biological effects of nitric oxide (NO). NO is synthesized by nitric oxide synthase (NOS) enzymes; produced by mammalian cells at an appropriate magnitude and tempo, it serves as a key signaling molecule in various physiological processes. $^{2}$ 
NO is a short-lived, endogenously produced gas that acts as a signaling molecule in the body. ${ }^{3}$ The discovery of the endogenous formation of nitric oxide (NO) led to an explosion in research centering on the question, "what role(s) does this free radical molecule play in various biologic events?" Surprisingly, this diatomic free radical has been shown to be involved in numerous regulatory functions ranging from altering the cardiovascular system to modulating neuronal function (Figure 1).

\subsection{Importance of NO}

Nitric oxide is known to carry crossed purposes. It carries important information in the nervous system: In males, it is the messenger that translates sexual excitement into an erect penis. In the brain, nitric oxide may be a long- sought mystery molecule that aids in learning and remembering. ${ }^{1}$ The production of nitric oxide is also important for nonspecific host defense, helping to kill tumors and intracellular pathogens. ${ }^{4}$

\subsection{Side Effects of NO}

The toxicity of nitric oxide is more likely to result from the diffusion-limited reaction of nitric oxide with superoxide $\left(\mathrm{O}_{2}^{-}\right)$to produce the powerful and toxic oxidant peroxynitrite $\left(\mathrm{ONOO}^{-}\right){ }^{4}$ a highly reactive compound, participating not only in mammalian defense mechanisms against microorganisms, but also in the pathophysiology during overexposure of tissues to radicals or other reactive species 


\subsection{Peroxynitrite}

A peroxy isomer of nitrate, peroxynitrite is a versatile oxidant that can be formed in biological systems from the reaction of nitric oxide (.NO) with superoxide and oxygenated heme proteins, in particular, oxyhemoglobin. ${ }^{5,6}$ The rate constant for the reaction of superoxide and nitric oxide $\left(\sim 10^{10} \mathrm{M}^{-1} \mathrm{~s}^{-1}\right)$ virtually assures that peroxynitrite anion $\left(\mathrm{ONOO}^{-}\right)$will be formed in any cell or tissue where both radicals exist simultaneously. ${ }^{5}$

\subsubsection{Peroxynitrite Chemistry}

The free energy of peroxynitrite is $150 \mathrm{~kJ}$ mol71 higher than that of isomeric nitrate; ${ }^{7}$ nevertheless, $\mathrm{ONOO}^{-}$anion is relatively stable, that is, it lives in alkali solutions for a few weeks. ${ }^{8}$ The reason is the conformation of this species. The order of the bond between the nitrogen atom and the peroxide oxygen atom, $\mathrm{O}(2)$, in peroxynitrite approaches a value of 1.5 , thus providing an explanation for the existence of cis- and trans-isomers .

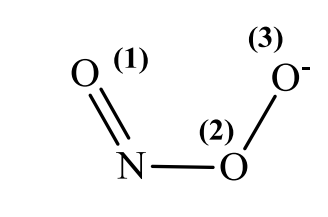

Cis-Peroxynitrite

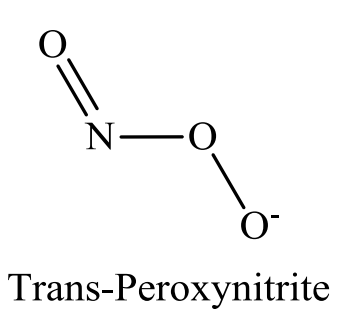

The cis-isomer is $8-17 \mathrm{~kJ} \mathrm{~mol}^{-1}$ more stable than the trans-isomer. due to (i) partial delocalisation of negative charge over the entire molecule and (ii) partial bonding between the $\mathrm{O}(1)$ and $\mathrm{O}(3)$ atoms (the bonding energy is comparable with the energy of a 
hydrogen bond). Delocalisation stabilises peroxynitrite in the cis-conformation and precludes either rotation of the $\mathrm{O}(3)$ atomabout the $\mathrm{N}-\mathrm{O}(2)$ bond axis or a change in the $\mathrm{N}-\mathrm{O}-\mathrm{O}$ bond angle in order to adopt the trans-configuration. Spectral studies confirmed that peroxynitrite in alkali solutions exists only as cis-isomer. ${ }^{9}$

Peroxynitrite has a pK of 6.8 at $37^{\circ} \mathrm{C}$ and is unstable with a half-life of under 1.0 $\mathrm{s}$ at $\mathrm{pH}$ 7.4. Peroxynitrite decomposes to give a species with hydroxyl radical-like reactivity, according to the following reactions $;^{5}$

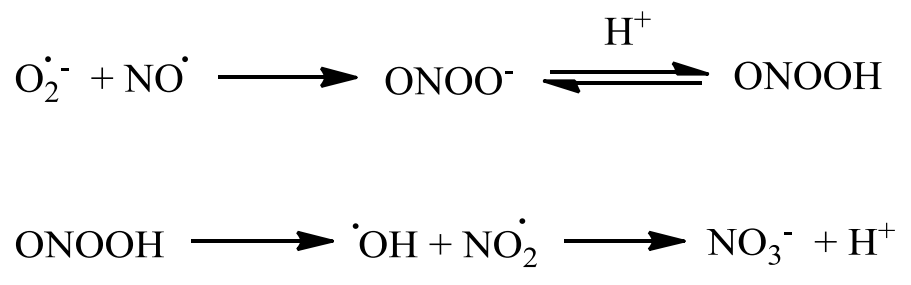

Peroxynitrite is an important mediator of tissue injury in various forms of in an inflammation, shock, and ischemia-reperfusion injury. ${ }^{10,11}$ The cytotoxic effect of peroxynitrite is attributed to inhibition of the mitochondrial respiratory chain, inactivation of ion channels, initiation of lipid peroxidation, protein oxidation, DNA damage, and interference with protein tyrosine phosphorylation. ${ }^{12,13}$

\subsubsection{Peroxynitrite Synthesis}

As early as 1901, the unusual oxidizing power of acidified nitrite mixed with hydrogen peroxide was noted. ${ }^{14}$ Peroxynitrite was synthesized as early as 1922 from a mixture of hydrogen peroxide and nitrous acid. 


$$
\mathrm{HOOH}+\mathrm{HNO}_{2} \stackrel{\mathrm{H}^{+}}{\longrightarrow} \mathrm{ONOOH}+\mathrm{H}_{2} \mathrm{O} \quad \mathrm{R} 1.3
$$

In 1970, several investigators more thoroughly characterized the chemistry of peroxynitrite showing that it decomposed to form hydroxyl radical and nitrogen dioxide. Hughes and Nicklin established the most commonly used extinction coefficient at $302 \mathrm{~nm}$ $\left(1.67 \mathrm{mM}^{-1} \cdot \mathrm{cm}^{-1}\right)$ through indirect measurements. ${ }^{15}$ Better results were achieved with the use of quench flow reactor, which was first described in $1974 .{ }^{16}$ To date there are so many methods that are being used and these include, autoxidation of hydroxylamine, ${ }^{17}$ photolysis of solid potassium superoxide,${ }^{18}$ nitric oxide and superoxide anion radical from a single source, ${ }^{19}$ reaction of hydrogen peroxide with alkyl nitrites (RONO), reaction of

ozone with azide ions,${ }^{20}$ reaction of hydrogen peroxide with nitrous acid, ${ }^{18,21}$ and reaction of nitric oxide and hydrogen peroxide. ${ }^{21}$

\subsubsection{Synthesis of Peroxinitrite in the Physiological Environment}

The production of oxidants is a crucial mechanism for neutrophils and macrophages to damage or kill microorganisms. ${ }^{14}$ Some of the oxidants produced by alveolar macrophages will lead to the production of peroxynitrite (Figure 1.2). In 1990, the first papers suggesting that peroxynitrite could be a biological oxidant were published. ${ }^{22}$ At the time, much of the literature suggested that NO was a scavenger of superoxide and thus acting as an antioxidant. ${ }^{23}$ However, Beckman et al. showed peroxynitrite was a far more effective means of producing hydroxyl radical than the widely accepted reaction of reduced iron with hydrogen peroxide (known as the Fenton reaction or the iron-catalyzed Haber-Weiss reaction). ${ }^{5}$ Peroxynitrite itself is also a strong oxidant and can react directly 
with electron-rich groups, such as sulfhydryls, ${ }^{5}$ iron-sulfur, ${ }^{24}$ zinc-thiolates $^{25}$ and the active site sulfhydryl in tyrosine phosphatases. $^{26}$

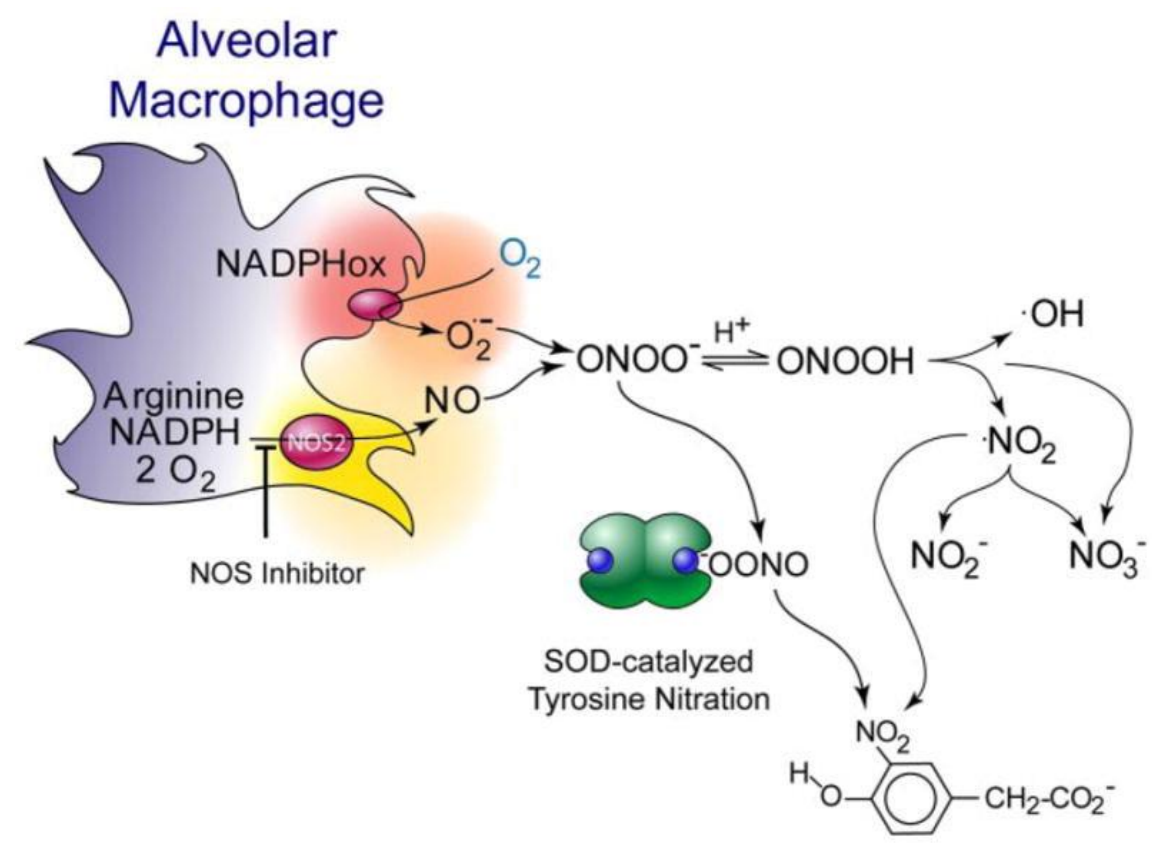

Figure 1. 2: Alveolar macrophages produce peroxynitrite. When alveolar macrophages are stimulated to produce both superoxide and nitric oxide, peroxynitrite is quantitatively produced as evidenced by the amount of nitric oxide and superoxide produced and the amount of oxygen consumed. Extracellular addition of superoxide dismutase (SOD) in high concentrations does not significantly reduce the amount of peroxynitrite formed and instead serves as a catalyst of tyrosine nitration. This suggests that superoxide produced at the membrane surface and nitric oxide diffusing through the membrane react at the membrane interface so quickly that SOD in the bulk phase cannot compete.

\subsubsection{Peroxynitrite and Carbon Dioxide}

A turning point in peroxynitrite chemistry came from the identification of the importance of the reaction of peroxynitrite with $\mathrm{CO}_{2}$ and form an unstable nitrosoperoxycarbonate anion adduct, $\mathrm{O}=\mathrm{N}-\mathrm{OOCO}{ }_{2}^{-27,28}$ When nitrosoperoxycarbonate anion is formed, the majority ( $\sim 70 \%$ ) of it is converted to the nitrocarbonate ion, 
ONOOCO${ }_{2}^{-}$, which in turn decomposes to give nitrate $\left(\mathrm{NO}_{3}{ }^{-}\right)$and regenerated $\mathrm{CO}_{2}{ }^{29,29}$ The remaining $(\sim 30 \%)$ of $\mathrm{ONOOCO}_{2}{ }^{-}$decomposes to nitrogen dioxide $\left(\mathrm{NO}_{2}\right)$ and the carbonate radical $\left(\mathrm{CO}_{3}{ }^{-{ }^{-}}\right){ }^{30,31}$ Alternatively the mechanism of ONOOH decomposition in the presence of $\mathrm{CO}_{2}$ may involve initial homolysis of $\mathrm{ONOOCO}_{2}^{-}$into a radical pair, $\left[{ }^{-N O} 2 / \mathrm{CO}_{3}{ }^{-}\right]$, which are caged radicals. ${ }^{27,32,33}$

\subsection{Thiols (Mercaptans) Biological Chemistry}

Thiols, also known as thioalcohols or mercaptans (RSH), are the sulfur analogues of alcohols and phenols in which the oxygen atom has been replaced by sulfur. In comparison to alcohols which oxidize to give carbonyl compounds, thiols are not readily oxidized to the corresponding thiocarbonyls. Reduced sulfur in organic compounds is essential to all living organisms and is a major constituent of proteins, coenzymes and major cellular metabolites which dictate structure, binding site characteristics and transport system function. Owing to the relative ease of oxidation of reduced sulfur compounds, they protect against oxygen toxicity and radiation damage. ${ }^{34}$ In proteins, it is well known that thiols present different reactivities according to the protein structure, hydrophobicity, and the electronic environment, as denaturing agents increase the reactivity of thiols by exposing hidden $-\mathrm{SH}$ groups.35 Thiols react faster than the other amino acids with oxidizing species, and some of their oxidation products can be reversibly reduced. ${ }^{36}$ Thiols are unable to undergo autoxidation in the absence of a catalyst, but several free metal ions markedly increase the rate of autoxidation. ${ }^{35}$ 


\subsection{Nitrosation of Thiols by Nitric Oxide Derivatives}

Nitric oxide $(\cdot \mathrm{NO})$ is an important second messenger that, among other functions, can elicit smooth muscle relaxation through the activation of the soluble form of the enzyme guanylate cyclase (sGC). Nitric oxide activates sGC by binding to the ferrous form of a regulatory heme group on the enzyme, leading to a dramatic increase in the rate of formation of cyclic GMP. ${ }^{35}$

However, other mechanistically distinct pathways of NO-mediated signaling have been proposed. The formation of nitrosothiol (RSNO) from protein cysteine may also be an important component of signaling by NO. ${ }^{37,38}$ A reaction of NO with $\mathrm{RSH}$ or $\mathrm{RS}^{-}$would not directly yield RSNO, but rather would give an intermediate thionitroxide (RSNHO·), if it happened at all. ${ }^{39}$ Generation of RSNO viaintermediary thionitroxides would require an additional one-electron oxidation, and this has been proposed as a possible mechanism of RSNO generation, whereby the oxidation is carried out by dioxygen. ${ }^{40}$ Nitric oxide can react with dioxygen to form nitrogen dioxide $\left(\cdot \mathrm{NO}_{2}\right)$.

$$
\begin{array}{lc}
2 \cdot \mathrm{NO}+\mathrm{O}_{2} \longrightarrow 2 \cdot \mathrm{NO}_{2} & \mathrm{R} 1.4 \\
\cdot \mathrm{NO}_{2}+\mathrm{RSH} \longrightarrow \mathrm{NO}_{2}^{-}+\mathrm{RS}^{\cdot}+\mathrm{H}^{+} & \mathrm{R} 1.5 \\
\mathrm{RS} \cdot+\mathrm{NO} \cdot \longrightarrow & \mathrm{R} 1.6
\end{array}
$$

Besides acting as a direct thiol oxidant, $\mathrm{NO}_{2}$ can also react with $\mathrm{NO}$ to give $\mathrm{N}_{2} \mathrm{O}_{3}$, an electrophilic species capable of nitrosating thiols. 


$$
\begin{aligned}
& \cdot \mathrm{NO}_{2}+\cdot \mathrm{NO} \longrightarrow \mathrm{N}_{2} \mathrm{O}_{3} \\
& \mathrm{RSH}+\mathrm{N}_{2} \mathrm{O}_{3} \longrightarrow \mathrm{RSNO}+\mathrm{NO}_{2}{ }^{-}+\mathrm{H}^{+}
\end{aligned}
$$

Transnitrosation which often results in the modification of physiological thiols can also take place ${ }^{41}$

$$
\mathrm{R}^{\prime} \mathrm{SNO}+\mathrm{R} \text { "SH } \longrightarrow \mathrm{R}^{\prime} \mathrm{SH}+\mathrm{R}^{\prime \prime} \mathrm{SNO}
$$

\subsection{Physiological Functions of RSNOs}

RSNOs have been shown to perform the same physiological role as nitric oxide itself. ${ }^{42}$ Like NO, RSNOs appear to have a role to play in host defense, affecting both viruses and bacteria. Levels of RSNOs in respiratory pathways are affected by diseases such as asthma and pneumonia and it is believed that RSNOs act as bronchodilators and relax bronchial smooth muscle and thus should have a role to play in the treatment of these diseases. ${ }^{43}$ RSNO have are also known to have therapeutic use for cystic fibrosis. ${ }^{44}$ S-nitroso-glutathione (GSNO) is already being administered in clinical trials (at lower concentrations than those required for vasodilation) for use during coronary angioplastic operations where it can be used to reduce clotting. ${ }^{45}$ GSNO has also been successful in treating the HELLP (hemolysis, elevated liver enzymes and low platelets) syndrome in pregnant women. ${ }^{43}$ RSNOs, together with NO, have also been implicated in suppression of HIV-1 replication by S-nitrosylation of the cysteine residues in the HIV-1 protease. ${ }^{43}$ 


\section{CHAPTER TWO}

\section{INSTRUMENTATION, MATERIALS AND METHODS}

\subsection{INSTRUMENTATION}

\subsubsection{Conventional UV/Vis Spectrophotometry}

Reactions which occur in minutes were measured using either a Perkin Elmer Lambda 25 UV/Vis spectrophotometer or a Beckman DU800 both featuring a doublebeam, total reflection system within the range 200 to $800 \mathrm{~nm}$. For instruments, holographic grating was used as the monochromator and two radiation sources, a deuterium lamp (UV) and a halogen lamp (visible range) were used in sequence as the polychromator light sources. The Perkin Elmer spectrophotometer was interfaced to a Pentium III computer and uses the UV WinLab Software for data collection and analyses while the Beckman spectrophotometer is interfaced to an IBM PC computer and used the DU Series 800 Software. Path length of the cuvette was $1 \mathrm{~cm}$. The Beckman spectrometer gave the option of using either a single cell holder or a multi-cell holder (maximum of 6), depending on the experiment. Constant temperature was maintained by use of a circulating water bath attached to the cell holders.

\subsubsection{Stopped Flow Spectrophotometry}

All rapid reactions (with time scales as short as 2-10 seconds) were measured using the stopped-flow technique, which can follow reactions with time scales as short as milliseconds. The Hi-Tech Scientific SF61 - DX2 Double mixing stopped-flow 
spectrophotometer was used for the acquisition of absorbance data. The instrument was interfaced to a Pentium III computer via a $413 \mathrm{kHz} 16$ bit A/D converter to enable the conversion of data to digital form. A high efficiency mixer mix small volumes of solutions, which were driven into it from high performance syringes. Small volumes of solutions are driven from high performance syringes through high efficiency mixer(s). The sample handling unit (Figure 2.1) facilitates both the single mixing of two reagents, using only one of the drives, and double mixing of three reactants by a push-push mode of operation. Double mixing mode enables transient species formed by mixing reactants in $\mathrm{A}$ and $\mathrm{B}$ to be subsequently mixed with a third reactant, $\mathrm{C}$, after a delay period. Reactant reservoir D is reserved for the buffer and this will push the premixed solutions $\mathrm{A}$ and $\mathrm{B}$ (from mixer 1) to a second mixer (mixer 2) where it reacts further with reactant C. The resultant mixture passes through a measurement flow cell and into a stopping syringe where the flow is stopped. Just prior to stopping, a steady state flow is achieved. The solution entering the flow cell is only milliseconds old. The age of this reaction mixture is also known as the dead time of the stopped-flow system. As the solution fills the stopping syringe, the plunger hits a block, causing the flow to be stopped instantaneously. Reactions in which three or more reactants that require separate mixing prior to introduction into the observation chamber are analyzed using the double mixing feature of the SF61-DX2. The kinetics of the reaction can be measured in the cell using the appropriate techniques. ${ }^{46}$ 


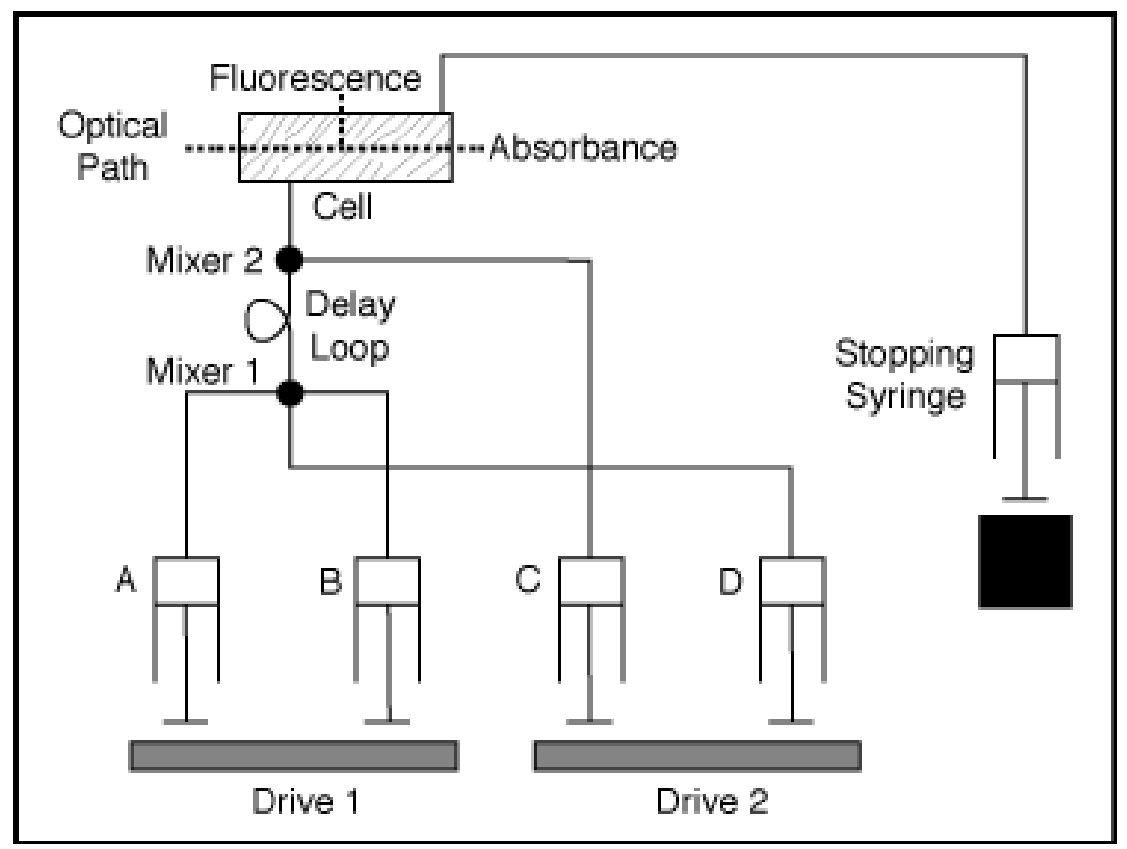

Figure 2. 1: Sample Handling Unit (SHU) flow circuit diagram for the SF61-DX2 HiTech KinetAsyst stopped-flow spectrometer. [Courtesy of Hi-Tech Scientific operator's Manual $]^{46}$

\subsubsection{Electron Paramagnetic Resonance (EPR) Spectroscopy}

Electron paramagnetic resonance (EPR) also known as electron spin resonance (ESR) spectroscopy is a technique for studying materials with unpaired electrons. The basic physical concepts of EPR are analogous to those of nuclear magnetic resonance (NMR) and magnetic resonance imaging (MRI), but it is electron spins that are excited instead of spins of atomic nuclei. 


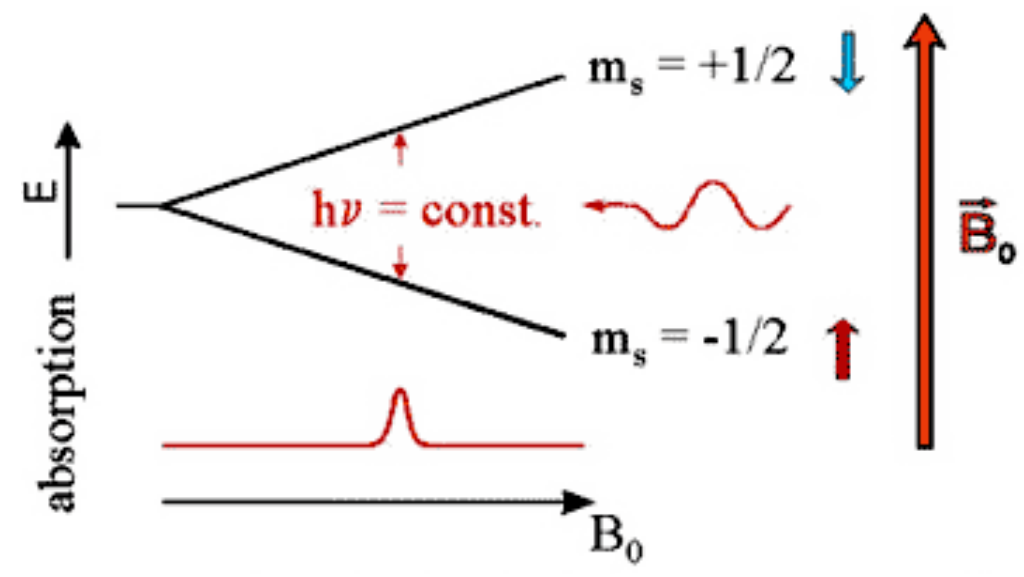

Figure 2. 2: Zeeman splitting of the two spin Eigenstates of an electron in an external magnetic field. The classical analogue to bar magnets is indicated on the right.

In EPR spectroscopy the energy differences, $\Delta \mathrm{E}$, due to interaction of unpaired electrons in the sample with a magnetic field produced by a magnet are studied. Absorption occurs when $\Delta \mathrm{E}$ equals the microwave energy, $\mathrm{h} v$.

Equation R2.1 and Figure 2.2 describe the general principle of EPR.

$$
\Delta \mathrm{E}=\mathrm{h} v=\mathrm{g} \beta_{\mathrm{e}} \mathrm{H}
$$

where $\mathrm{h}$ is Planck's constant, $v$ is microwave frequency, $\beta$ is Bohr magneton (a constant related to electron charge and mass), $\mathrm{H}$ is magnetic field at which resonance occurs and $\mathrm{g}$ is a spectroscopic factor, which is a characteristic of a given paramagnetic center. The shape and width of the spectral line as well as the hyperfine (splitting) and area under the 
absorption curve are other important parameters in EPR spectroscopy. The area which is the double integral of the 1st derivation curve is proportional to the amount of a given paramagnetic center (spin) present in the resonator cavity of the EPR instrument.

EPR spectroscopy was carried out using a Bruker (Fremont, CA) EMX spectrometer equipped with a high-sensitivity cavity and an Aqua-X sample holder. Spectra were obtained at room temperature. Typical EPR parameters were as follows: $100 \mathrm{G}$ sweep width (for the spin trapping experiments with 5,5-dimethyl-1-pyrroline Noxide, (DMPO)); $9.77 \mathrm{GHz}$ microwave frequency; $32 \mathrm{~mW}$ power; $2 \times 10^{5}$ receiver gain; modulation frequency of $86 \mathrm{kHz}$; modulation amplitude of $2 \mathrm{G}$; with the conversion time $5 \mathrm{~ms}$ and time constant being $10 \mathrm{~ms}$ with $200 \mathrm{X}$-scans for each 512 point spectrum.

\subsubsection{Electrospray-Ionization Mass Spectrometry (ESI-MS)}

Mass spectrometry (MS), is an analytical technique that sorts and measures ionized molecules based on their mass-to-charge ratios. This spectrometric method works on the basic principle of separation of ions of a compound on the basis of their mass-tocharge ratio $(\mathrm{m} / \mathrm{z})$. ESI uses electrical energy to assist the transfer of ions from solution into the gaseous phase before they are subjected to mass spectrometric analysis. Ionic species in solution can thus be analysed by ESI-MS with increased sensitivity. Neutral compounds can also be converted to ionic form in solution or in gaseous phase by protonation or cationisation (e.g., metal cationisation), and hence can be studied by ESIMS. 


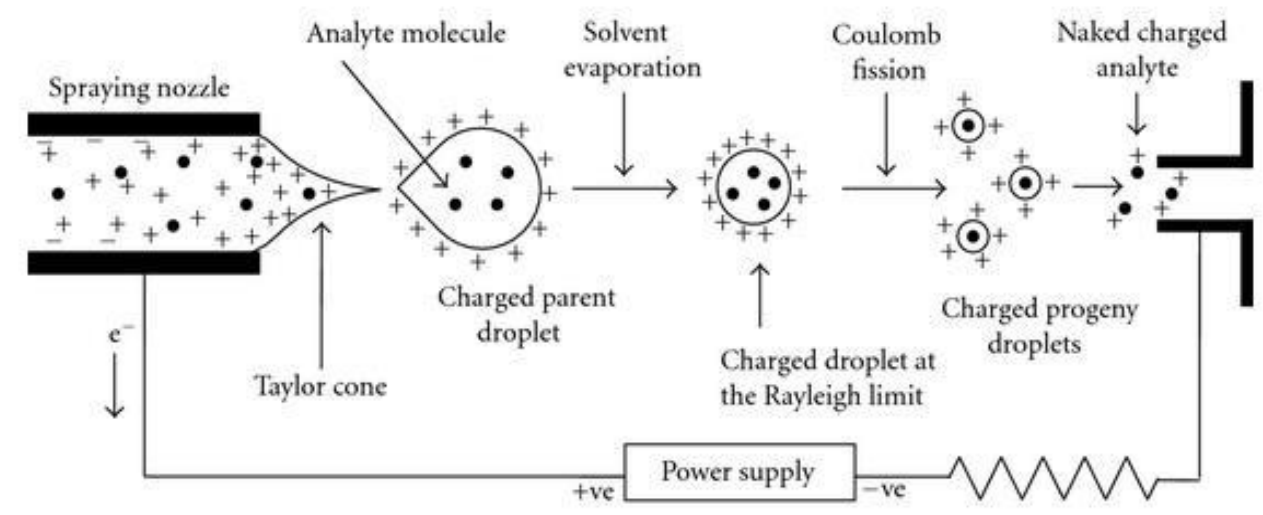

Figure 2. 3: Schematic representation of the electrospray ionization(ESI) process. ${ }^{47}$

The transfer of ionic species from solution into the gas phase by ESI involves three steps:

(1) dispersal of a fine spray of charge droplets, followed by (2) solvent evaporation and

(3) ion ejection from the highly charged droplets (Figure 2.3) into the tube, which is maintained at a high voltage (e.g., $2.5-6.0 \mathrm{kV}$ ) relative to the wall of the surrounding chamber.

A mist of highly charged droplets with the same polarity as the capillary voltage is generated. The application of a nebulizing gas (e.g. nitrogen), which shears around the eluted sample solution, enhances a higher sample flow rate. The charged droplets, generated at the exit of the electrospray tip, pass down a pressure and potential gradient toward the analyzer region of the mass spectrometer. With the aid of an elevated ESIsource temperature and/or another stream of nitrogen drying gas, the charged droplets are continuously reduced in size by evaporation of the solvent, leading to an increase of surface charge density and a decrease of the droplet radius. Finally, the electric field 
strength within the charged droplet reaches a critical point at which it is kinetically and energetically possible for ions at the surface of the droplets to be ejected into the gaseous phase. The emitted ions are sampled by a sampling skimmer cone and are then accelerated into the mass analyzer for subsequent analysis of molecular mass and measurement of ion intensity. The mass spectrum is a graphical display of the relative abundance of ion signals against the $\mathrm{m} / \mathrm{z}$ ratios. It is a common practice that the highest signal is taken as $100 \%$ abundance and all the other signals are expressed as a percentage of this. $^{48}$

Mass spectra of products from reaction mixtures were taken on a high-resolution $(\mathrm{m} / \Delta \mathrm{m}=30$ 000) Thermo Scientific LTQ-Orbitrap Discovery mass spectrometer (San Jose, CA) equipped with an electrospray ionization source. All mass spectrometer samples were dissolved in $\mathrm{MeOH} / \mathrm{H}_{2} \mathrm{O}$ (1:1) mixture. The ESI-MS source parameters were set as follows: spray voltage of $2.5 \mathrm{kV}$, spray current of $1.96 \mu \mathrm{A}$, sheath gas flow rate of 20, auxiliary gas flow rate of 0.01 , capillary voltage of $-16 \mathrm{~V}$, capillary temperature of $300{ }^{\circ} \mathrm{C}$ and tube lens of $-115 \mathrm{~V}$. Detection was carried out in the negative ionization mode (-ESI) for 2 minutes in mass range $m / z$ of $100-1000$. The detection parameters were set up as follows: Analyzer was Fourier transform mass spectrometry (FTMS), negative polarity; mass range was normal with resolution of 30000 and scan type was centroid. 


\subsubsection{Methods}

Peroxynitrite Synthesis. Peroxynitrite was synthesized in a quenched-flow reactor. Solutions of (i) $0.6 \mathrm{M} \mathrm{NaNO}_{2}$ and (ii) $0.6 \mathrm{M} \mathrm{HCl} / 0.7 \mathrm{M} \mathrm{H}_{2} \mathrm{O}_{2}$ were pumped at $26 \mathrm{ml} / \mathrm{min}$ into a tee-junction and mixed in a $3-\mathrm{mm}$ diameter by $2.5-\mathrm{cm}$ glass tube. The acid catalyzed reaction of nitrous acid with $\mathrm{H}_{2} \mathrm{O}_{2}$ to form peroxynitrous acid was quenched by pumping $1.5 \mathrm{M} \mathrm{NaOH}$ at the same rate into a second tee-junction at the end of the glass tubing. Excess $\mathrm{H}_{2} \mathrm{O}_{2}$ was removed by passage over a 1 x $5 \mathrm{~cm}$ column filled with $4 \mathrm{~g}$ of granular $\mathrm{MnO} 2$. Fresh peroxynitrite solution was prepared every day. Peroxynitrite as determined by absorbance at $302 \mathrm{~nm}$ in $1 \mathrm{M} \mathrm{NaOH}\left(\varepsilon_{302} \mathrm{~nm}=1670 \mathrm{M}^{-1} \mathrm{~cm}^{-1}\right)$.

Interference by other absorbing compounds (e.g., nitrite) was corrected by subtracting the final absorbance after adding peroxynitrite to $100 \mathrm{mM}$ potassium phosphate ( $\mathrm{pH} 7.4) .{ }^{49}$

Spectroscopic determination was made using wavelength absorbance maximum of peroxynitrite at $302 \mathrm{~nm}$, with molar absorptivity coefficient of $1670 \mathrm{M}^{-1} \mathrm{~cm}^{-1}$. In the case of iodometric determination, the oxidizing power of peroxynitrite was determined by titration with excess acidified iodide. Released iodine was titrated against standard thiosulfate solution. The end point of titration was enhanced by starch indicator spiked with micromolar concentration of iodide ions for preservative purpose. Concentration of peroxynitrite was then back calculated from moles of thiosulfate.

$$
\begin{array}{lr}
\mathrm{ONOOH}+2 \mathrm{I}^{-}+2 \mathrm{H}^{+} \rightarrow \mathrm{I}_{2}+\mathrm{HNO}_{2}+\mathrm{H}_{2} \mathrm{O} & \mathrm{R} 2.2 \\
\mathrm{HNO}_{2}+2 \mathrm{I}^{-}+2 \mathrm{H}^{+} \rightarrow 2 \mathrm{NO}+\mathrm{I}_{2}+2 \mathrm{H}_{2} \mathrm{O} & \mathrm{R} 2.3
\end{array}
$$




$$
4 \mathrm{~S}_{2} \mathrm{O}_{3}{ }^{2-}+2 \mathrm{I}_{2} \rightarrow 2 \mathrm{~S}_{4} \mathrm{O}_{6}{ }^{2-}+4 \mathrm{I}^{-}
$$

\subsubsection{Computer Simulation:}

The proposed step-by step mechanisms of the kinetic reactions in this study were computer simulated to check for plausibility. These simulations are important as they allow detailed models to be developed and tested as data accumulate. They provide a means of evaluating various hypotheses for further experimental investigation. These include reaction mechanism, with appropriate rate constants and a set of parameter values describing the initial conditions which are similar to those used in the experiment. The models give concentrations of the chemical variables as a function of time, which can be compared to the experimental traces. Usually, guessed variables like rate constants are altered until the simulated traces are comparable to the experimental traces. Those rate constants derived from literature values are not altered. Kintecus software developed by

James C. Ianni was used for carrying out simulations in this study. ${ }^{50}$ It is a reliable compiler used to model the reactions of chemical, biological, nuclear and atmospheric processes using three input data files: a reaction spreadsheet, a species description spreadsheet and a parameter description file. In addition, one can fit/optimize almost any numerical value (rate constants, initial concentrations, starting temperature, etc.) against an experimental dataset. Normalized sensitivity coefficients are used in accurate mechanism reduction, determining which reactions are the main sources and sinks (network analysis) and also shows which reactions require accurate rate constants and which ones can have essentially guessed rate constants. ${ }^{51}$ Kintecus software is a user friendly package requiring no programming or compiling skills by the user. 


\section{CHAPTER THREE}

\section{KINETICS AND MECHANISMS OF NITROSATION OF CYSTEAMINE AND DECOMPOSITION OF PEROXYNITRITE}

\subsection{INTRODUCTION}

\subsubsection{Cysteamine}

Cysteine, homocysteine, and cysteamine are three related amino-thiols that exist in tissues and body fluids at low levels. ${ }^{52}$ Although cysteineamine is neurotoxic, ${ }^{53}$ it is a rate-limiting synthetic precursor of glutathione in neurons. ${ }^{54}$ The latter plays a critical role in defending cells against oxidative stress. It is the simplest stable amino-thiol and a degradation product of the amino acid cysteine. Cysteamine is medically known as Cystagon and can be used as oral therapy for the prevention of hypothyroidism and as a growth enhancer in patients with nephropathic cystinosis. ${ }^{55}$ Cystinosis clinically recognized since 1903, is an autosomal recessive lysosomal storage disease caused by mutations in cystinosin, lysosomal cystine transporter (CTNS). This gene codes for a lysosomal cystine transporter, whose absence leads to intracellular cystine crystals, widespread cellular destruction, renal Fanconi syndrome in infancy, renal glomerular failure in later childhood and other systemic complications. ${ }^{56}$ Cysteamine can cross the lysosome membrane, react with the cystine to form a mixed disulfide which can be transported out of the lysosome. ${ }^{57}$ Cysteamine has also been shown to be an effective molecule against hepatotoxicity caused by excessive production of nitric oxide. ${ }^{58}$ Some work has been done on the nitrosating agent is produced in situ, by premixing $\mathrm{H}^{+}$and 
$\mathrm{NO}_{2}{ }^{-}{ }^{59}$ In this work we report both the S-nitrosation of cysteamine by a binary toxin (Peroxynitrite) assembled spontaneously whenever nitric oxide and superoxide are produced together and also communicate on the decomposition of peroxyinitrite. The study of mechanism of the oxidation the sulfhydryl ( $\mathrm{SH}$ ) group of cysteamine is thus important because it predicts possible bioactivation metabolites and controls the inhibitory potency of the drug.

\subsection{RESULTS}

\subsubsection{Reaction Dynamics}

The kinetics of oxidation and nitrosation of CA by peroxynitrite was followed by monitoring the formation of CANO at $545 \mathrm{~nm}$ and depletion of peroxynitrite at $302 \mathrm{~nm}$ on the stopped-flow spectrophotometer. At $545 \mathrm{~nm}$, there is no interference from $\mathrm{NO}_{2}^{-}$ peak and the peak from the products. The depletion of PN reactions could be followed at $302 \mathrm{~nm}$ only in the very initial stages before accumulation of products that absorb much more strongly at $332 \mathrm{~nm}$ and this peak's shoulder overlapped with the peak at $302 \mathrm{~nm}$.

Figure 3.1 shows the superimposition of the three spectra for peroxynitrite (PN), cysteamine (CA) and the product of $\mathrm{PN}$ and $\mathrm{CA}$ in phosphate buffer of $\mathrm{pH}$ 7.4. The CANO peak was isolated from the organic species, and thus formation of CANO could be followed without any interference. The value of the absorption coefficient of CANO adopted for this study of $16.0 \mathrm{M}^{-1} \mathrm{~cm}^{-1}$ was derived from mixing order. 


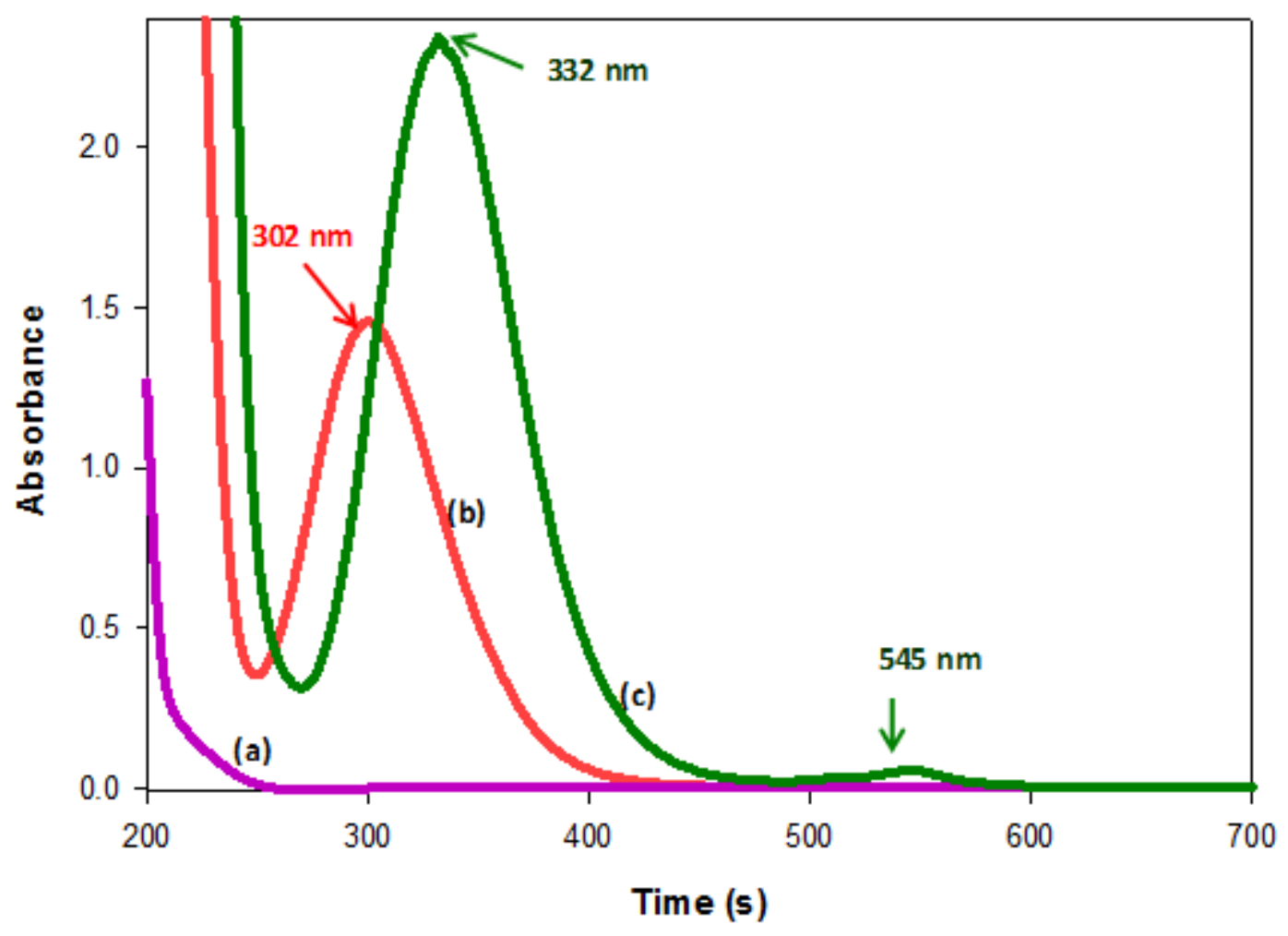

Figure 3. 1: Spectral scans of $C A, P N$, and the product of a mixture of acidified $P N$ and $C A$. CA has no significant absorbance in either the near-UV or vis regions; $P N$ absorbs in the $U V$ region at $302 \mathrm{~nm}$; product of a mixture of acidified PN and CA absorbs at two wavelengths, 332 and $545 \mathrm{~nm}$. The 545 $\mathrm{nm}$ peak is isolated and can be used to quantify CANO concentrations.

\subsubsection{Stoichiometric Determinations}

Stoichoimetric determinations of cysteamine and peroxinitrite were performed in excess of the oxidant (peroxynitrite) concentrations. CA concentration was maintained at 0.001 M, whilst the concentration of the PN used was 0.005 M. Excess acidified iodide was added to the reaction mixture and then quantified the iodine formed using iodometric 
titration. Iodine formation was faster than the rate of PN depletion; as a result iodine was then quantitatively formed as a function of the excess unreacted PN. The iodine formed was titrated against standardized thiosulfate using start as the indicator. The concentration of PN was then calculated from the moles of thiosulfate. The Stoichiometric ratio was a 1:2, PN to CA and this is confirmed by the ESI-MS results shown in Figure 3.3 and Figure 3.4 in which the dimer (CA-CA) was the dominant product. The stoichiometric ratio of CA oxidation by PN was determined as follows:

Formation of sulfenic acid intermediate:

$$
\mathrm{ONOO}^{-}+\mathrm{CA} \longrightarrow \mathrm{CAOH}+\mathrm{NO}_{2}^{-}
$$

Disulfide formation:

$$
\mathrm{CAOH}+\mathrm{CA} \longrightarrow \mathrm{CA}-\mathrm{CA}+\mathrm{H}_{2} \mathrm{O}
$$

Overall Stoichiometric ratio:

$$
\mathrm{ONOO}^{-}+\mathrm{CA}-\mathrm{CA} \longrightarrow \mathrm{CA}-\mathrm{CA}+\mathrm{NO}_{2}^{-}+\mathrm{H}_{2} \mathrm{O}
$$

\subsubsection{Product Identification}

Product identification and verification was achieved by complementary techniques: UV/vis spectrophotometry, Orbitrap ESI-MS and EPR spectrometry. CANO was identified by its distinct spectral absorption peak at $332 \mathrm{~nm}$ with extinction coefficient of $536 \mathrm{M}^{-1} \mathrm{~cm}^{-1}$ and by another peak at $545 \mathrm{~nm}$ with a smaller extinction 
coefficient of $16.0 \mathrm{M}^{-1} \mathrm{~cm}^{-1}$ which was used in this study. It has a pink color, which is consistent with the characteristic of primary S-nitrosothiols. ${ }^{60}$ Orbitrap ESI mass spectrometry was used to prove that identity of product of nitrosation was CANO and that of decomposition of CANO to be disulfide of cysteamine called cystamine (CACA).

\subsubsection{Electrospray-Ionization Mass Spectrometer (ESI-MS) Study on the Oxidation Products of CA}

Figure 3.2 shows 2 oxidation products that were obtained in the positive mode for the reaction in basic conditions namely hypotaurine $\left[\mathrm{H}_{2} \mathrm{NCH}_{2} \mathrm{CH}_{2} \mathrm{SO}_{2} \mathrm{H}+\mathrm{H}^{+}\right]=110 \mathrm{~m} / \mathrm{z}$ ratio and 2-aminoethyl-2-aminoethanethiolsulfonate $\left[\mathrm{H}_{2} \mathrm{NCH}_{2} \mathrm{CH}_{2} \mathrm{SO}_{2} \mathrm{SCH}_{2} \mathrm{CH}_{2} \mathrm{NH}_{2}+2 \mathrm{H}^{+}\right]=93 \mathrm{~m} / \mathrm{z}$ ratio (positive mode) and $\left[\mathrm{H}_{2} \mathrm{NCH}_{2} \mathrm{CH}_{2} \mathrm{SO}_{2} \mathrm{SCH}_{2} \mathrm{CH}_{2} \mathrm{NH}_{2}-2 \mathrm{H}^{+}\right]=91 \mathrm{~m} / \mathrm{z}$ ratio (negative mode, Figure 3.3). There was no evidence from ESI-MS for the formation of the sulfenic acid in the oxidation pathway as the thiol group is rapidly oxidized to the sulfonic acid. The sulfonic acid was captured in the negative mode (Figure 3.3), as $\left[\mathrm{H}_{2} \mathrm{NCH}_{2} \mathrm{CH}_{2} \mathrm{SO}_{3} \mathrm{H}-\mathrm{H}^{+}\right]=124 \mathrm{~m} / \mathrm{z}$ ratio. The S-nitrosocysteamine (CANO) was also observed in the negative mode as $\left[\mathrm{H}_{2} \mathrm{NCH}_{2} \mathrm{CH}_{2} \mathrm{SNO}-\mathrm{H}^{+}\right]=106 \mathrm{~m} / \mathrm{z}$ ratio with very small relative abundance of approximately $3 \%$. In the positive mode CANO was also observed with even lower relative abundance of about $1 \%$. The dimer was capture in the negative mode as $\left[\left(\mathrm{H}_{2} \mathrm{NCH}_{2} \mathrm{CH}_{2} \mathrm{~S}\right)_{2}-\mathrm{H}^{+}\right]=151 \mathrm{~m} / \mathrm{z}$ ratio.

Scheme 3.1 shows route (i) which is the proposed dominant oxidation pathway of CA by PN under basic conditions. There is a 2-electron oxidation of CA by PN to give 
the sulfenic acid of cysteamine $(\mathrm{CAOH})$ and the reaction is then followed by either a series of 2 electron oxidations to give sulfinic acid $\left(\mathrm{CAO}_{2} \mathrm{H}\right)$ and sulfonic acid $\left(\mathrm{CAO}_{3} \mathrm{H}\right)$ respectively or to produce a dimer. On each 2 electron oxidation stage a nitrite ion was formed. Lobachev at el, observed that nitrite ions are formed for PN oxidations at alkali $\mathrm{pH}$ below 12 compared to nitrate ions. ${ }^{8}$ An alternative pathway when the sulfenic acid reacts with free $\mathrm{CA}$ it will lead to dimerization. When barium chloride was added to the solution a white precipitate was observed which suggest that a sulfate was being formed in the oxidation of CA by PN under basic conditions. The sulfenic acid should be very reactive in the polar aqueous environment used for these sets of studies. In water, the sulfenic acid will form an equilibrium mixture with its hydrated form. The cleaving of the $\mathrm{C}-\mathrm{S}$ bond occurs at this point, leaving a very highly reducing sulfur leaving group which is rapidly oxidized to sulfate. ${ }^{61}$ The sequence is depicted in Scheme 2 shows a proposed reaction pathway which led to the formation of the sulfate ions.

Route (ii) shows oxidation pathway which was is proposed to be the dominant route for acidified reactions between $\mathrm{CA}$ and $\mathrm{PN}$ in which cysteamine radical (CA.) is formed from reaction peroxynitrous acid. The cysteamine radical can then with another radical of its kind to form a dimer or react with a nitroso radical to form $\mathrm{S}$ nitrosocysteamine (CANO). 


\subsection{Peroxynitrite Oxidation Pathways}

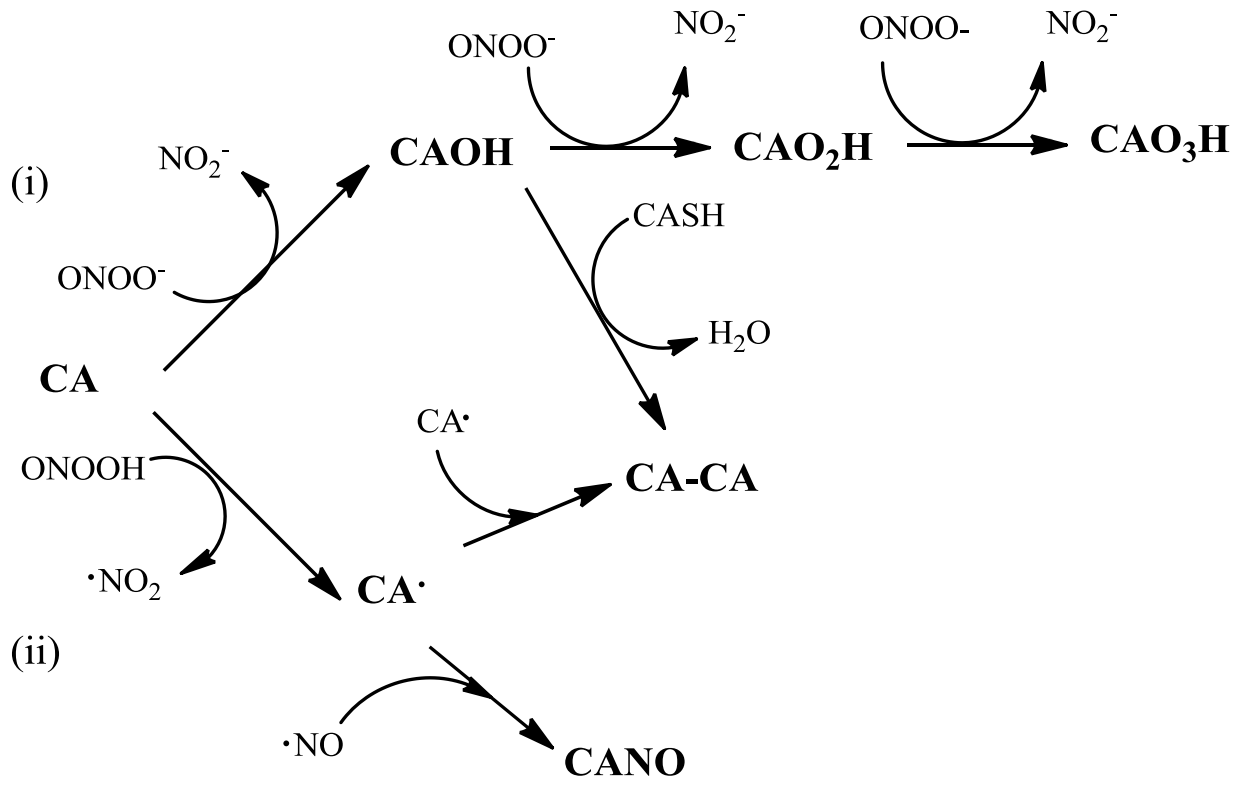

Scheme 3. 1: (i) Two-electron oxidation pathway. Peroxynitrite reacts with the thiol group producing the unstable sulphenic acid which can either go through 2 similar oxidation reactions to form sulfinic and sulfonic acid respectively or reacts with another thiol yielding the disulphide. (ii) One-electronoxidation pathway. Peroxynitrous acid reacts with the thiol producing the thiyl radical. The latter can dimerize to the disulphide, or can react with the nitroso radical yielding the S-nitrosocysteamine. 


\subsection{Sulfate Ion Formation Pathways}

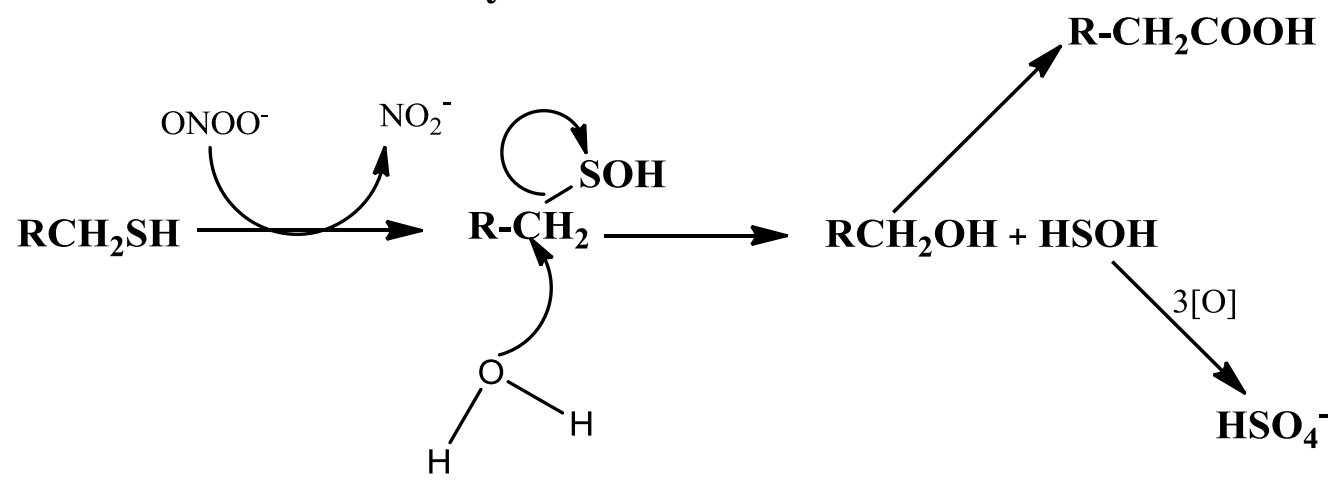

Scheme 3. 2: Two-electron oxidation pathway of CA. Peroxynitrite reacts with the thiol group producing the unstable sulphenic acid which reacts with water to form a primary alcohol which can be further oxidized to form a carboxylic acid. This sulfoxide can go through a series of oxidation stages to form the sulfate ion.

A resolvable mass spectrum taken at basic conditions will generally show the reagent, $\mathrm{CA}$, and the single product, $\mathrm{CANO}$, the the mass spectrum is shown in Figure 3.4. gave 4 distinct peaks. The peak of the cystamine(dimer) was observed as $\left[\left(\mathrm{H}_{2} \mathrm{NCH}_{2} \mathrm{CH}_{2} \mathrm{~S}_{2}\right)+\mathrm{H}^{+}\right]=153 \mathrm{~m} / \mathrm{z}$ ratio and $\left[\left(\mathrm{H}_{2} \mathrm{NCH}_{2} \mathrm{CH}_{2} \mathrm{~S}_{2}\right)+\mathrm{Na}^{+}\right]=175 \mathrm{~m} / \mathrm{z}$ ratio can be discerned from the reaction mixture. Apart from the one from $107 \mathrm{~m} / \mathrm{z}$ from Snitrosocysteamine, another $107.9 \mathrm{~m} / \mathrm{z}$ ratio was observed which was due to (2aminoethyl)disulfen-1-ium $\left[\mathrm{H}_{2} \mathrm{NCH}_{2} \mathrm{CH}_{2} \mathrm{SS}^{+}\right]$which is a result of fragmentation of the dimer (scheme 3.3). $\left[\mathrm{H}_{2} \mathrm{NCH}_{2} \mathrm{CH}_{2} \mathrm{SO}_{2} \mathrm{SCH}_{2} \mathrm{CH}_{2} \mathrm{NH}_{2}+2 \mathrm{Na}^{+}\right]=115 \mathrm{~m} / \mathrm{z}$ ratio peak of 2aminoethyl-2-aminoethanethiolsulfonate was also observed. These results suggest that S-nitrosation of CA is high in acidic medium than in basic medium. 


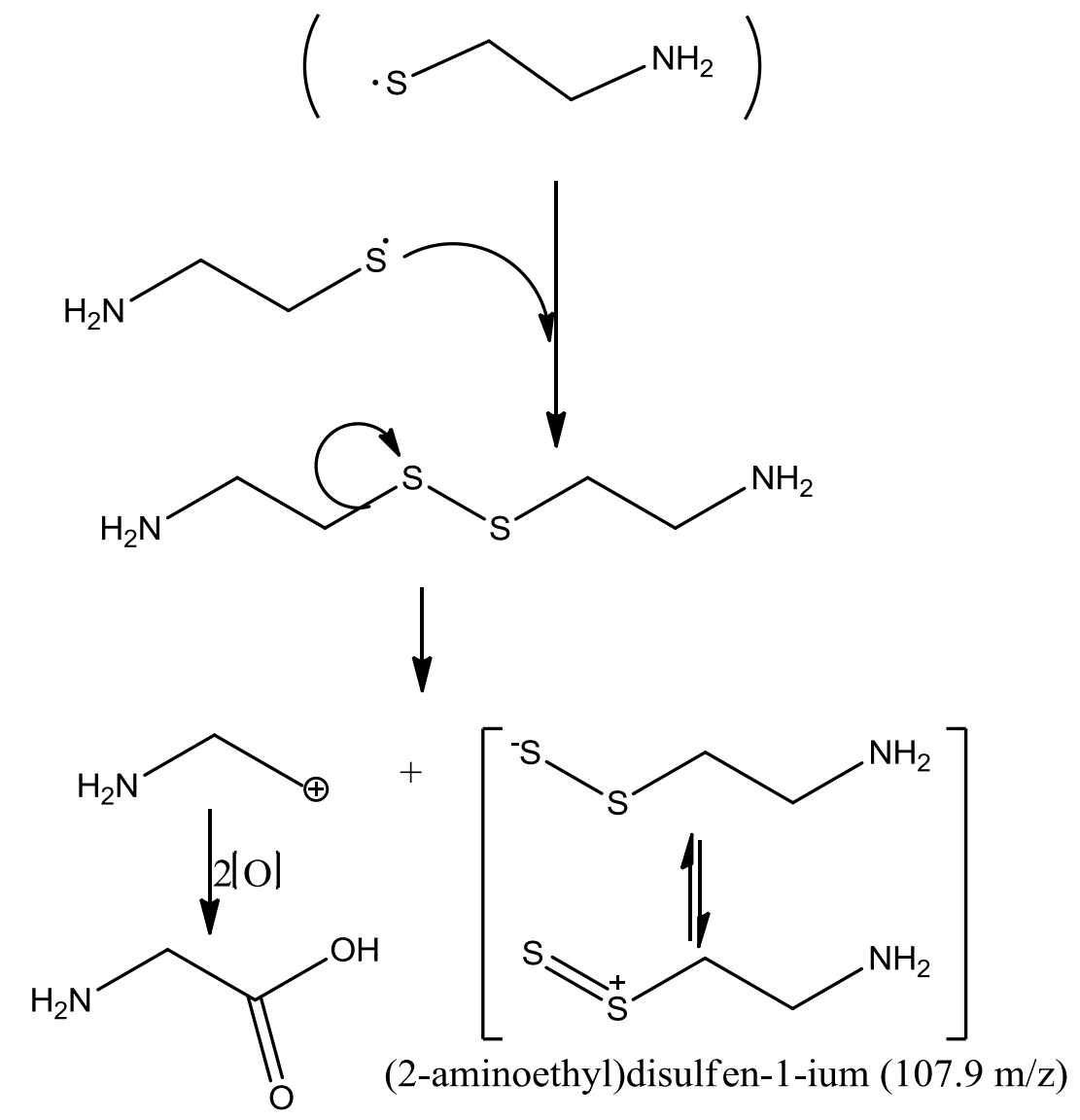

2-aminoacetic acid

Scheme 3. 3: Shows one-electron oxidation of cysteamine radial to form cystamine (dimer). The C-S bond can break to form (2-aminoethyl)disulfen-1-ium ion and 2aminoethane carbocation with can be oxidized to give 2-minoacetic acid. 


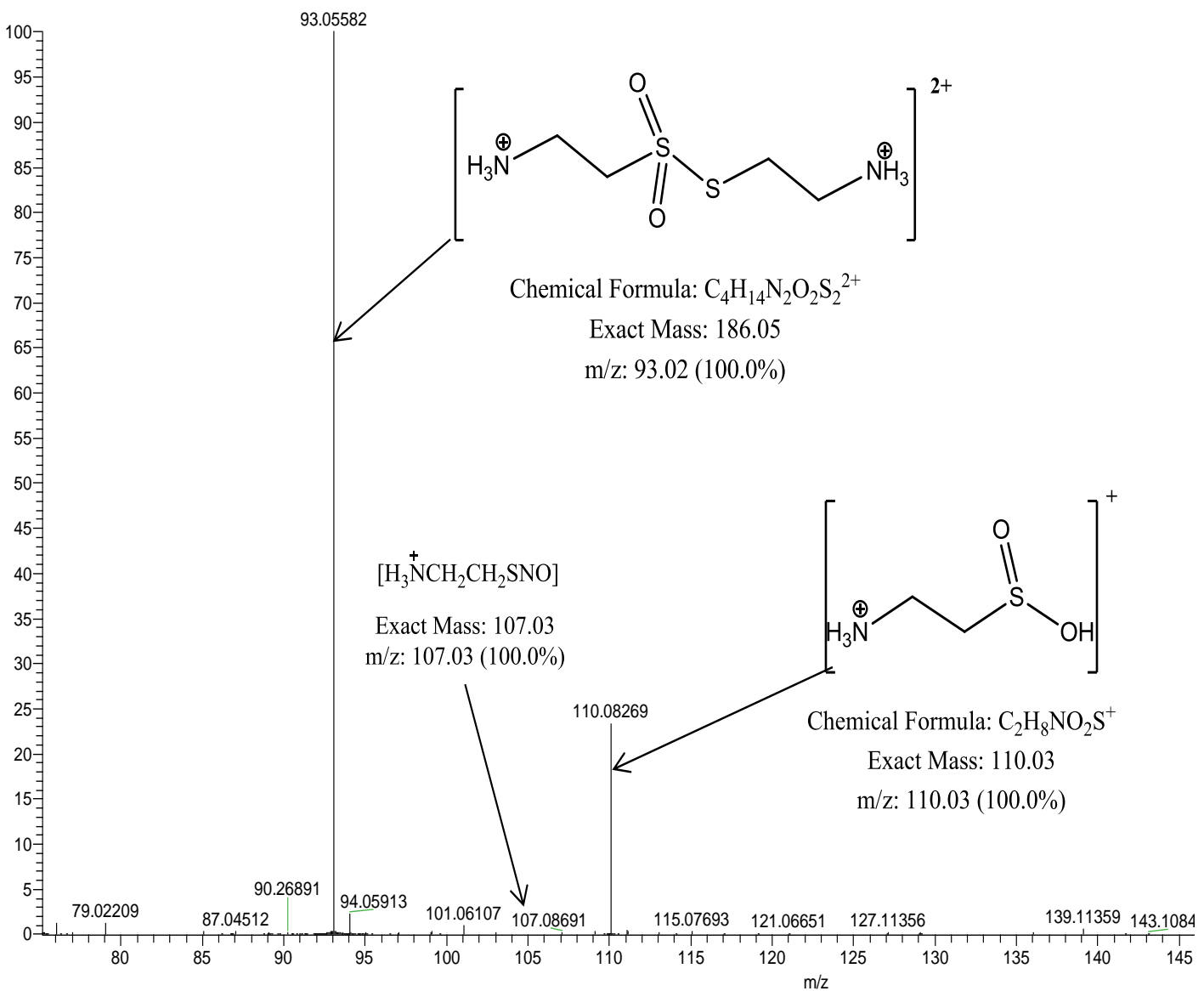

Figure 3. 2: Positive ESI-MS spectrum of a stoichiometric CA-PN in basic medium using 10:90 methanol:water as solvent. This spectrum was taken 24 hours into the reaction. 


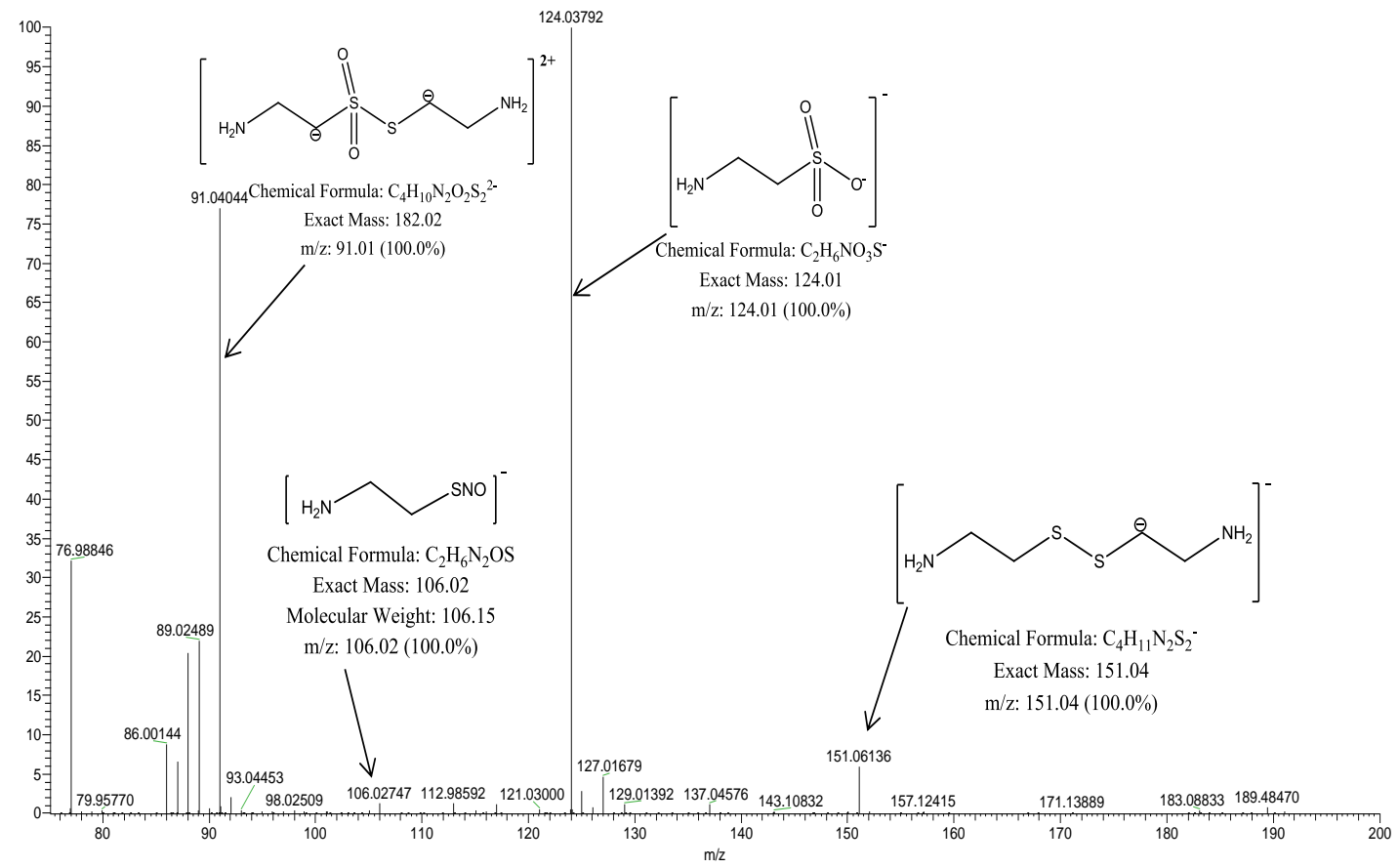

Figure 3. 3: Negative ESI-MS spectrum of a stoichiometric CA-PN in basic medium using 10:90 methanol:water as solvent. This spectrum was taken 24 hours into the reaction. 


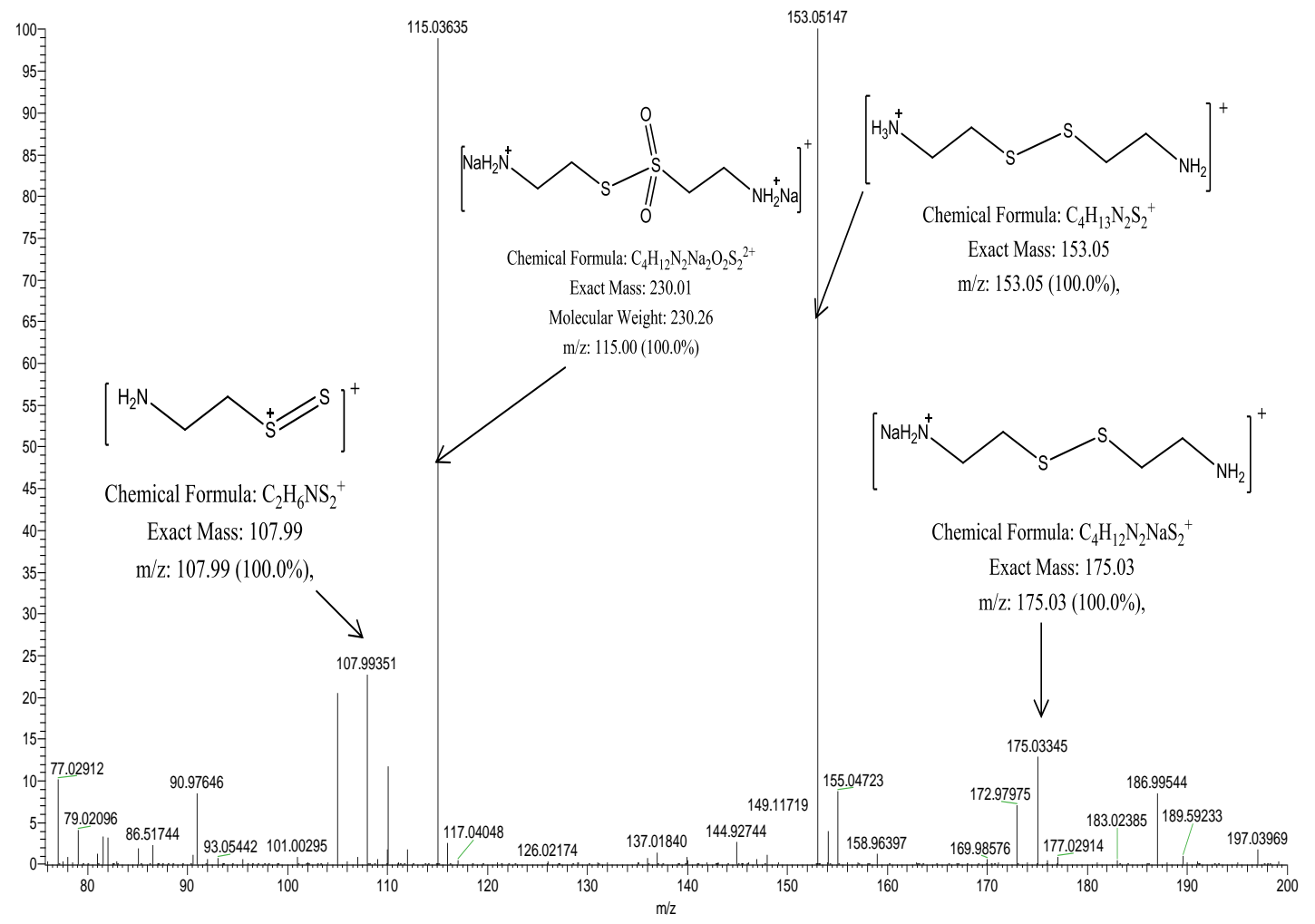

Figure 3. 4: Positive ESI-MS spectrum of a stoichiometric CA-PN in acidic medium taken after $24 \mathrm{~h}$ of the start of reaction. 


\subsection{Peroxynitrite and Free Radical Formation}

From the proposed reaction mechanism in scheme 3.1, it shows that nitrosation and oxidation of $\mathrm{CA}^{A}$ involves some $\mathrm{NO}^{*}$ and $\mathrm{CA}^{*}$ radicals. For that reason we embarked on another set of experiments to test the existence of these radicals using EPR. Figure 3.5 shows spectra for of the reaction between $\mathrm{CA}$ and $\mathrm{PN}$ in 3 different buffer $\mathrm{pHs}$, namely 3.0, 7.4 and 11.5. The EPR signal that was observed during PN-CA reaction in pH 3.0 phosphate buffer gave sextet of lines, with a peak height ratio of 1:1:1:1:1:1 and was of low EPR signal intensity.

$$
\begin{array}{ll}
\mathrm{ONOO}^{-}+\mathrm{H}^{+} \rightleftharpoons & \mathrm{R} 3.1 \\
\mathrm{ONOOH} \longrightarrow \mathrm{ONOOH}+\mathrm{OOH} & \mathrm{R} 3.2
\end{array}
$$

The sextet splitting was due to DMPO-OOH adduct generated from equation R3.2. As the $\mathrm{pH}$ increased from 3.0 to 7.4 the hyperfine splitting changed with second and the fifth peaks going down whilst the remaining 4 peaks grew. These peaks were due to DMPOSAC adduct which was overpowering the DMPO-OOH adduct. At a high alkaline (Figure 3.5(c)) pH 11.5 the PN reaction with CA gave a clear quartet of lines, with peak height ration of 1:2:2:1 with parameters including hyperfine constants, $\mathrm{a}^{\mathrm{N}}=15.8 \mathrm{G}$ and $\mathrm{a}^{\mathrm{H}}=16.4 \mathrm{G}$. Spin trapping by DMPO was used for the detection of radicals $(\mathrm{OH}$ radicals) in Fenton media. In Fenton reagents based on Fe (II) radicals ( $\mathrm{OH}$ ) are produced and can react further to produce the hydroperoxy $(\cdot \mathrm{OOH})$ radical and the superoxide radical $\left(\mathrm{O}_{2}{ }^{--}\right)$shown by R3.3-R3.6. 


$$
\begin{array}{lc}
\mathrm{Fe}^{2+}+\mathrm{H}_{2} \mathrm{O}_{2} \longrightarrow \mathrm{Fe}^{3+}+\mathrm{OH}+\mathrm{OH}^{-} & \mathrm{R} 3.3 \\
\mathrm{OH}+\mathrm{H}_{2} \mathrm{O}_{2} \longrightarrow \mathrm{OOH}+\mathrm{H}_{2} \mathrm{O} & \mathrm{R} 3.4 \\
\mathrm{OOH}+\mathrm{H}_{2} \mathrm{O} \longrightarrow \mathrm{O}_{2}^{-}+\mathrm{H}_{3} \mathrm{O}^{+} & \mathrm{R} 3.5 \\
\mathrm{DMPO}+\mathrm{OH} \longrightarrow & \begin{array}{l}
\text { DMPO-OH } \\
\text { (EPR Active) }
\end{array}
\end{array}
$$
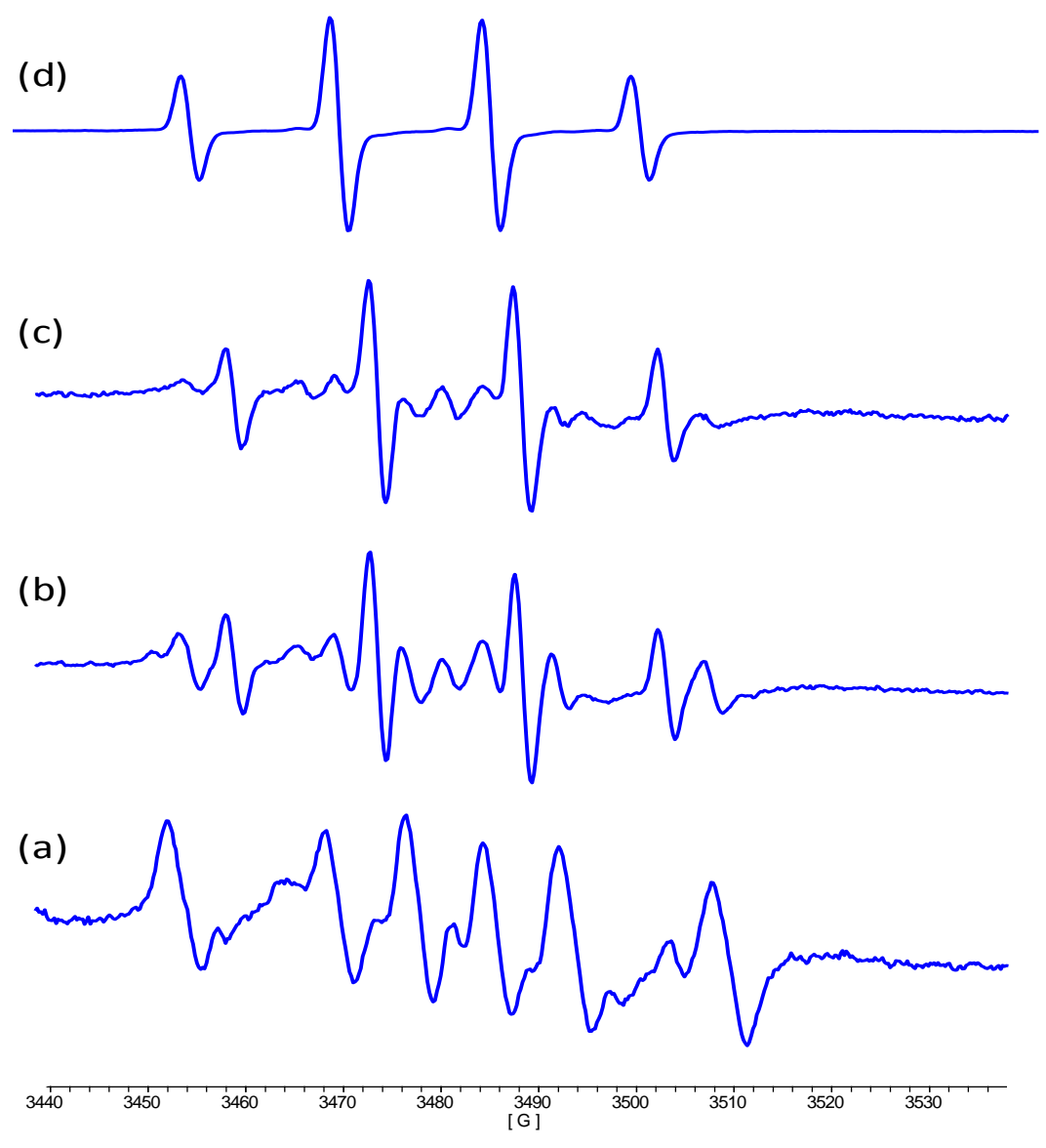

Figure 3.5 The EPR spectra of peroxynitrite and cysteamine on different $\mathrm{pHs}$. The spectra were obtained 2 mins after the addition of peroxynitrite to incubation mixtures containing 0.02 M DMPO with: (a) $[C A]_{0}=2 \mathrm{mM}$ in phosphate buffer pH 3.0, (b) $[C A]_{0}=2 \mathrm{mM}$ in phosphate buffer $\mathrm{pH} 7.4$, (c) $[C A]_{0}=2 \mathrm{mM}$ in phosphate buffer $\mathrm{pH}$ 11.5 and (d) DMPO-OH EPR Signal form DMPO, $\mathrm{Fe}^{2+}$ and $\mathrm{H}_{2} \mathrm{O}_{2}$. 
Hyperfine splitting constant of $\mathrm{a}^{\mathrm{N}}=\mathrm{a}^{\mathrm{H}}=14.8 \mathrm{G}$ and was attributed was attributed to the DMPO-OH. DMPO in Fenton media results agreed with what was obtained by Lloyd and co-workers in their studies on the origin of the hydroxyl radical oxygen in the Fenton reaction. ${ }^{62}$ This confirms that the EPR signal that was obtained at $\mathrm{pH} 11.5$ was due to DMPO-SAC adducts not DMPO-OH.

\subsection{Effect of pH Variation on Radical Formation}

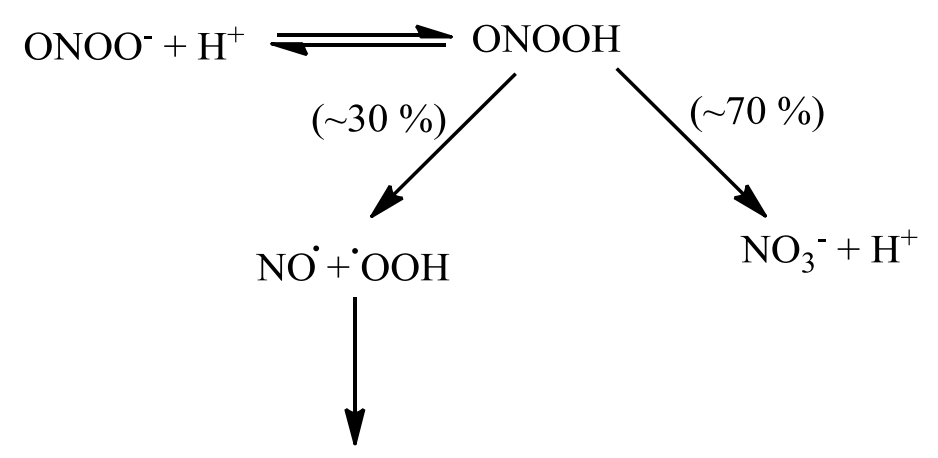

One electron oxidation

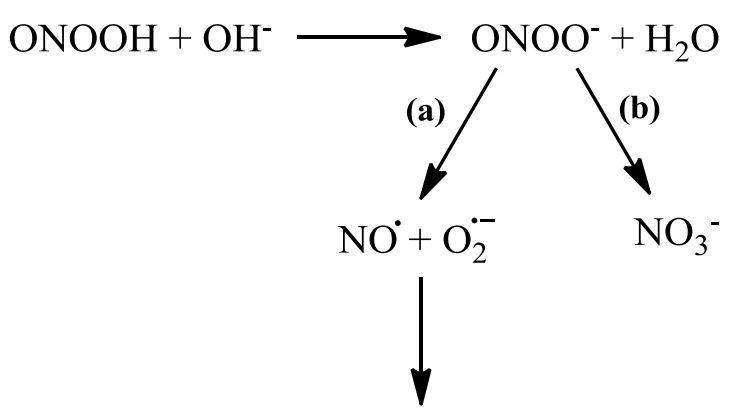

One electron oxidation and nitrations

Scheme 3. 4: Proposed reaction of peroxynitrite in (a) acidic and (b) basic medium respectively 
Figure 3.6 shows that the increase in $\mathrm{pH}$ resulted in corresponding increase in EPR signal intensity. At pH 1.5 which is acidic had the lowest EPR signal intensity of $45 \%$ and it rose up to $100 \%$ in alkaline $\mathrm{pH}$ of 11.5 . The mixture of $\mathrm{CA}$ and $\mathrm{PN}$ at $1: 2$ molar quantities resulted in about $45 \%$ increase in EPR signal at $\mathrm{pH} 1.5$. When $\mathrm{pH}$ was increase to 7.4, it was associated with 1.5 fold increase in EPR signal intensity. When $\mathrm{pH}$ was raised to 11.5 , the EPR signal intensity increased to $100 \%$. Lower EPR signal at lower $\mathrm{pHs}$ was due to the fast that $\mathrm{PN}$ is converted to its isomer nitrate and as the $\mathrm{pH}$ increases, less of PN will be converted hence more PN will be available for reaction (scheme 3.4).

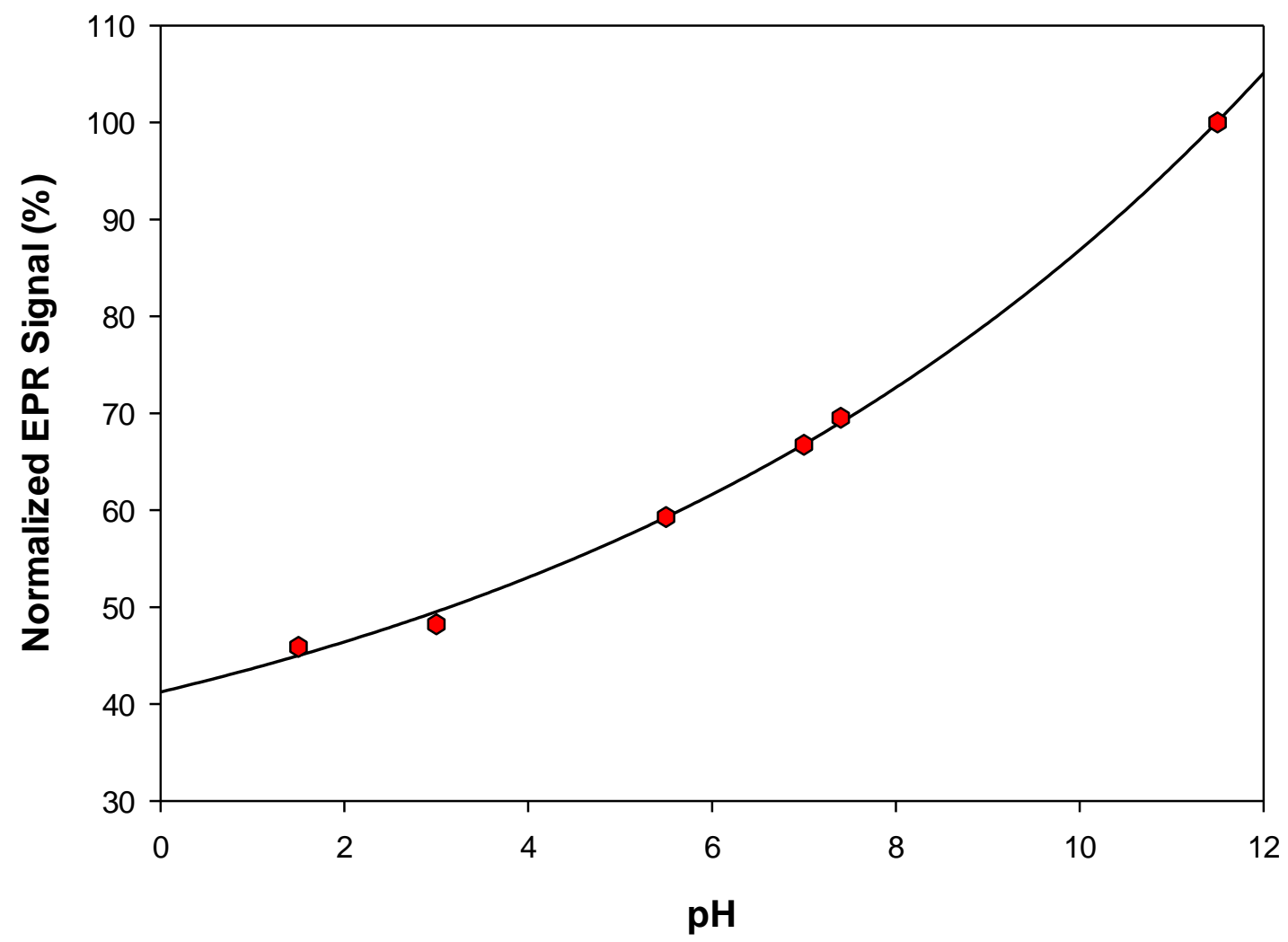

Figure 3. 6: Plot of changes in EPR signal intensity DMPO-SAC with $\mathrm{pH}$ variation at 25 ${ }^{o} \mathrm{C} .[\mathrm{DMPO}]_{0}=50 \mathrm{mM},[\mathrm{PN}]_{0}=0.02 \mathrm{M},[\mathrm{CA}]_{0}=0.05 \mathrm{mM}$, and varied $\mathrm{pH}=$ from 1.5 to 11.5, $100 \mathrm{mM}$ phosphate buffer of $\mathrm{pH}$ 7.4. 


\subsection{Nitric Oxide Radical Detection}

Nitric oxide was trapped and analyzed using EPR and nitroethane was used a spin trap. The aci-anion of this trap, generated in basic environments, generates a long-lived spin adduct with NO, which is detectable and quantifiable by its distinct ESR spectrum pattern and g-value:

$$
\left.\mathrm{CH}_{3} \mathrm{CH}=\mathrm{NO}_{2}^{-}+\mathrm{NO}^{-}+\mathrm{OH}^{-} \longrightarrow \mathrm{CH}_{3} \mathrm{C}(\mathrm{NO})\left(\mathrm{NO}_{2}\right)\right]^{2-}+\mathrm{H}_{2} \mathrm{O}
$$

The adduct $\left[\mathrm{CH}_{3} \mathrm{C}(\mathrm{NO})\left(\mathrm{NO}_{2}\right)\right]^{2-}$ is EPR-active. On Figure 3.7 (A), No EPR signal peaks were obtained in the EPR spectrum when the nitroethane trap was utilized in the absence of $\mathrm{PN}$, this indicates that $\mathrm{NO}$ radicals are not formed. Upon addition of PN which forms CANO and upon decomposition of CANO, however, a strong EPR spectrum indicating the presence of NO is obtained, proving stoichiometry R3.3. Figure 3.7 shows a series of EPR spectra that proves the release of NO radicals upon decomposition of CANO. The last 2 spectra ((B) and (C)) show that, $\mathrm{NO}$ radicals' formation is dependent on the concentration of PN. Production of $\mathrm{HNO}_{2}$ plays a significant role in the S-nitrosation and that it is not a major nitrosation agent in this mechanism that involves in situ. 


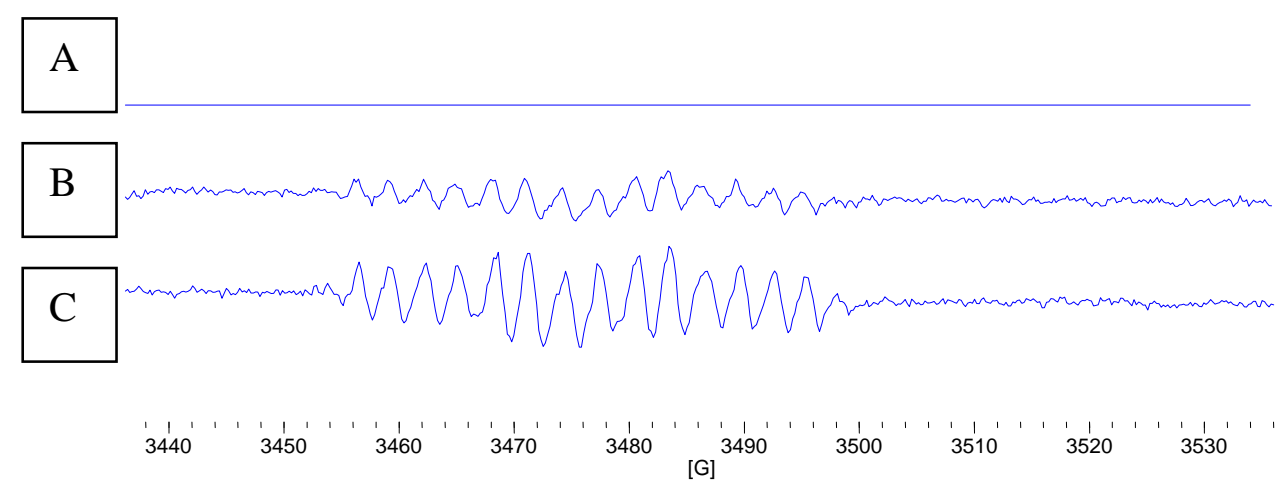

Figure 3. 7: Identification of $N O$ as a product of decomposition of S-nitrosocysteamine $(\mathrm{CANO})$ using Nitroethane as the spin trap. $[\mathrm{NE}]_{0}=0.5 \mathrm{M},[\mathrm{NaOH}]_{0}=1.0 \mathrm{M},[\mathrm{CA}]_{0}=$ $0.01 \mathrm{M}_{\left[\mathrm{NO}_{2}\right]_{0}}^{-}=0.01 \mathrm{M}$ and $[\mathrm{PN}]=(\mathrm{A}) \mathrm{O} \mathrm{M}$, (B) $6.12 \times 10^{-3} \mathrm{M}$ and $(\mathrm{C}) 1.0 \times 10^{-2} \mathrm{M}$. Nitroethane was prepared in $1.0 \mathrm{M} \mathrm{NaOH}$

\subsection{Effect of Peroxynitrite Variation on S-nitrosocysteamine Formation}

Figure 3.5 shows a series of experiments carried out with varying initial PN concentrations which CA was in excess $(([\mathrm{CA}] /[\mathrm{PN}])>230)$ while keeping all other parameters invariant. 


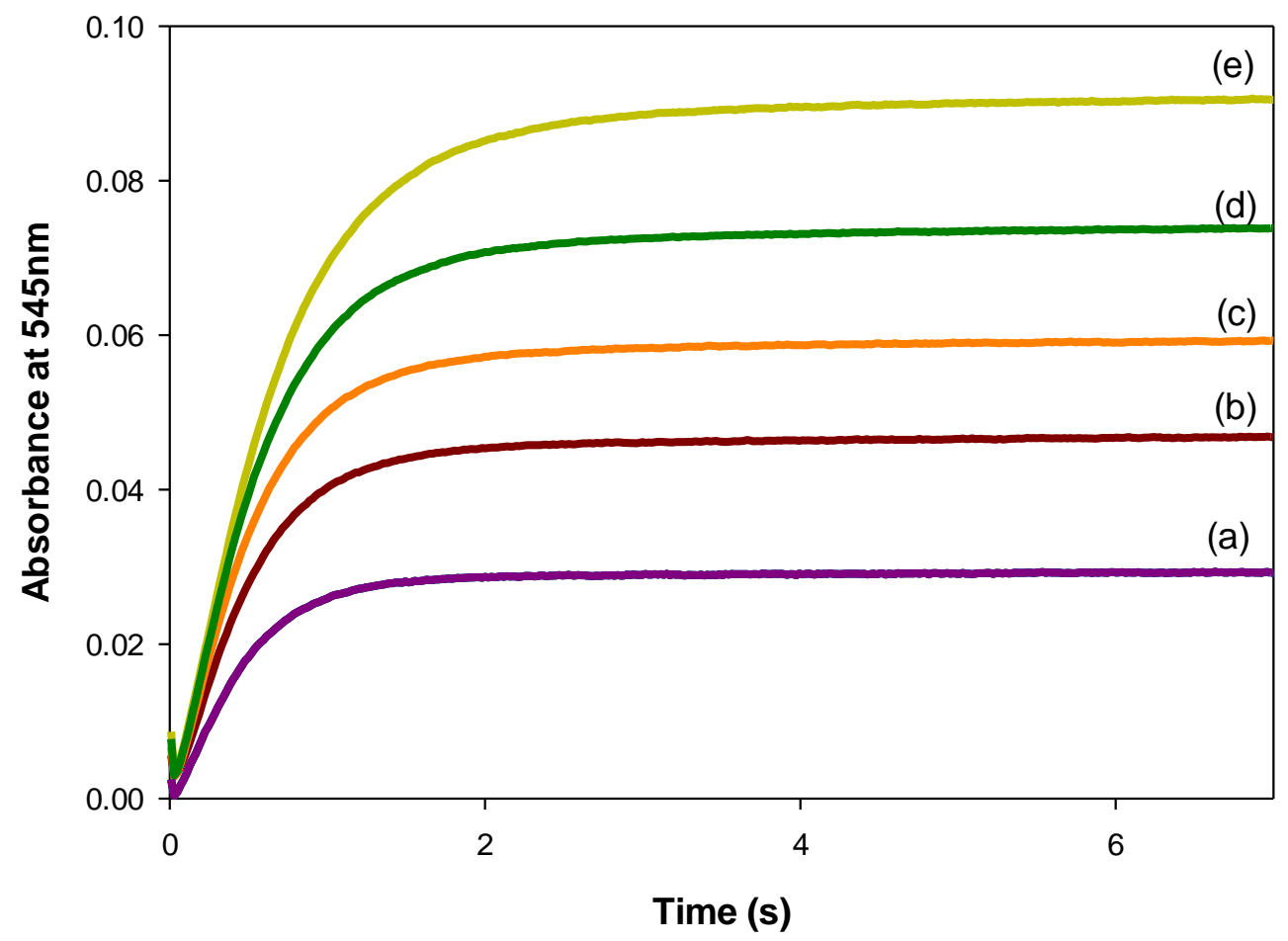

Figure 3. 8: Effect of peroxynitrite variation on Nitroso-cysteamine formation. Fixed, $[C A]_{0}=5.0 \times 10^{-2} \mathrm{M},[\mathrm{EDTA}]_{0}=1.0 \times 10^{-4} \mathrm{M},\left[\mathrm{H}^{+}\right]_{0}=6.25 \times 10^{-3} \mathrm{M}$ and varied $[\mathrm{PN}] \mathrm{x}$ $10^{-4} \mathrm{M}=(a) 0.42 \mathrm{M}$, (b) $0.84 \mathrm{M}$, (c) $1.27 \mathrm{M}$, (d) $1.69 \mathrm{M}$, (e) $2.11 \mathrm{M}$.

Increasing PN concentrations only affected the rate and the final amount of CANO produced according to the 1:1 ratio between ONOO- and CA (Scheme 3.1, route 2). In these series of experiments $\mathrm{PN}$ was the limiting reagent as a result, the concentration of PN determined the amount of CANO formed. The reaction was so fast that there was no induction period observed. 


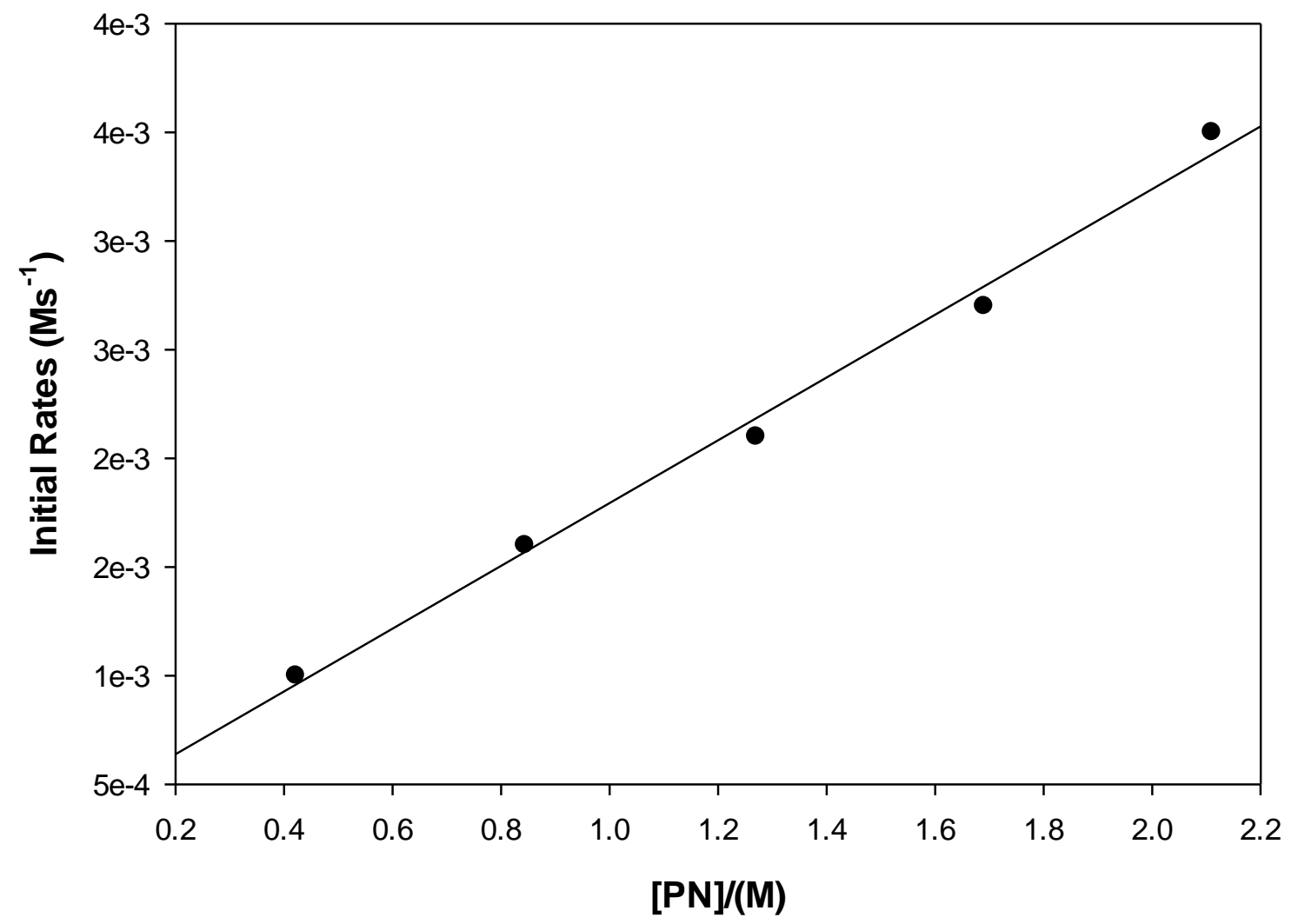

Figure 3. 9: This plot shows that there is a direct relationship between the initial rates and Peroxynitrite concentration for conditions shown in Figure 3.8.

The initial rate against PN concentration (Figure 3.6) shows that a linear relationship between initial rate and PN concentration meaning that the formation of CANO with respect to PN concentrations is first order. 


\subsection{Effect CA Variation on the Formation of CANO}

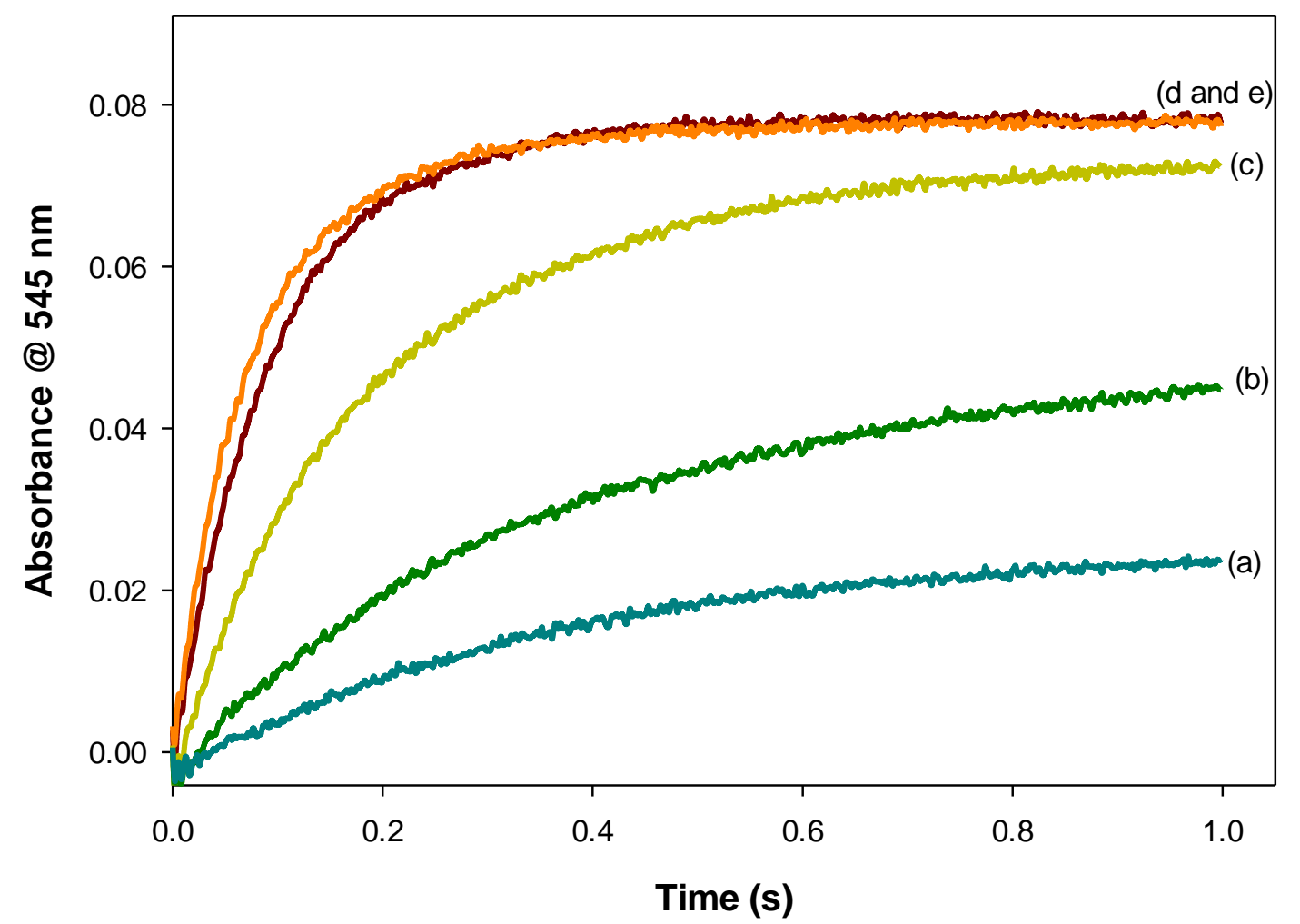

Figure 3. 10: Effect of $C A$ variation on Nitroso-cysteamine formation. Fixed $[E D T A]_{0}=1.0 x$ $10^{-4} \mathrm{M},\left[\mathrm{H}^{+}\right]_{0}=2.5 \times 10^{-2} \mathrm{M},[\mathrm{PN}]_{0}=2.8 \times 10^{-4} \mathrm{M}$ and varied $,[C A]_{0} \times 10^{-2} \mathrm{M},=(a) 0.25 \mathrm{M},(\mathrm{b})$ $0.50 \mathrm{M}$, (c) $1.0 \mathrm{M},(d) 2.0 \mathrm{M},(e) 3.0 \mathrm{M}$. 
Figure 3.10 shows that, the final amount of CANO formed was depended on the initial amount of CA. As a result, the final amount of CSHNO produced increased with an increase in $[\mathrm{CA}]_{0}$. This is would be expected because CA was in acid, and the acid compete with $\mathrm{CA}$ for $\mathrm{PN}$. When acid reacts with $\mathrm{ONOO}^{-}, \mathrm{ONOO}^{-}$decomposes to form $\mathrm{NO}_{3}{ }^{-}$(nitrate ion) which is unreactive towards CA. As CA concentration increases, acid will be out competed hence higher CANO is formed, until the rate rate of reaction reaches a limit (Figure 3.8, traces (d) and (e)). 


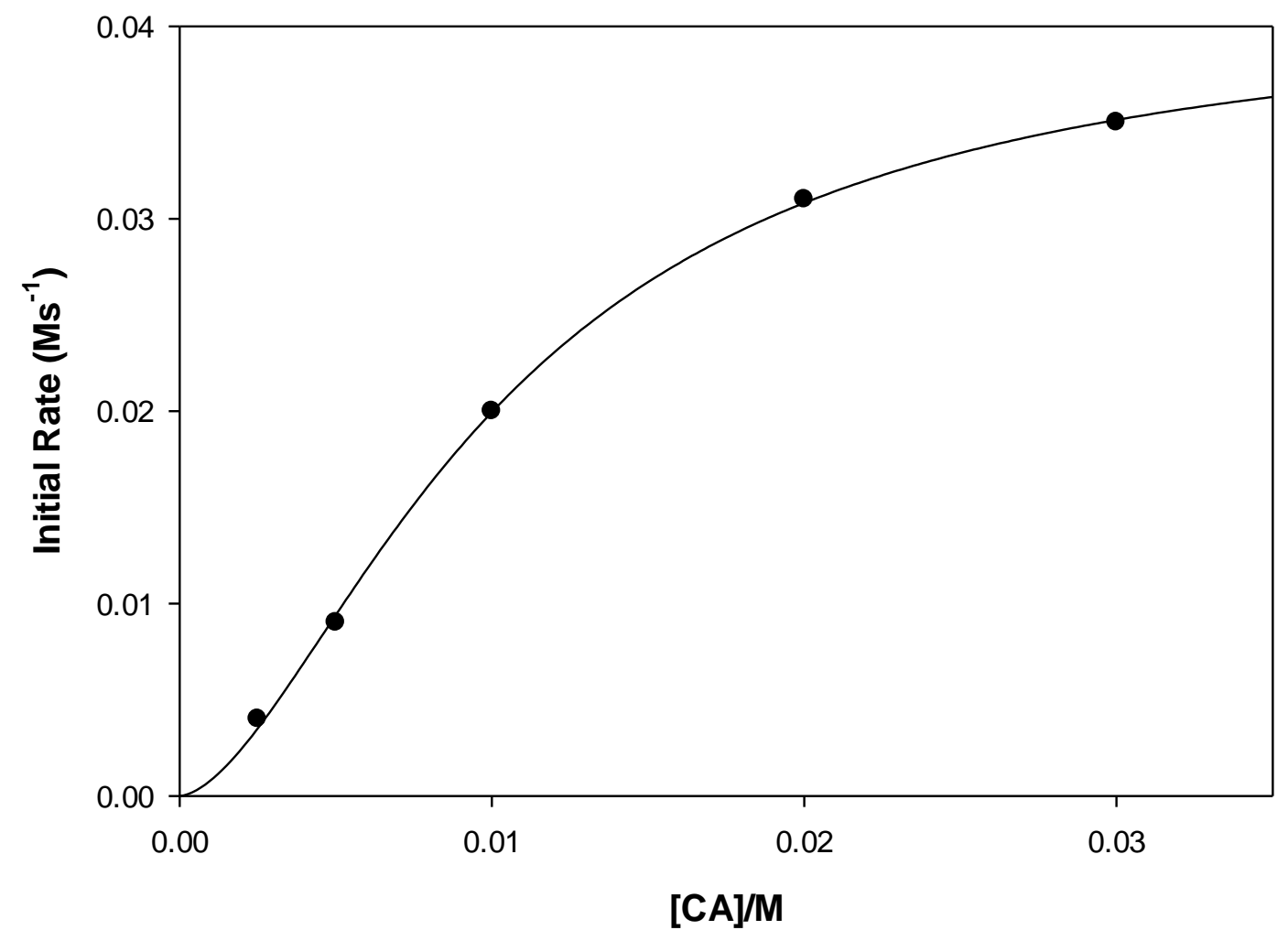

Figure 3. 11: A plot of initial rate of nitrosation of $C A$ versus $C A$ concentrations showing sigmoidal increase in the rate of formation of CANO with increase in the initial concentrations of CA for results shown in Figure 3.10.

\subsection{Effect of acid variation on the Formation of S-nitrosocysteamine}

We have also examined the reaction of peroxynitrous acid with CA at a much higher acidity $(>0.18 \mathrm{M})$. Here we find that S-nitrosothiols are generated when the thiol is present in a large excess $(([\mathrm{CA}] /[\mathrm{PN}])>500)$, in a very rapid reaction and the kinetic traces simple first-order plots. In order to obtain high yields of RSNO it is necessary to maintain a large excess of thiol over peroxynitrous acid. ${ }^{63}$ The final absorbance of CANO observed in Figure 3.10 arises from the use of stoichiometry R3.3 in which the limiting 
reagent to formation of CANO is PN. Higher acid concentrations increase the rate of formation of CANO and these reaction solutions attain the final CANO absorbance much more rapidly. Increasing the overall acid concentration show that the yield of CANO increases, this means that S-nitrosation of thiols is acid catalyzed. The yield of CANO did not decrease with increasing acidity meaning that the rate of CANO formation is faster that the rate of PN decomposition is lower at higher acidity.

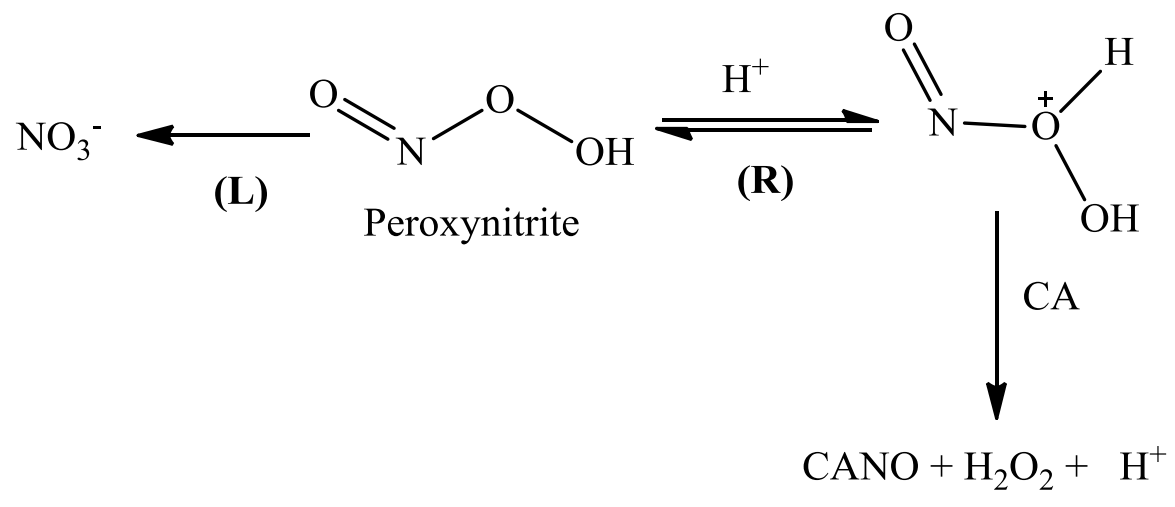

Scheme 3. 5: In acidic medium peroxynitrite gets protonated ( $R$ route) to form a cation of peroxynitrous acid which then reacts with $C A$ to form $C A N O$ or decompose to form nitrate ion (L route). 


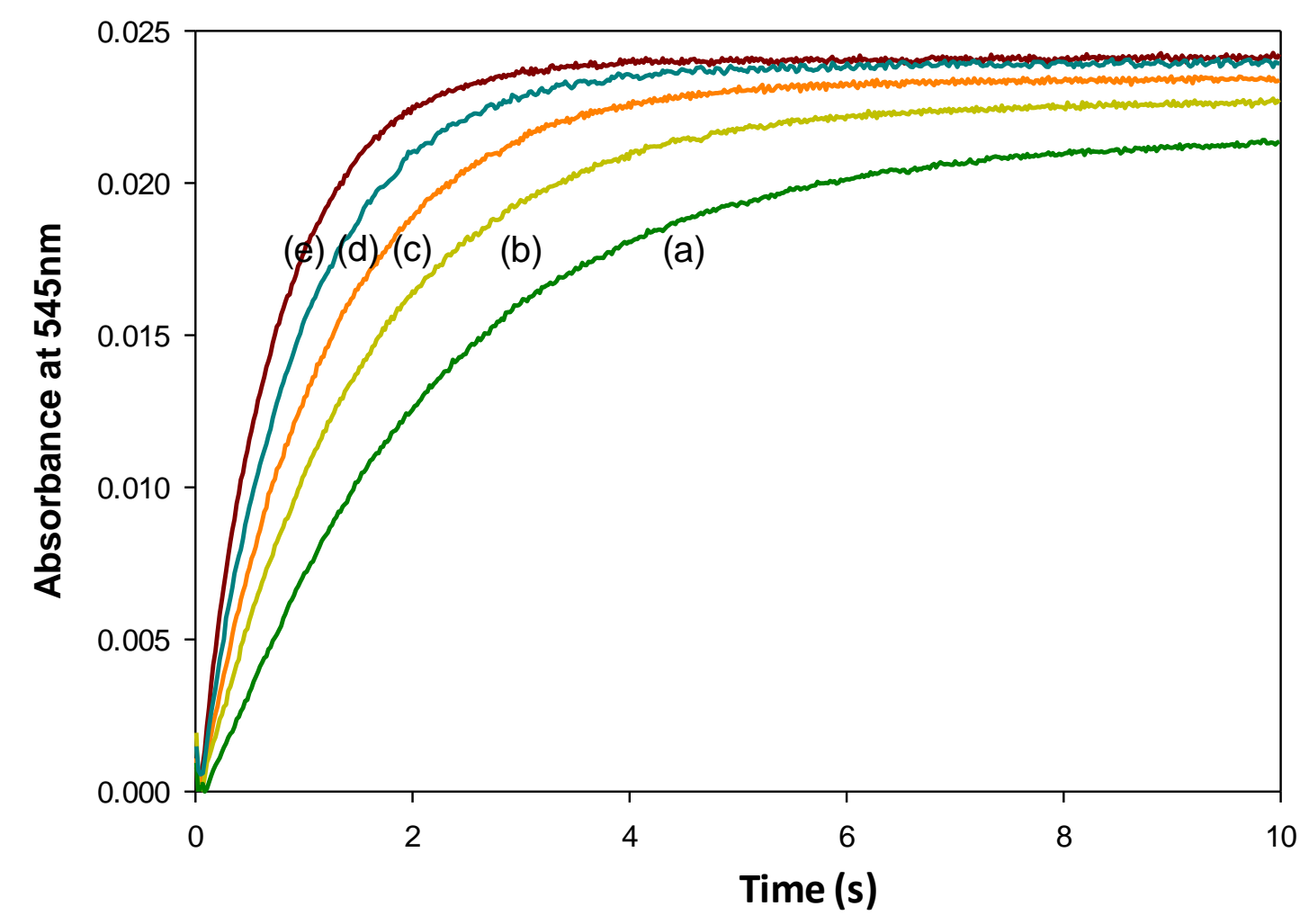

Figure 3. 12: Effect of acid variation on nitroso-cysteamine formation. Fixed $[C A]_{0}=5.0$ $\times 10^{-2} \mathrm{M},[\mathrm{PN}]_{0}=1.14 \times 10^{-4} \mathrm{M},[\mathrm{EDTA}]_{0}=1.0 \times 10^{-4} \mathrm{M}$ and varied $\left[\mathrm{H}^{+}\right] \times 10^{-1}=(\mathrm{a})$ $1.875 \mathrm{M}$, (b) $2.5 \mathrm{M}$, (c) $3.125 \mathrm{M}$, (d) $3.75 \mathrm{M}$ and (e) $4.375 \mathrm{M}$.

High acidic $\mathrm{pH}$ of 0.3 to 0.7 used in these variations confines the majority of the $\mathrm{ONOOH}$ into the protonated form of the peroxynitrous acid( $\mathrm{ONOHOH}+)$ shown in scheme 3.5.

Figure 3.11 shows that reactions were acid catalyzed, and rate equation for the formation of CANO from scheme $1(\mathrm{R})$ was:

$$
\text { Rate }=\mathrm{K}_{\mathrm{R}}[\mathrm{CASH}]\left[\mathrm{ONOO}^{-}\right]\left[\mathrm{H}^{+}\right] \quad \mathrm{R} 3.8
$$




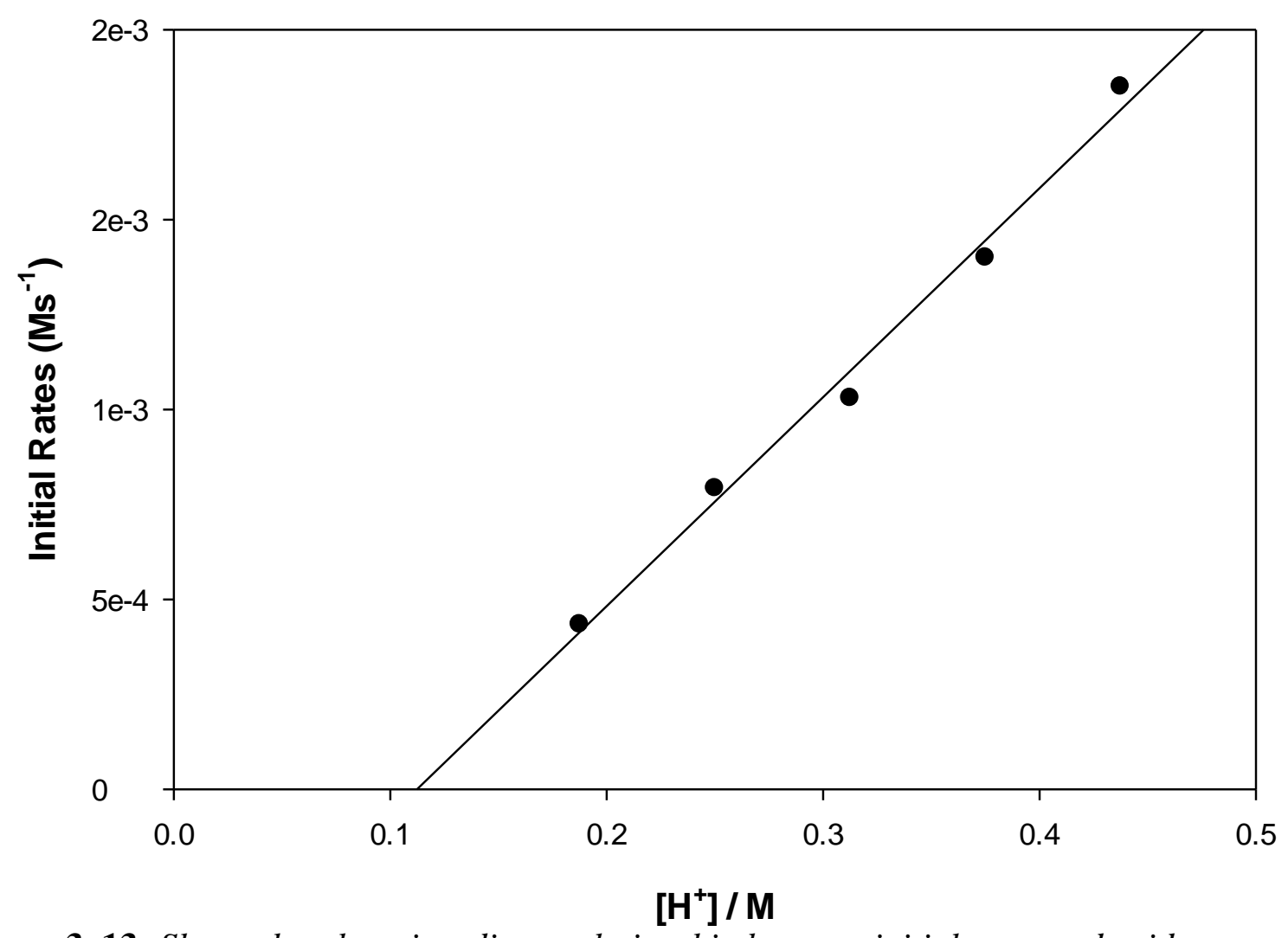

Figure 3. 13: Shows that there is a direct relationship between initial rates and acid concentration for conditions in Figure 3.12.

Figure 3.11 above shows that this process is first order in high acid concentrations although, which agrees with equation R3.8. 


\subsection{Effect Nitrite Variation on CANO Formation}

Nitrite with one of the ingredients which are used in the synthesis of peroxynitrite ${ }^{49}$ and under acidic conditions it can form $\mathrm{HNO}_{2}$ which is another important parameter for nitrosation of thiols $(\mathbf{R 3 . 9}-\mathbf{R 3 . 1 0}){ }^{59}$

$$
\begin{aligned}
& \mathrm{H}^{+}+\mathrm{NO}_{2}^{-} \longrightarrow \mathrm{HNO}_{2} \\
& \mathrm{H}_{2} \mathrm{NCH}_{2} \mathrm{CH}_{2} \mathrm{SH}+\mathrm{HNO}_{2} \longrightarrow \mathrm{H}_{2} \mathrm{NCH}_{2} \mathrm{CH}_{2} \mathrm{SNO}+\mathrm{H}_{2} \mathrm{O}
\end{aligned}
$$

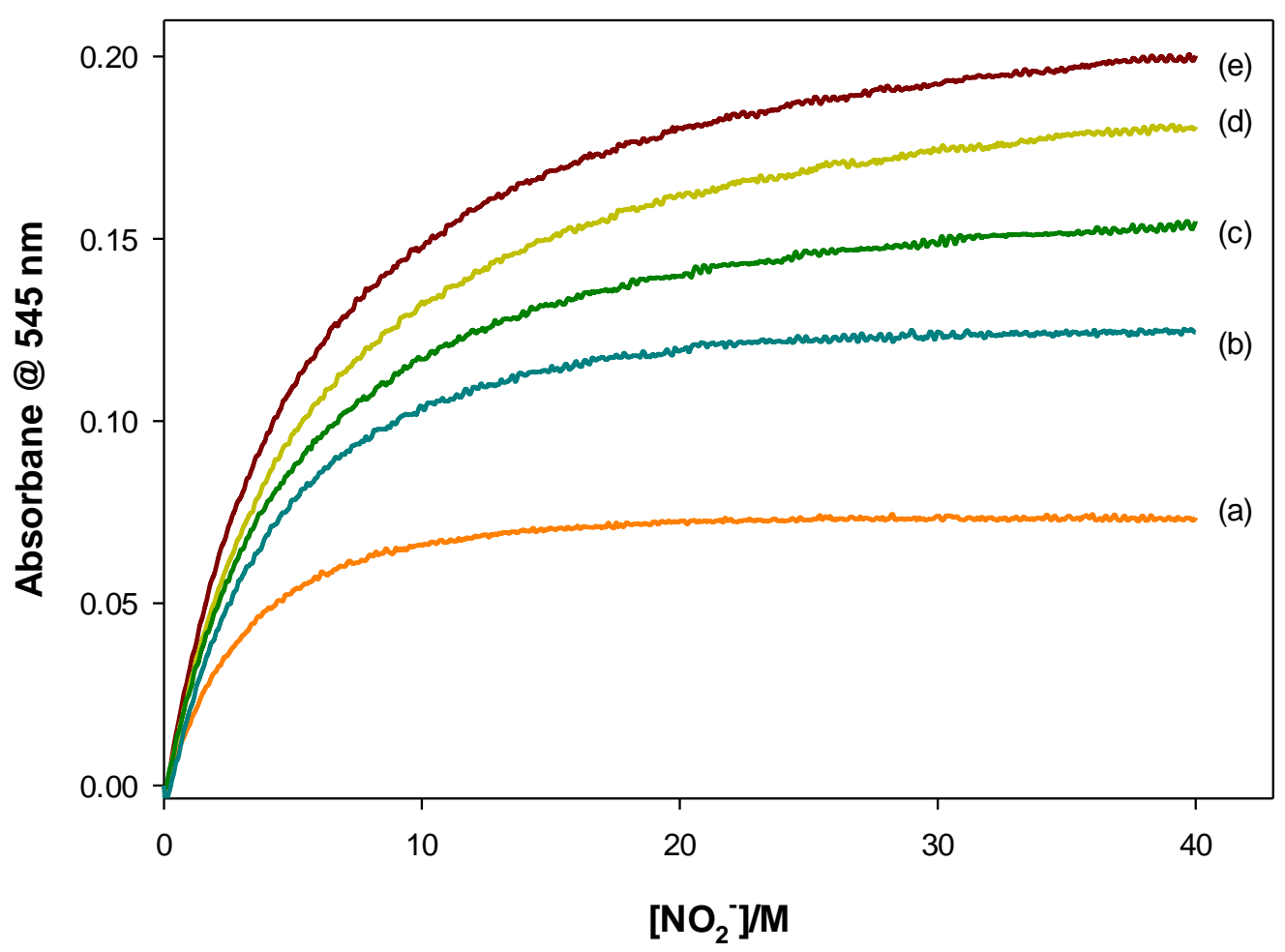

Figure 3. 14: Effect of nitrite variation on S-nitroso-cysteamine formation. Fixed [CA]

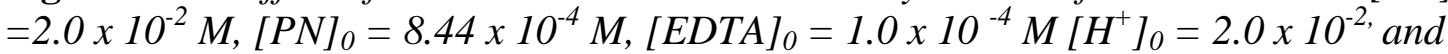
varied $\left[\mathrm{NO}_{2}^{-}\right]_{0} \times 10^{-3}=($ a) $0 \mathrm{M}$, (b) $3.75 \mathrm{M}$, (c) $5.0 \mathrm{M}$, (d) $6.25 \mathrm{M}$, and (e) $7.5 \mathrm{M}$. 
High nitrite concentrations as expected, delivered high CANO concentrations. The experiments did not show any induction period (Figure 3.14). The CANO was being formed from $\mathrm{ONOHOH}$, but when the $\mathrm{NO}_{2}^{-}$was being added some of the CANO was being formed from $\mathrm{HNO}_{2}$ the observed increase in CANO formation as the nitrite concentrations increased.

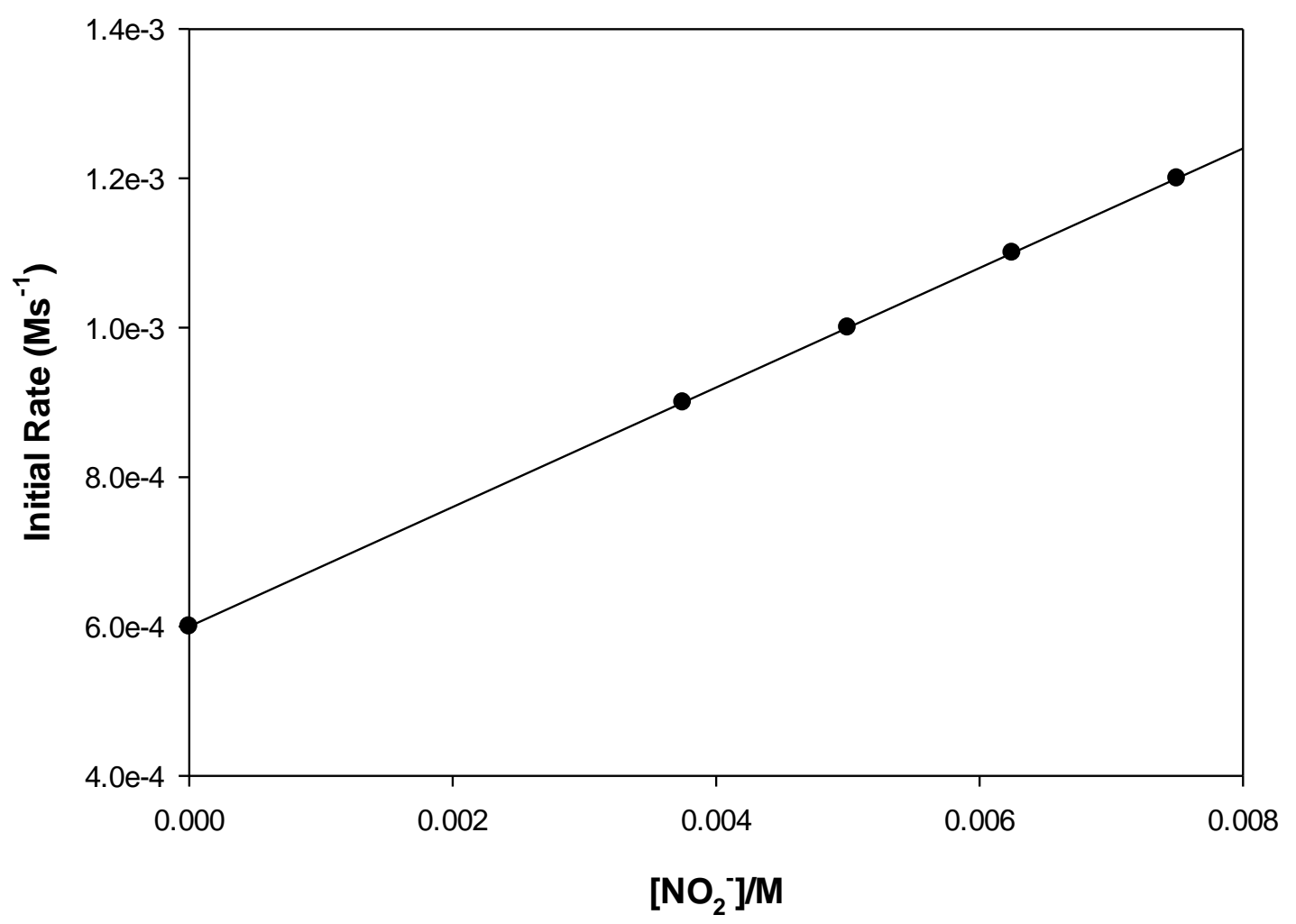

Figure 3. 15: Shows that there is a direct relationship between initial rates and nitrite concentration for conditions in Figure 3.14.

Figure 3.15 shows strong first-order dependence on initial rate of formation of Snitrosocysteamine (CANO) on nitrite. 


\subsection{Effect of Cysteamine Dependence}

The role of CA in oxidation of CA by PN was examined by varying concentrations of $\mathrm{CA}$ and keeping PN constant. All $\mathrm{ONOO}^{-}$oxidations in Figure 3.16 showed a strong rapid autocatalytic decay kinetics. Increasing CA concentrations increases the consumption of PN by CA with the highest concentration having the highest rate of consumption.

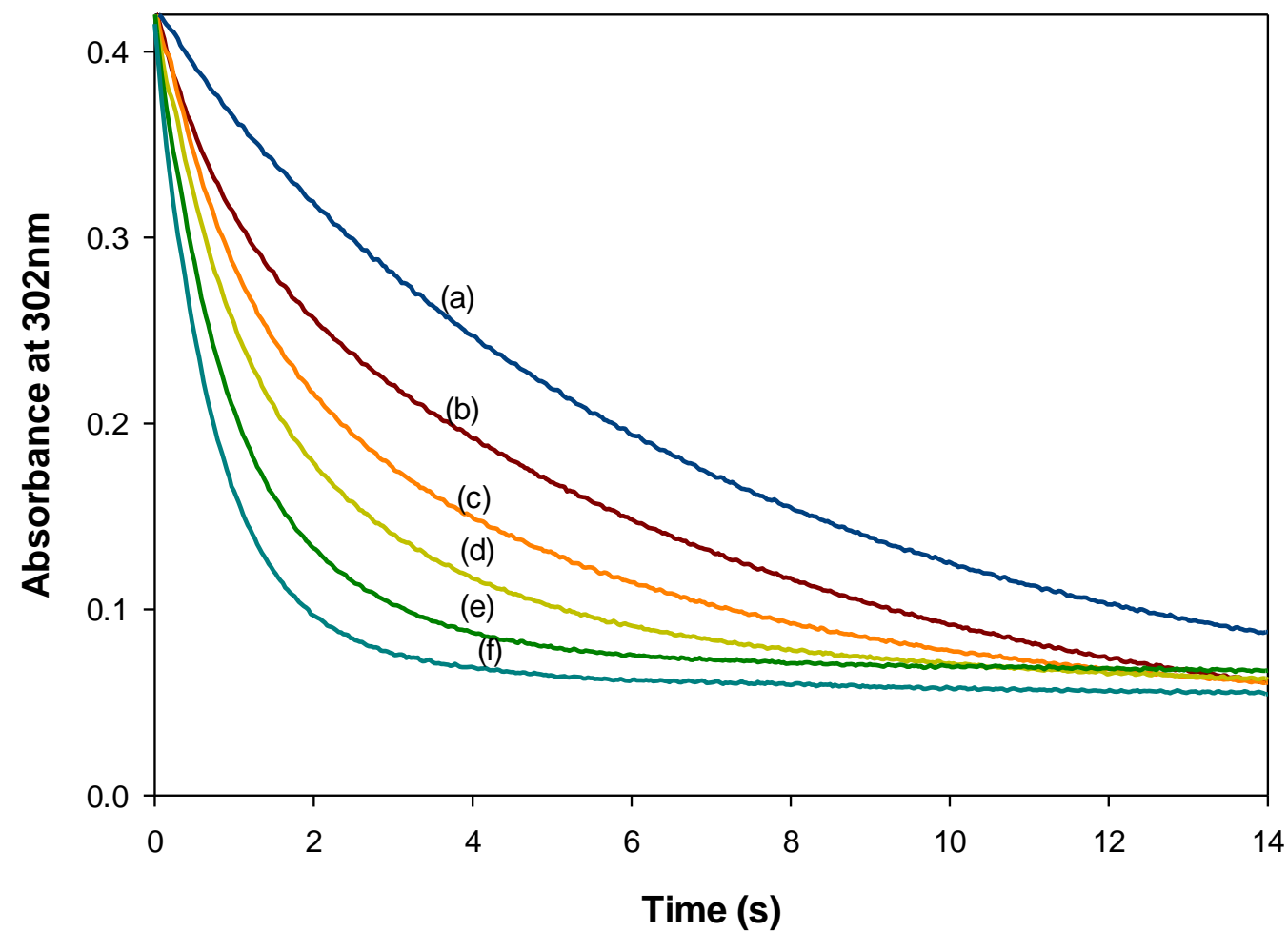

Figure 3. 16: Absorbance traces from the $P N-C A$ reaction and the reaction was done in less than 15 seconds. Fixed $[P N]_{0}=6.63 \times 10^{-4} \mathrm{M},[\mathrm{EDTA}]_{0}=1.0 \times 10^{-4} \mathrm{M}$ and varied $[C A]_{0} \times 10^{-4} \mathrm{M}=(a) 0 \mathrm{M}$, (b) $5 \mathrm{M}$, (c) $10 \mathrm{M}$, (d) $15 \mathrm{M}$, (e) $20 \mathrm{M}$ and (f) $25 \mathrm{M}$ in phosphate buffer $\mathrm{pH}$ 7.4. 


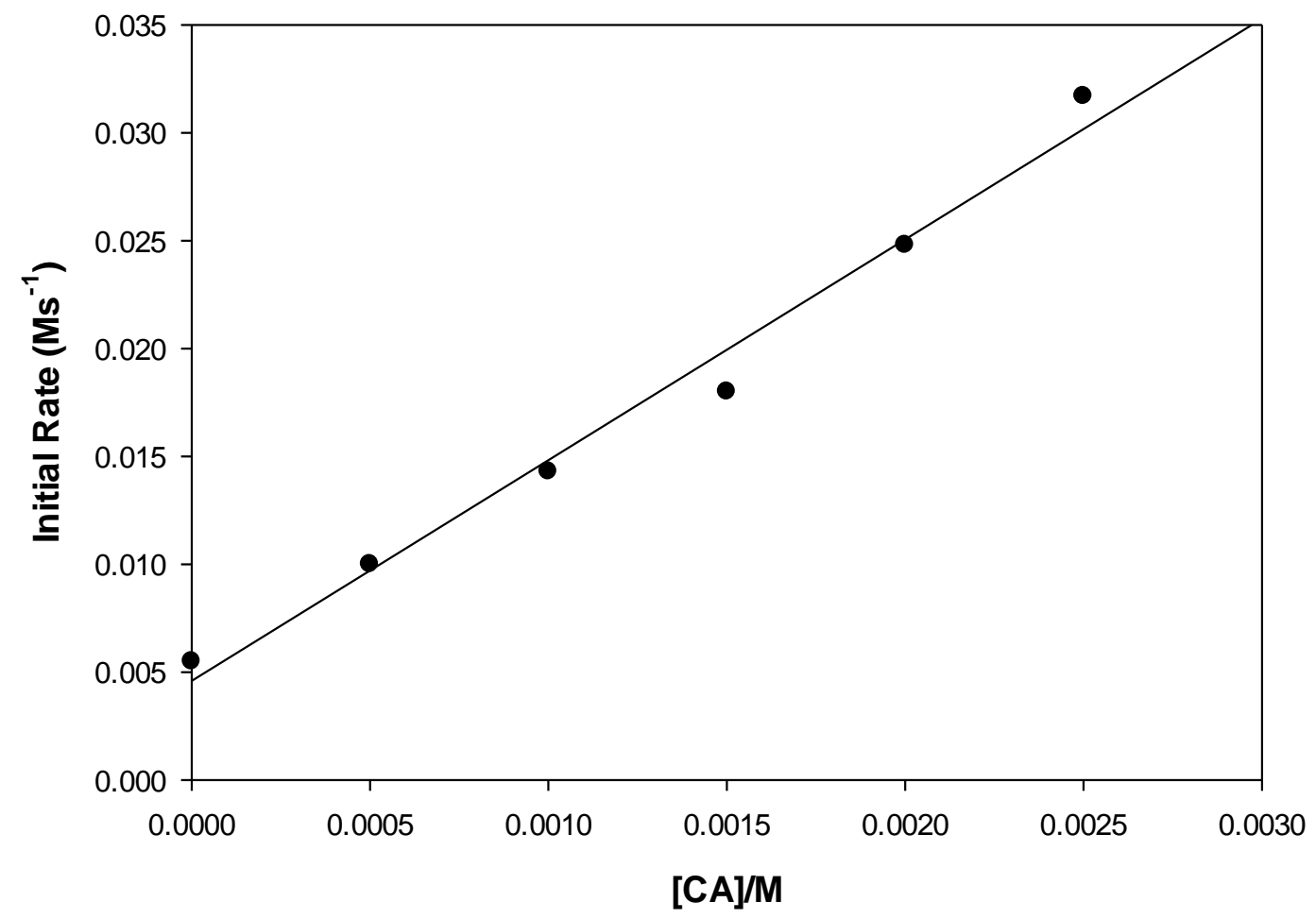

Figure 3. 17: Shows that there is a direct relationship between initial rates and $C A$ concentration for conditions in Figure 3.16.

We evaluated a lower limit bimolecular rate constant to be $10.23 \mathrm{M}^{-1} \mathrm{~s}^{-1}$, for the direct oxidation of $\mathrm{CA}$ by $\mathrm{PN}$ which was derived from Figure 3.17. For $[\mathrm{PN}]_{0}:[\mathrm{CA}]_{0}$ ratios used in this set of experiments, Figure 3.17 shows that the rate of formation of cysteamine nitrsothiol (CANO) with respect to PN concentrations is first order.

\subsection{Effect of Peroxynitrite Dependence}


To determine the effect of $\mathrm{PN}$ on the oxidation of $\mathrm{CA}, \mathrm{PN}$ concentrations were varied while the concentrations of CA were kept constant. Since the absorbance is directly proportional to concentration, absorbance varied with varying $\mathrm{PN}$ concentrations.

Figure 3.18 shows that the direct reaction is extremely fast essentially complete in at least $1 \mathrm{~s}$ with a complete consumption of PN.

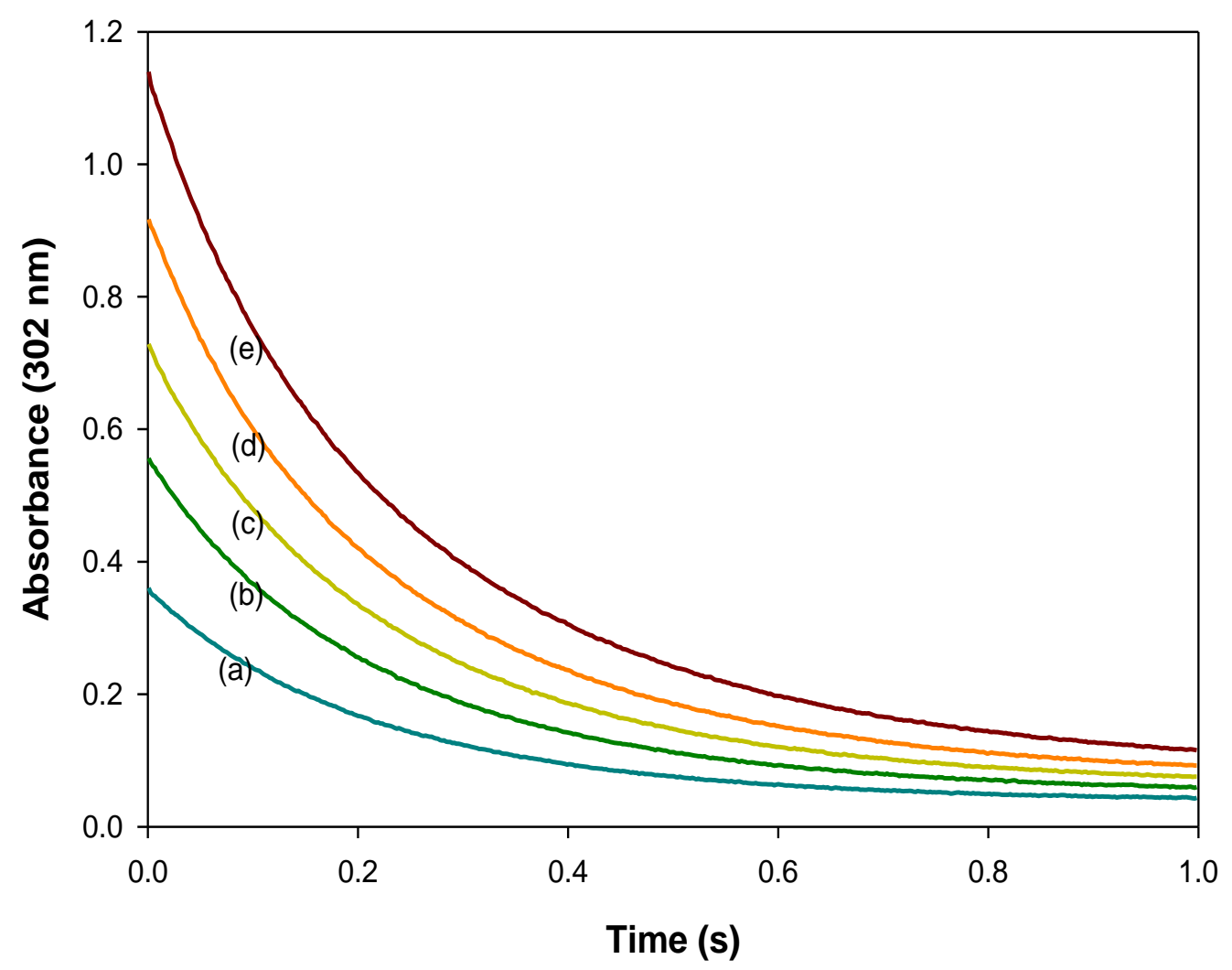

Figure 3. 18: Absorbance traces showing the effect of varying $P N$ concentrations on its $S$-nitrosation by $C A$. The plot shows the decomposition of $P N$ at $360 \mathrm{~nm}$. $[C A]_{0}=5.0 x$ $10^{-3} \mathrm{M}$, phosphate buffer $\mathrm{pH} 7.4$ and varied $[\mathrm{PN}]_{0} \times 10^{-4}=($ a) $2.6 \mathrm{M}$, (b) $4.0 \mathrm{M}$, (c) 5.2 $M$, (d) $6.4 M$ and (e) $7.8 M$.

Highest PN concentrations had the highest rate of depletion. We evaluated a lower limit bimolecular rate constant of $3.76 \times 10^{-1} \mathrm{M}^{-1} \mathrm{~s}^{-1}$ for the direct oxidation of CA by PN. 
This estimation was derived from data in Figure 3.19 where oxidation of CA was taking occurring ( stoichiometry R3.3).

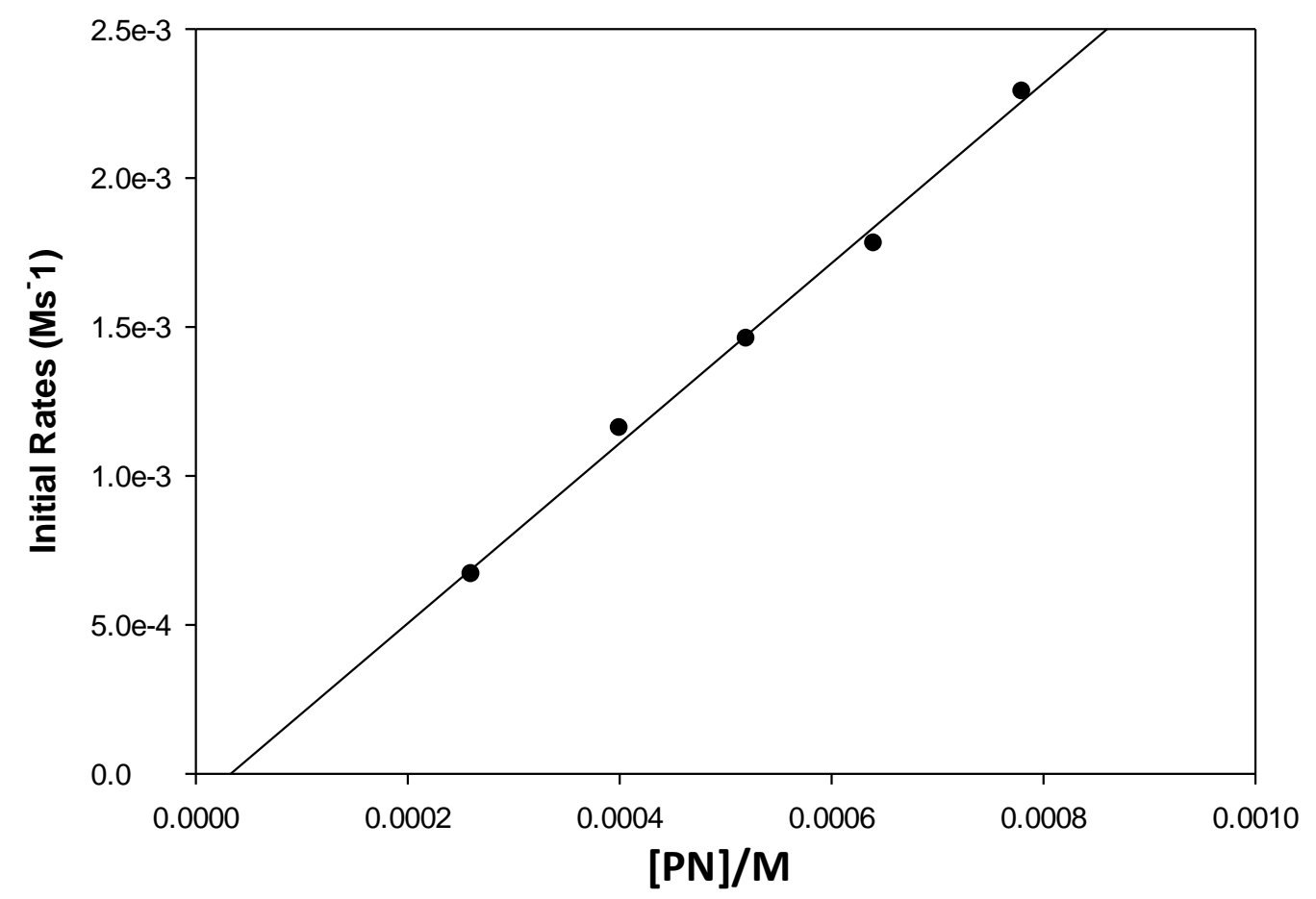

Figure 3. 19: Initial rate plot of the data in Figure 3.18. The plot shows linear dependence on initial rate of decomposition of PN on CA in the S-nitrosation of CA.

Figure 3.19 show that the rate of consumption of $P N$ in the presence of a fixed concentration of CA follows a first order dependence with respect to PN concentrations.

\subsection{Effect of pH Variation on Peroxynitrite Stability}

PN concentrations were kept constant and the reaction was monitored when PN was mixed with phosphate buffers of various $\mathrm{pHs}$. $\mathrm{PN}$ was stable at $\mathrm{pH}$ of 8.1 since no 
depletion of PN concentration was observed at $302 \mathrm{~nm}$. A decrease in $\mathrm{pH} 7.8$ to $\mathrm{pH} 6.3$ was associated with a fast rate of PN depletion. Initial rates were determined from the decrease in absorbance and a linear plot of initial rate against $\mathrm{pH}$ was observed.

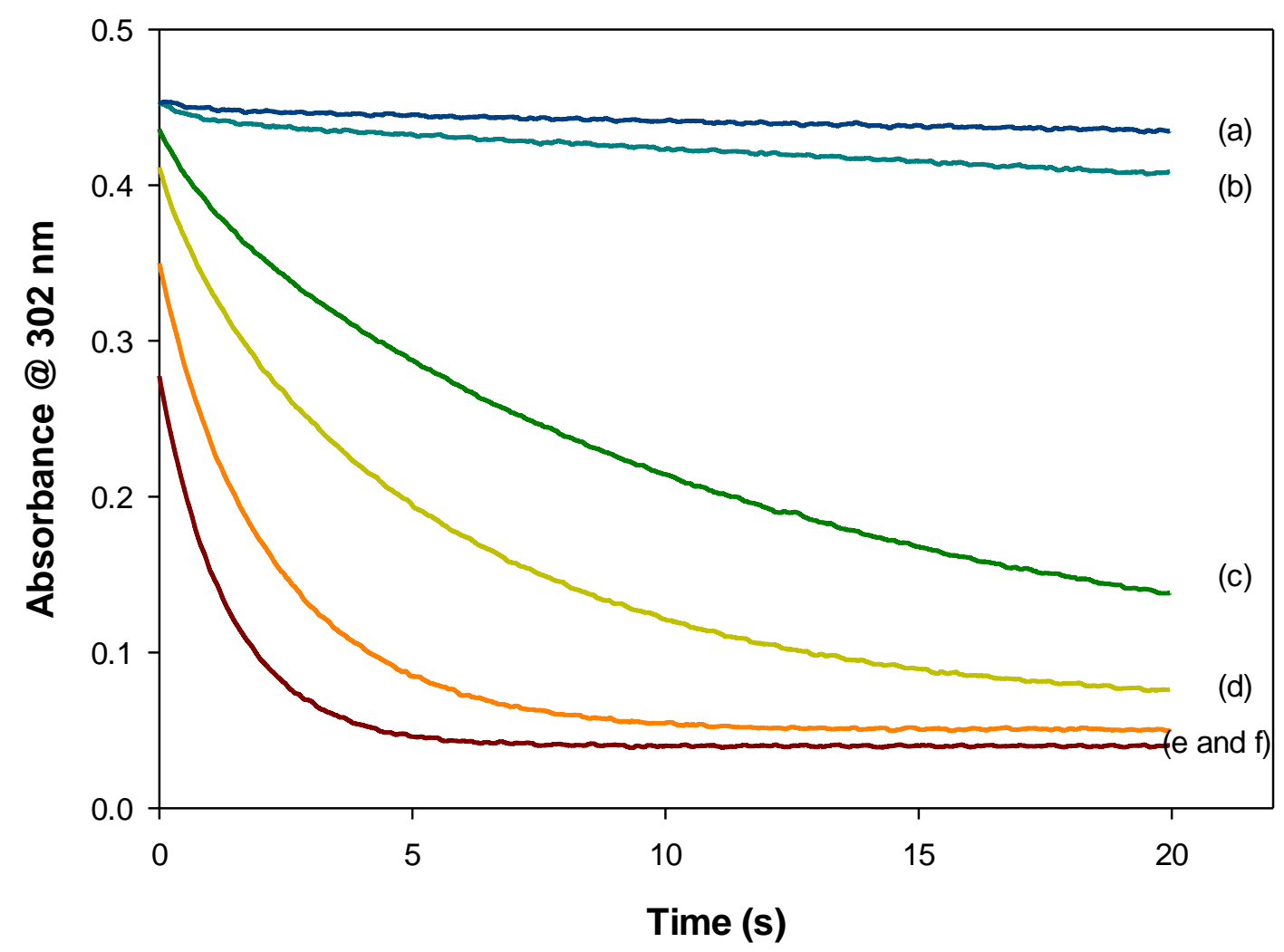

Figure 3. 20: Absorbance traces showing the effect of $p H$ variation on $P N$ depletion at $302 \mathrm{~nm} .[\mathrm{PN}]_{0}=4.4 \times 10^{-4} \mathrm{M}$, phosphate buffer $\mathrm{pH}=(\mathrm{a}) \mathrm{8.1}$, (b) 7.8, , (c) 7.4 (d) 7.0, (e) 6.6 and $(f) 6.3$ at $25^{\circ} \mathrm{C}$. 


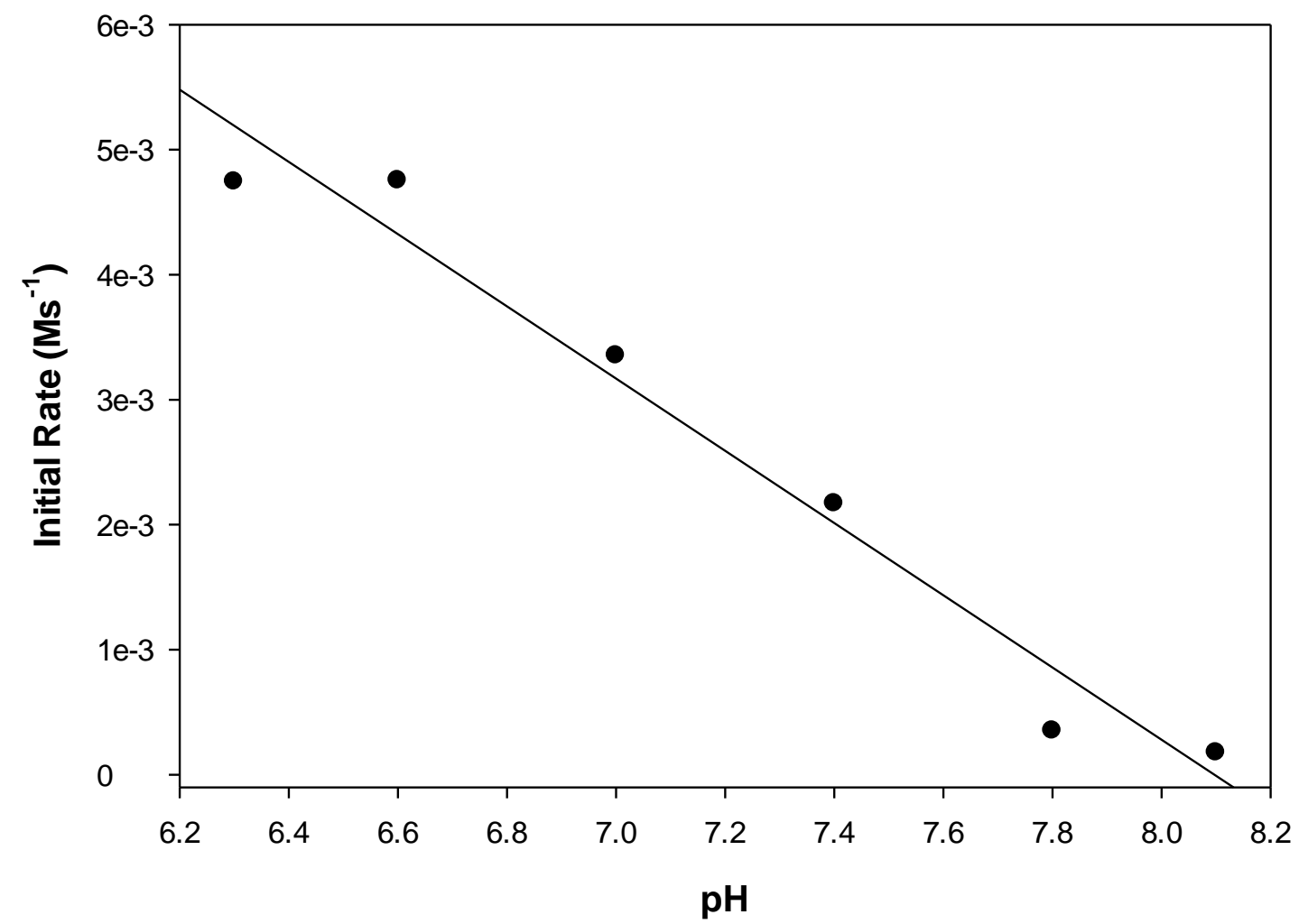

Figure 3. 21: This plot shows that there is a direct inverse relationship between the initial rate and $\mathrm{pH}$ for conditions shown in Figure 3.20.

The linear plot of initial rates against $\mathrm{pH}$ suggests that the depletion of PN within this range is first order. 


\subsection{Comparison of Phosphate Buffer to Bicarbonate Buffer}

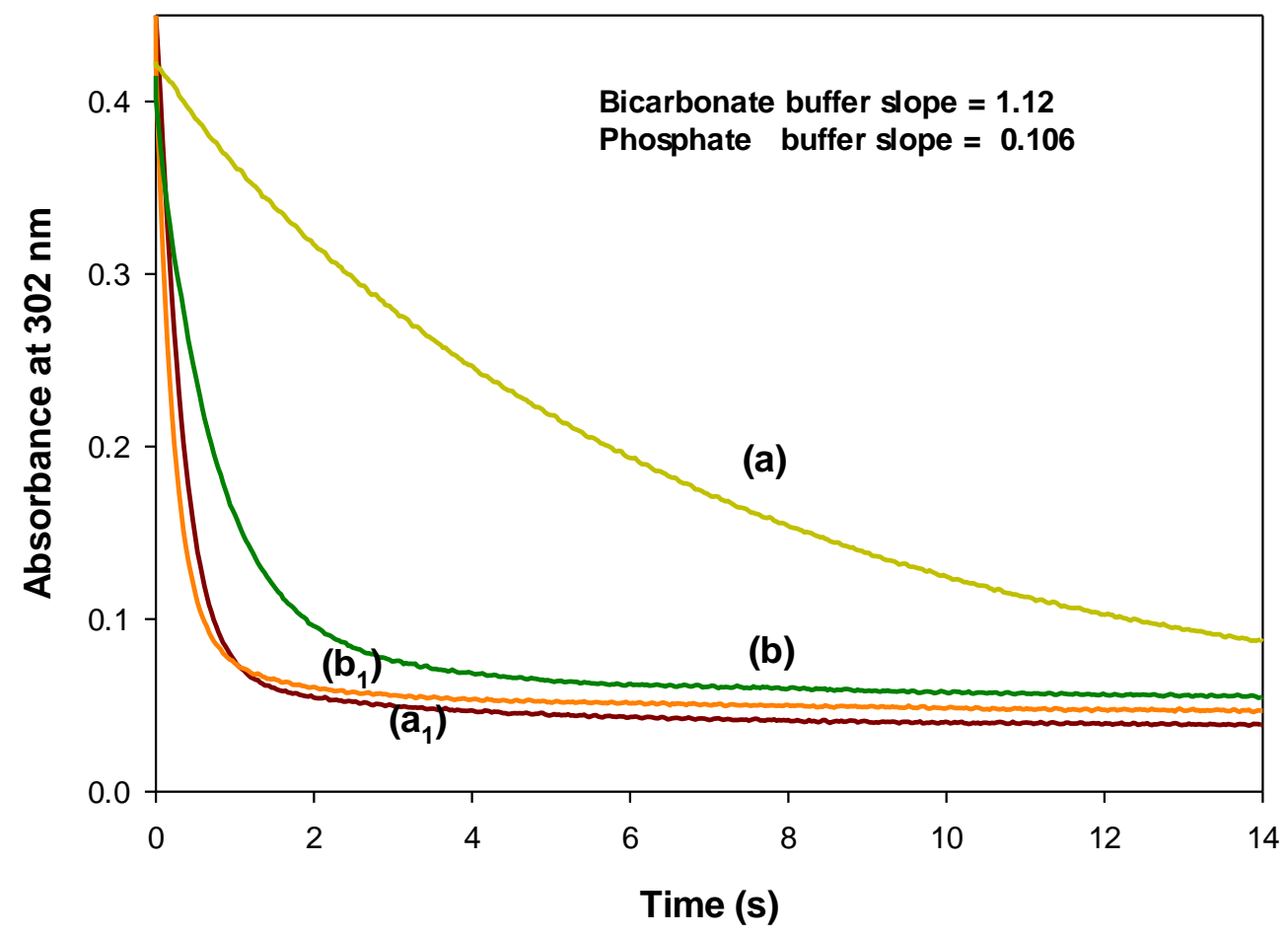

Figure 3. 22: Effect of carbonate on the decomposition of PN: $0.0005 \mathrm{M} \mathrm{CA}$, [EDTA]0 $=1.0 \times 10^{-4} \mathrm{M},(\mathrm{a})$ phosphate buffer $\mathrm{pH} 7.0$ and $0 \mathrm{M}[\mathrm{CA}]_{0}$ and $(\mathrm{b})[\mathrm{CA}]_{0}=5.0 \times 10^{-4} \mathrm{M}$ and $\left(a_{1}\right)$ and $\left(b_{1}\right)$ same conditions but with bicarbonate buffer $p H$ 7.0. The slopes of bicarbonate buffered reaction were 10 times faster than phosphate buffered reactions.

Figure 3.22 above shows the decomposition of PN in 2 different buffer systems (phosphate and bicarbonate buffer) both of $\mathrm{pH}$ 7.0. Trace (a) shows a least 10 times slower decomposition of PN compared to trace (a1) of bicarbonate buffer. This shows that bicarbonate buffer has a catalytic effect on the decomposition of PN. The introduction of CA into PN did show a slight increase in the initial rate of PN decomposition, whilst CA in phosphate buffer it gave a marked increase in the initial 
rates of PN decomposition by 9 times. This shows that bicarbonate accelerates PN decomposition more than CA. Upon neutralization bicarbonate is converted to carbon dioxide and water (R3.11).

$$
\mathrm{H}^{+}+\mathrm{HCO}_{3}^{-} \rightleftharpoons \mathrm{CO}_{2}+\mathrm{H}_{2} \mathrm{O}
$$

The difference in depletion of PN between phosphate buffer and bicarbonate buffer is due to the bicarbonate ion which is converted to $\mathrm{CO}_{2}(\mathbf{R 3 . 1 1})$.

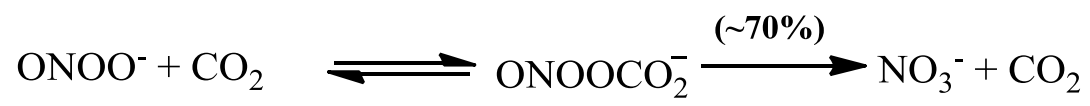

When peroxynitrite reacts with carbon dioxide it will form nitrosoperoxycarbonate when nitrosoperoxycarbonate anion is formed, the majority $(\sim 70 \%)$ of it is converted to the nitrocarbonate ion, $\mathrm{ONOOCO}_{2}^{-}$, which in turn decomposes to give nitrate $\left(\mathrm{NO}_{3}{ }^{-}\right)$and regenerated $\mathrm{CO}_{2}(\mathbf{R 3 . 1 2})$. In the bicarbonate buffer the presence of bicarbonate is also main contributing factor to PN depletion.

\subsection{Computer Simulation and Detailed Mechanism}

Kintecus model developed by James Ianni was chosen for modeling this reaction scheme. To avoid termolecular reactions above, solvent water was ignored throughout the simulations and acid concentrations could be taken as buffered without loss of precision. The kinetics of the nitrosation of cysteamine by peroxynitrite were studied in acidic conditions and monitored under pseudo-first-order conditions using excess CA. The concise mechanism that was be used to model the PN - CA reaction is shown in Table 
3.1. It can be effectively divided into five separate sections. The first set of reactions, M1 is the overall reaction equation. M2 - M3 represents the formation of nitrous acid (HNO2) which can react with CA to form CANO. The formation of $\mathrm{HNO}_{2}$ set of reactions primarily builds up $\mathrm{NO}$ radical concentrations as well as other NOs species which are also reactive oxidants. The reaction rate will initially be controlled by reaction M2 until enough $\mathrm{HNO}_{2}$ has built up before reaction M3 takes place. The third set of reactions, M4 - M5, represent an alternative way of $\mathrm{HNO} 2$ formation between NO+ and $\mathrm{H} 2 \mathrm{O}$ leading to the formation of CANO in M5. These reactions that have been known for a long time and whose kinetics constants are available from literature. ${ }^{8,64}$

The fourth set of reactions, M6 - M8, together with M2 - M4, represents the oxidations of CA by the oxidants HNO2, and ONOO-. Reaction M7 is known to be fast, and its rapid rate of reaction was used to ignore most oxidations by $\mathrm{HNO}_{2}$. The inclusions of equations M1-M5 did not alter the calculated curves for ONOO - CA reaction, and made a very insignificant contribution to the overall reaction. 
Table 3. 1: Detailed Mechanism of the Cysteamine-Peroxynitrite Reaction

\begin{tabular}{|c|c|c|c|}
\hline Reaction & Reaction & $\mathbf{k}_{\mathbf{f}} ; \mathbf{k}_{\mathbf{r}}$ & \\
\hline M1 & $\mathrm{H}^{+}+\mathrm{NO}_{2}^{-} \leftrightarrow \mathrm{HNO}_{2}$ & $1.1 \times 10^{8} ; 6.18 \times 10^{5}$ & 59 \\
\hline M2 & $\mathrm{HNO}_{2}+\mathrm{CA} \rightarrow \mathrm{H}_{2} \mathrm{O}+\mathrm{CANO}$ & $4.0 \times 10^{1}$ & 59 \\
\hline M3 & $\mathrm{NO}^{+}+\mathrm{H}_{2} \mathrm{O}+\equiv \mathrm{HNO}_{2}+\mathrm{H}^{+}$ & $2.1 ; 1.0 \times 10^{-4}$ & 59 \\
\hline M4 & $\mathrm{NO}^{+}+\mathrm{CA} \equiv \mathrm{CANO}+\mathrm{H}^{+}$ & $1.0 \times 10^{4} ; 1.0 \times 10^{-2}$ & ${ }^{59}$ (adjusted) \\
\hline M5 & $\mathrm{NO}^{\circ}+\mathrm{O}^{2-} \equiv \mathrm{ONOO}^{-}$ & $6.7 \times 10^{9}$ & 4,6 \\
\hline M6 & $\mathrm{ONOO}^{-}+\mathrm{CA} \rightarrow \mathrm{NO}_{2}^{-}+\mathrm{CAOH}$ & $2.0 \times 10^{2}$ & This work \\
\hline M7 & $\mathrm{ONOO}^{-}+\mathrm{CAOH} \rightarrow \mathrm{NO}_{2}^{-}+\mathrm{CAO}_{2} \mathrm{H}$ & $1.6 \times 10^{4}$ & This work \\
\hline M8 & $\mathrm{ONOO}^{-}+\mathrm{CAO}_{2} \mathrm{H} \rightarrow \mathrm{NO}_{2}^{-}+\mathrm{CAO}_{3} \mathrm{H}$ & $1.0 \times 10^{-3}$ & This work \\
\hline M9 & $\mathrm{CAOH}+\mathrm{CA} \rightarrow \mathrm{CA}-\mathrm{CA}+\mathrm{H}_{2} \mathrm{O}$ & $2.0 \times 10^{4}$ & This work \\
\hline M10 & $\mathrm{ONOOH} \rightarrow{ }^{\circ} \mathrm{OH}+\mathrm{NO}_{2}^{-}$ & 3.5 & ${ }^{65}$ (adjusted) \\
\hline M11 & $\mathrm{CA}+{ }^{\circ} \mathrm{OH} \rightarrow \mathrm{H}_{2} \mathrm{O}+\mathrm{CA}^{\cdot}$ & $1.0 \times 10^{9}$ & This work \\
\hline M12 & $\mathrm{CA}^{*}+\mathrm{CA}^{\cdot} \rightarrow \mathrm{CA}-\mathrm{CA}$ & $1.0 \times 10^{9}$ & This work \\
\hline
\end{tabular}




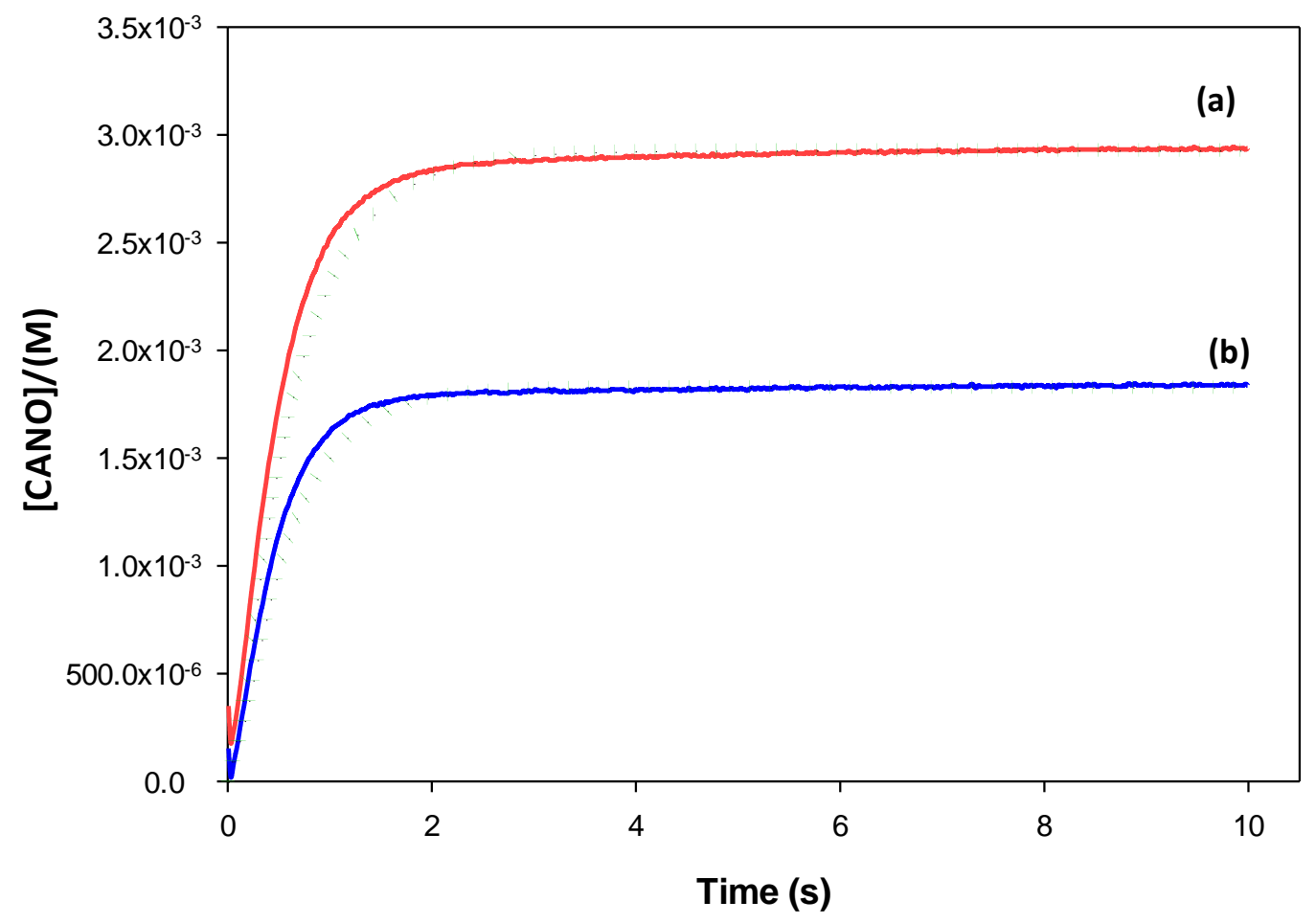

Figure 3. 23: Computer modeling for reaction for the data shown in Figure 3.8 using the scheme shown in Table 3.1. There seems to a satisfactory agreement between experiments and the model.

The model satisfactorily predicted data in Figure 3.8 (b) and (e), and the results are shown in Figure 2.23 above.

\subsection{CONCLUSION}

The S-nitrosation of the CA by peroxynitrite is quite complex, with the complexities being derived from the possible 2 nitrosating pathways, one by peroxynitrite and the 
second one by nitrous acid, under acidic conditions. The study of kinetics and mechanism of S-nitrosation and oxidation of cysteamine is characterized by a fast formation of CANO, and no induction period was observed. The acid acted as a catalyst and an increase in nitrite concentration resulted in increased CANO formed. S-nitrosocysteamie (CANO) was formed in strong acid conditions and whilst disulfides were formed in both acidic and basic conditions. Clear cysteamine radicals were formed at $\mathrm{pH} 11.5$ showing that one electron oxidations are dominates in alkali $\mathrm{pH}$. The weak S-C bond was broken down to yield sulfate ion. 


\section{REFERENCE LIST}

1. Culotta, E.; Koshland, D. E. No News Is Good-News. Science 1992, 258 (5090), 1862-1865.

2. Wink, D. A.; Mitchell, J. B. Chemical biology of nitric oxide: Insights into regulatory, cytotoxic, and cytoprotective mechanisms of nitric oxide. Free Radical Biology and Medicine 1998, 25 (4-5), 434-456.

3. Aranda, E.; Lopez-Pedrera, C.; Haba-Rodriguez, J. R.; Rodriguez-Ariza, A. Nitric Oxide and Cancer: The Emerging Role of S-Nitrosylation. Current Molecular Medicine 2012, 12 (1), 50-67.

4. Beckman, J. S.; Koppenol, W. H. Nitric oxide, superoxide, and peroxynitrite: The good, the bad, and the ugly. American Journal of Physiology-Cell Physiology 1996, 271 (5), C1424-C1437.

5. Beckman, J. S.; Beckman, T. W.; Chen, J.; Marshall, P. A.; Freeman, B. A. Apparent Hydroxyl Radical Production by Peroxynitrite - Implications for Endothelial Injury from Nitric-Oxide and Superoxide. Proceedings of the National Academy of Sciences of the United States of America 1990, 87 (4), 1620-1624.

6. Huie, R. E.; Padmaja, S. The Reaction of No with Superoxide. Free Radical Research Communications 1993, 18 (4), 195-199.

7. Koppenol, W. H.; Moreno, J. J.; Pryor, W. A.; Ischiropoulos, H.; Beckman, J. S. Peroxynitrite, A Cloaked Oxidant Formed by Nitric-Oxide and Superoxide. Chemical Research in Toxicology 1992, 5 (6), 834-842.

8. Lobachev, V. L.; Rudakov, E. S. The chemistry of peroxynitrite. Reaction mechanisms and kinetics. Uspekhi Khimii 2006, 75 (5), 422-444.

9. Tsai, H. H.; Hamilton, T. P.; Tsai, J. H. M.; vanderWoerd, M.; Harrison, J. G.; Jablonsky, M. J.; Beckman, J. S.; Koppenol, W. H. Ab initio and NMR study of peroxynitrite and peroxynitrous acid: Important biological oxidants. Journal of Physical Chemistry 1996, 100 (37), 15087-15095.

10. Szabo, E.; Virag, L.; Bakondi, E.; Gyure, L.; Hasko, G.; Bai, P.; Hunyadi, J.; Gergely, P.; Szabo, C. Peroxynitrite production, DNA breakage, and poly(ADP-ribose) polymerase activation in a mouse model of oxazoloneinduced contact hypersensitivity. Journal of Investigative Dermatology 2001, 117 (1), 74-80. 
11. Szabo, C.; Modis, K. Pathophysiological Roles of Peroxynitrite in Circulatory Shock. Shock 2010, 34, 4-14.

12. Gow, A. J.; Duran, D.; Malcolm, S.; Ischiropoulos, H. Effects of peroxynitriteinduced protein modifications on tyrosine phosphorylation and degradation. Febs Letters 1996, 385 (1-2), 63-66.

13. Groves, J. T. Peroxynitrite: reactive, invasive and enigmatic. Current Opinion in Chemical Biology 1999, 3 (2), 226-235.

14. Pacher, P.; Beckman, J. S.; Liaudet, L. Nitric oxide and peroxynitrite in health and disease. Physiological Reviews 2007, 87 (1), 315-424.

15. Hughes, M. N.; Nicklin, H. G. The chemistry of peroxonitrites. Part II. Copper(II)catalysed reaction between hydroxylamine and peroxonitrite in alkali. $J$. Chem. Soc. A 1970, 0 (0), 925-928.

16. Reed, J. W.; Ho, H. H.; Jolly, W. L. Chemical synthesis with a quenched flow reactor. Hydroxytrihydroborate and peroxynitrite. J. Am. Chem. Soc. 1974, 96 (4), 1248-1249.

17. Hughes, M. N.; Nicklin, H. G. Autoxidation of hydroxylamine in alkaline solutions. J. Chem. Soc. A 1971, 0 (0), 164-168.

18. Robinson, K. M.; Beckman, J. S. Synthesis of peroxynitrite from nitrite and hydrogen peroxide. Nitric Oxide, Pt e 2005, 396, 207-214.

19. Hogg, N.; Darleyusmar, V. M.; Wilson, M. T.; Moncada, S. Production of Hydroxyl Radicals from the Simultaneous Generation of Superoxide and Nitric-Oxide. Biochemical Journal 1992, 281, 419-424.

20. Uppu, R. M.; Squadrito, G. L.; Cueto, R.; Pryor, W. A. Synthesis of peroxynitrite by azide-ozone reaction. Nitric Oxide, Pt B 1996, 269, 311-321.

21. Koppenol, W. H.; Kissner, R.; Beckman, J. S. Syntheses of peroxynitrite: To go with the flow or on solid grounds? Nitric Oxide, Pt B 1996, 269, 296-302.

22. Beckman, J. S. Ischemic-Injury Mediator. Nature 1990, 345 (6270), 27-28.

23. Mccall, T. B.; Boughtonsmith, N. K.; Palmer, R. M. J.; Whittle, B. J. R.; Moncada, S. Synthesis of Nitric-Oxide from L-Arginine by Neutrophils - Release and Interaction with Superoxide Anion. Biochemical Journal 1989, 261 (1), 293-296. 
24. Crow, J. P.; Beckman, J. S.; Mccord, J. M. Sensitivity of the Essential ZincThiolate Moiety of Yeast Alcohol-Dehydrogenase to Hypochlorite and Peroxynitrite. Biochemistry 1995, 34 (11), 3544-3552.

25. Han, D.; Canali, R.; Garcia, J.; Aguilera, R.; Gallaher, T. K.; Cadenas, E. Sites and mechanisms of aconitase inactivation by peroxynitrite: Modulation by citrate and glutathione. Biochemistry 2005, 44 (36), 11986-11996.

26. Takakura, K.; Beckman, J. S.; MacMillan-Crow, L. A.; Crow, J. P. Rapid and irreversible inactivation of protein tyrosine phosphatases PTP1B, CD45, and LAR by peroxynitrite. Archives of Biochemistry and Biophysics 1999, 369 (2), 197-207.

27. Lymar, S. V.; Hurst, J. K. Rapid Reaction Between Peroxonitrite Ion and CarbonDioxide - Implications for Biological-Activity. J. Am. Chem. Soc. 1995, 117 (34), 8867-8868.

28. Lymar, S. V.; Hurst, J. K. Carbon dioxide: Physiological catalyst for peroxynitritemediated cellular damage or cellular protectant? Chemical Research in Toxicology 1996, 9 (5), 845-850.

29. Pryor, W. A.; Lemercier, J. N.; Zhang, H. W.; Uppu, R. M.; Squadrito, G. L. The catalytic role of carbon dioxide in the decomposition of peroxynitrite. Free Radical Biology and Medicine 1997, 23 (2), 331-338.

30. Goldstein, S.; Czapski, G. Formation of peroxynitrate from the reaction of peroxynitrite with $\mathrm{CO} 2$ : Evidence for carbonate radical production. $J$. Am. Chem. Soc. 1998, 120 (14), 3458-3463.

31. Bonini, M. G.; Radi, R.; Ferrer-Sueta, G.; Ferreira, A. M. D.; Augusto, O. Direct EPR detection of the carbonate radical anion produced from peroxynitrite and carbon dioxide. Journal of Biological Chemistry 1999, 274 (16), 1080210806.

32. Uppu, R. M.; Squadrito, G. L.; Pryor, W. A. Acceleration of peroxynitrite oxidations by carbon dioxide. Archives of Biochemistry and Biophysics 1996, 327 (2), 335-343.

33. Zhang, H. W.; Squadrito, G. L.; Uppu, R. M.; Lemercier, J. N.; Cueto, R.; Pryor, W. A. Inhibition of peroxynitrite-mediated oxidation of glutathione by carbon dioxide. Archives of Biochemistry and Biophysics 1997, 339 (1), 183-189.

34. Shimazu, F.; Kumta, U. S.; Tappel, A. L. Radiation Damage to Methionine and Its Derivatives. Radiation Research 1964, 22 (2), 276-287. 
35. Bindoli, A.; Fukuto, J. M.; Forman, H. J. Thiol chemistry in peroxidase catalysis and redox signaling. Antioxidants \& Redox Signaling 2008, 10 (9), 15491564.

36. Turell, L.; Botti, H.; Carballal, S.; Ferrer-Sueta, G.; Souza, J. A.; Duran, R.; Freeman, B. A.; Radi, R.; Alvarez, B. Reactivity of sulfenic acid in human serum albumin. Biochemistry 2008, 47 (1), 358-367.

37. Hess, D. T.; Matsumoto, A.; Kim, S. O.; Marshall, H. E.; Stamler, J. S. Protein Snitrosylation: Purview and parameters. Nature Reviews Molecular Cell Biology 2005, 6 (2), 150-166.

38. Martinez-Ruiz, A.; Lamas, S. S-nitrosylation: a potential new paradigm in signal transduction. Cardiovascular Research 2004, 62 (1), 43-52.

39. Zhao, Y. L.; Houk, K. N. Thionitroxides, RSNHO center dot: The structure of the SNO moiety in "S-nitrosohemoglobin", a possible NO reservoir and transporter. J. Am. Chem. Soc. 2006, 128 (5), 1422-1423.

40. Gow, A. J.; Buerk, D. G.; Ischiropoulos, H. A novel reaction mechanism for the formation of S-nitrosothiol in vivo. Journal of Biological Chemistry 1997, 272 (5), 2841-2845.

41. Crawford, J. H.; White, C. R.; Patel, R. P. Vasoactivity of S-nitrosohemoglobin: role of oxygen, heme, and NO oxidation states. Blood 2003, 101 (11), 44084415.

42. Jia, L.; Bonaventura, C.; Bonaventura, J.; Stamler, J. S. S-nitrosohaemoglobin: A dynamic activity of blood involved in vascular control. Nature 1996, 380 (6571), 221-226.

43. Richardson, G.; Benjamin, N. Potential therapeutic uses for S-nitrosothiols. Clinical Science 2002, 102 (1), 99-105.

44. Zaman, K.; Fraser-Butler, M.; Bennett, D. Novel S-Nitrosothiols Have Potential Therapeutic Uses for Cystic Fibrosis. Current Pharmaceutical Design 2013, 19 (19), 3509-3520.

45. Butler, A. R.; Rhodes, P. Chemistry, analysis, and biological roles of Snitrosothiols. Analytical Biochemistry 1997, 249 (1), 1-9.

46. Hi-Tech Scientific Operator's Manual for the SF-61 DX2 Double-Mixing StoppedFlow Spectroflourimeter. 1997. Salisbury, UK, Hi-Tech Limited.

Ref Type: Catalog 
47. Banerjee, S.; Mazumdar, S. Electrospray Ionization Mass Spectrometry: A Technique to Access the Information beyond the Molecular Weight of the Analyte. International Journal of Analytical Chemistry 2011, 2012, 1-40.

48. Ho, C. S.; Lam, C. W.; Chan, M. H.; Cheung, R. C.; Law, L. K.; Lit, L. C.; Ng, K. F.; Suen, M. W.; Tai, H. L. Electrospray ionisation mass spectrometry: principles and clinical applications. The Clinical biochemist. Reviews / Australian Association of Clinical Biochemists 2003, 24 (1), 3-12.

49. Merenyi, G.; Lind, J.; Czapski, G.; Goldstein, S. The decomposition of peroxynitrite does not yield nitroxyl anion and singlet oxygen. Proceedings of the National Academy of Sciences of the United States of America 2000, 97 (15), 8216-8218.

50. Eddingsaas, N. C.; VanderVelde, D. G.; Wennberg, P. O. Kinetics and Products of the Acid-Catalyzed Ring-Opening of Atmospherically Relevant Butyl Epoxy Alcohols. Journal of Physical Chemistry A 2010, 114 (31), 81068113.

51. Leone, A. M.; Palmer, R. M. J.; Knowles, R. G.; Francis, P. L.; Ashton, D. S.; Moncada, S. Constitutive and Inducible Nitric-Oxide Synthases Incorporate Molecular-Oxygen Into Both Nitric-Oxide and Citrulline. Journal of Biological Chemistry 1991, 266 (35), 23790-23795.

52. Stipanuk, M. H. Sulfur amino acid metabolism: Pathways for production and removal of homocysteine and cysteine. Annual Review of Nutrition 2004, $24,539-577$.

53. Janaky, R.; Varga, V.; Hermann, A.; Saransaari, P.; Oja, S. S. Mechanisms of Lcysteine neurotoxicity. Neurochemical Research 2000, 25 (9-10), 13971405.

54. Dringen, R.; Gutterer, J. M.; Hirrlinger, J. Glutathione metabolism in brain Metabolic interaction between astrocytes and neurons in the defense against reactive oxygen species. European Journal of Biochemistry 2000, 267 (16), 4912-4916.

55. Gahl, W. A. Early oral cysteamine therapy for nephropathic cystinosis. European Journal of Pediatrics 2003, 162, S38-S41.

56. Kleta, R.; Gahl, W. A. Pharmacological treatment of nephropathic cystinosis with cysteamine. Expert Opinion on Pharmacotherapy 2004, 5 (11), 2255-2262. 
57. Kessler, A.; Biasibetti, M.; Melo, D. A. D.; Wajner, M.; Dutra, C. S.; Wyse, A. T. D.; Wannmacher, C. M. D. Antioxidant effect of cysteamine in brain cortex of young rats. Neurochemical Research 2008, 33 (5), 737-744.

58. Ozaki, T. Effect of thiol-containing molecule cysteamine on the induction of inducible nitric oxide synthase in hepatocytes - Discussant - Response. Journal of Parenteral and Enteral Nutrition 2007, 31 (5), 371-372.

59. Morakinyo, M. K.; Chipinda, I.; Hettick, J.; Siegel, P. D.; Abramson, J.; Strongin, R.; Martincigh, B. S.; Simoyi, R. H. Detailed mechanistic investigation into the S-nitrosation of cysteamine. Canadian Journal of Chemistry-Revue Canadienne de Chimie 2012, 90 (9), 724-738.

60. Wang, P. G.; Xian, M.; Tang, X. P.; Wu, X. J.; Wen, Z.; Cai, T. W.; Janczuk, A. J. Nitric oxide donors: Chemical activities and biological applications. Chemical Reviews 2002, 102 (4), 1091-1134.

61. Ajibola, R. O.; Simoyi, R. H. S-Oxygenation of Thiocarbamides IV: Kinetics of Oxidation of Tetramethylthiourea by Aqueous Bromine and Acidic Bromate. J. Phys. Chem. A 2011, 115 (13), 2735-2744.

62. Miao, Z. H.; Tao, S. Y.; Wang, Y. C.; Yu, Y. X.; Meng, C. G.; An, Y. L. Hierarchically porous silica as an efficient catalyst carrier for high performance vis-light assisted Fenton degradation. Microporous and Mesoporous Materials 2013, 176, 178-185.

63. Coupe, P. J.; Williams, D. L. H. Formation of peroxynitrite at high $\mathrm{pH}$ and the generation of S-nitrosothiols from thiols and peroxynitrous acid in acid solution. Journal of the Chemical Society-Perkin Transactions 2 2001, (9), 1595-1599.

64. Padmaja, S.; Squadrito, G. L.; Lemercier, J. N.; Cueto, R.; Pryor, W. A. Peroxynitrite-mediated oxidation of D,L-selenomethionine: Kinetics, mechanism and the role of carbon dioxide. Free Radical Biology and Medicine 1997, 23 (6), 917-926.

65. Beckman, J. S.; Beckman, T. W.; Chen, J.; Marshall, P. A.; Freeman, B. A. Apparent Hydroxyl Radical Production by Peroxynitrite - Implications for Endothelial Injury from Nitric-Oxide and Superoxide. Proceedings of the National Academy of Sciences of the United States of America 1990, 87 (4), 1620-1624. 